\section{Pacific Northwest}

National Laboratory

Operated by Battelle for the

U.S. Department of Energy

\title{
Demonstration of the Whole-Building Diagnostician in a Single-Building Operator Environment
}

\author{
S. Katipamula \\ N. Bauman \\ R.G. Pratt \\ M.R. Brambley
}

March 2003

Prepared for the

U.S. D epartment of Energy

Office of Energy Efficiency and Renewable Energy under Contract DE-AC06-76RL01830 


\title{
DISCLAIMER
}

This report was prepared as an account of work sponsored by an agency of the United States Government. Neither the United States Government nor any agency thereof, nor Battelle Memorial Institute, nor any of their employees, makes any warranty, express or implied, or assumes any legal liability or responsibility for the accuracy, completeness, or usefulness of any information, apparatus, product, or process disclosed, or represents that its use would not infringe privately owned rights. Reference herein to any specific commercial product, process, or service by trade name, trademark, manufacturer, or otherwise does not necessarily constitute or imply its endorsement, recommendation, or favoring by the United States Government or any agency thereof, or Battelle Memorial Institute. The views and opinions of authors expressed herein do not necessarily state or reflect those of the United States Government or any agency thereof.

\author{
PACIFIC NORTHWEST NATIONAL LABORATORY \\ operated by \\ BATTELLE \\ for the \\ UNITED STATES DEPARTMENT OF ENERGY \\ under Contract DE-AC06-76RL01830
}

Printed in the United States of America
Available to DOE and DOE contractors from the Office of Scientific and Technical Information, P.O. Box 62, Oak Ridge, TN 37831-0062; ph: (865) 576-8401 fax: $(865) 576-5728$
email: reports@adonis.osti.gov

\footnotetext{
Available to the public from the National Technical Information Service, U.S. Department of Commerce, 5285 Port Royal Rd., Springfield, VA 22161 ph: (800) 553-6847 fax: $(703) 605-6900$ email: orders@ntis.fedworld.gov online ordering: http://www.ntis.gov/ordering.htm This document was printed on recycled paper. $(8 / 00)$
} 


\title{
Demonstration of the Whole- Building Diagnostician in a Single-Building Operator Environment
}

\author{
S. Katipamula \\ N. Bauman \\ R.G. Pratt \\ M.R. Brambley
}

March 2003

\author{
Prepared for \\ the U.S. Department of Energy \\ Office of Energy Efficiency and \\ Renewable Energy \\ under Contract DE-AC06-76RL01830 \\ Pacific Northwest National Laboratory \\ Richland, Washington 99352
}




\section{Executive Summary}

This report on On-line Test for the Single-Building Operator Demonstration of the WholeBuilding Diagnostician documents the results of the single-building-operator, on-line, demonstration conducted at the Symphony Towers building in San Diego, California.

The on-line test was designed to evaluate the Outdoor-Air Economizer (OAE) diagnostic module's capabilities to automatically and continually diagnose operational problems with airhandling units (AHUs). As part of this demonstration, all four AHUs at Symphony Towers were monitored. The measured data that were collected on a continuous basis included: 1) outdoorair temperature, 2) return-air temperature, 3) mixed-air temperature, 4) supply-air temperature, 5) chilled-water valve position, 6) supply-fan status, 7) outdoor-air relative humidity, and 8) returnair relative humidity. The relative humidities of the air streams were needed because the AHUs at Symphony Towers used enthalpy-based economizer control. Because the building was heated using hot water that was supplied directly to the terminal units, hot-water valve position was not monitored at this site.

The air-handler control strategy for outdoor-air ventilation and economizing, and the schedule (times of day and days of week) for which the minimum outdoor air must be supplied for the occupants were entered into the WBD's configuration for each air handler. This information was largely obtained from Symphony Towers' staff; some items were ascertained by observation of the raw data delivered, as is typical in most WBD installations. Symphony Towers was found to not have a fixed schedule for outdoor-air supply.

For on-line tests, data from the AHUs were automatically collected and logged into the diagnostician's database using a data acquisition module, which is part of the Whole Building Diagnostician. Although data requests can be made at any frequency, at Symphony Towers, the data were requested at 5-minute intervals and integrated over the hour before being processed by the OAE diagnostic module. The on-line data collection process started in April of 2000 for all four AHUs. The data collection process worked well when all parts of the software were properly running. There were several occasions where the data acquisition module on the operator's workstation was manually terminated and this went undetected for several weeks. Although several weeks of data were lost as a result of this problem, all four AHUs have more than a year of data.

All four AHUs at Symphony Towers had unresolved problems. The predominant problem for each of the four AHUs are: 1) AHU-1 had the minimum damper position set too high, 2) AHU-2 had a temperature sensor problem (most likely the mixed-air temperature sensor), 3) AHU-3 had a temperature sensor problem (either outdoor- or mixed-air sensor) and 4) AHU-4 also had a temperature sensor problem (the outdoor-air sensor).

When an AHU has a faulty temperature sensor, cost impacts cannot be calculated directly. More detailed analysis using estimation procedures is required to estimate the energy impacts from faulty temperature sensors. As a result, energy impacts were not estimated for the three AHUs with faulty temperature sensors. Energy impacts for AHU-1 were estimated using a simplified method implemented in a spreadsheet, which is described in the report. The annual cooling 
energy impact for this problem for typical San Diego weather is about $81,000 \mathrm{kWh}$, and the corresponding annual cost impact is about $\$ 12,000$.

Although the problems identified by the OAE diagnostician were known to the building operators, only one problem (which was found during the off-line test and corrected immediately after it) was corrected during the demonstration.

Mr. Dishman, energy manager for Symphony Towers, indicated that the WBD tool set was useful and added that he would like more diagnostic tools such as WBD for other heating ventilation and air-conditioning (HVAC) systems. Mr. Dishman indicated that the user interface for both the WBD and the OAE diagnostician were easy to use. Although the problems identified by the OAE diagnostician were know to the building manager and operators, only one problem was corrected (immediately after the off-line test). In addition, the building operators were trained on how to view OAE results and interpret the information it provides; none of them actually reviewed the results during the demonstration. This may be a critical missing link in the process of using such tools that needs further investigation in future applications.

The OAE diagnostician successfully identified problems with all four AHUs at Symphony Towers. These findings are consistent with the other field demonstrations of the WBD where the OAE found similar problems that should have been detected during commissioning. The demonstration showed that diagnostic technology can provide useful information on equipment status but its value isn't realized unless building staff implement fixes to the problems. It is insufficient to merely identify problems and their impacts; building staff must correct them. If users are not proficient in using their control systems to correct problems, are too busy with other duties, or lack resources to obtain help from contractors, diagnostic technologies alone will not provide system-efficiency improvements. The staff at Symphony Towers were occupied with renovation and upgrading activities during this demonstration and did not find time to correct the problems detected by the OAE. If timing had been different, staff might have corrected these problems. In general, however, improvements can only be realized in buildings where identified problems are corrected. Future demonstrations or broad deployment of the WBD must include a mechanism for ensuring that identified problems get fixed. This could be done by building staff or outside service providers, but it is necessary if diagnostics are to do more than simply identify problems and actually proceed to deliver energy savings. 


\section{Contents}

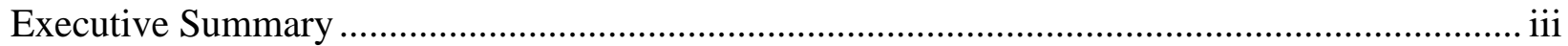

Purpose of This Task Report......................................................................................... 1

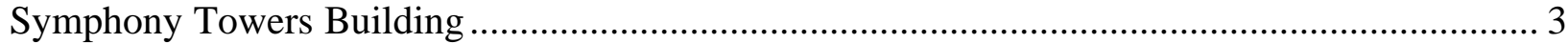

The Need for Diagnostics in Building Systems …………..................................................... 5

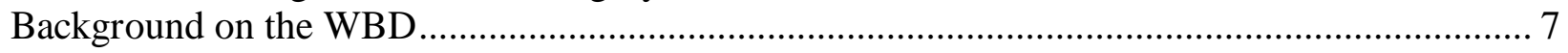

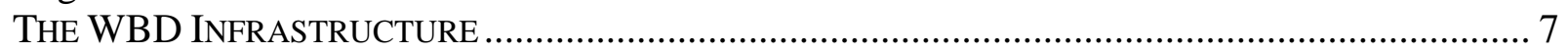

The Outside-Air Economizer (OAE) Diagnostic Module ............................................................... 9

TYPES OF ECONOMIZER CONTROLS SUPPORTED …………............................................... 9

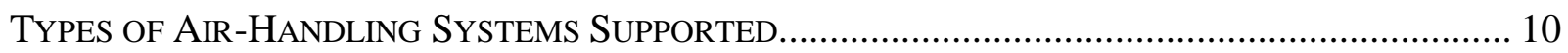

METERED DATA REQUIREMENTS FOR THE OAE MODULE ……............................................ 10

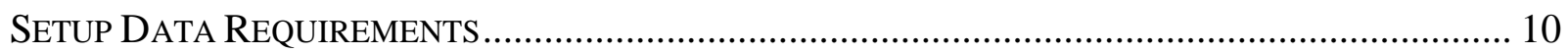

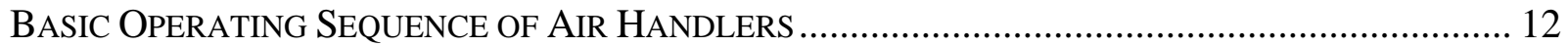

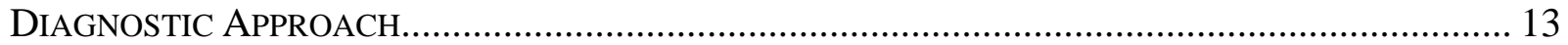

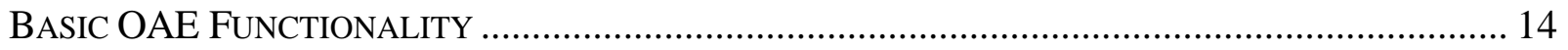

REQUIREMENTS FOR USING THE WBD AND OAE ………................................................ 17

Summary of Off-line Results for Symphony Towers ............................................................... 19

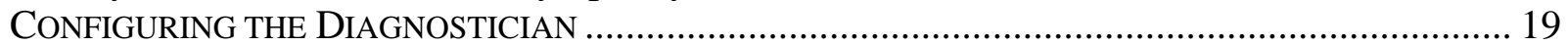

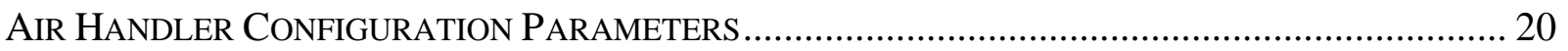

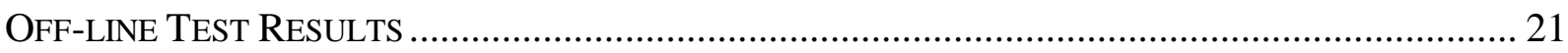

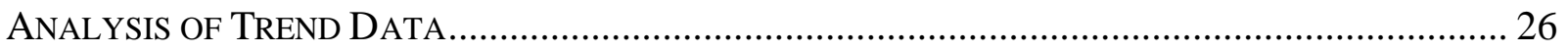

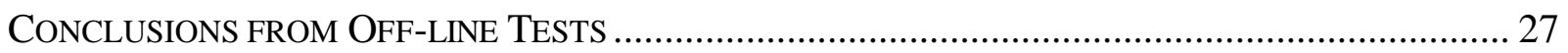

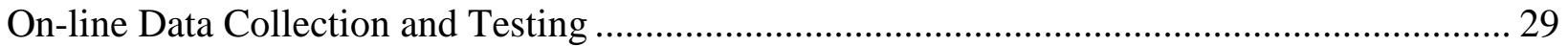

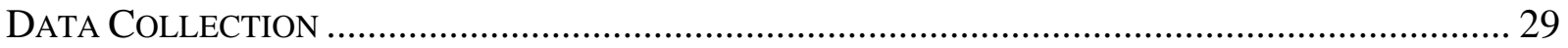

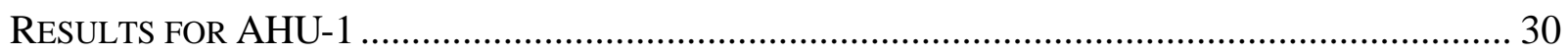

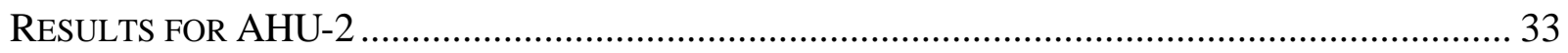

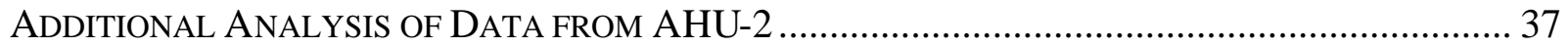

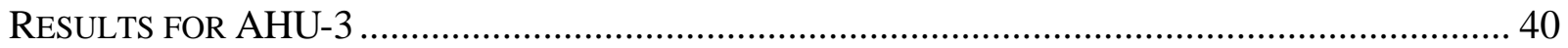

ADDITIONAL ANALYSIS OF DATA FROM AHU-3 …………................................................. 42

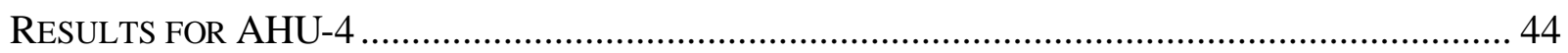

ADDITIONAL ANALYSIS OF DATA FROM AHU-4 ……………............................................. 45

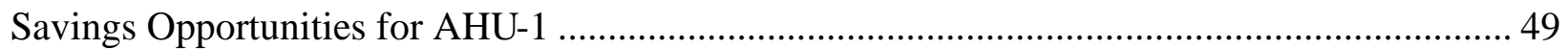

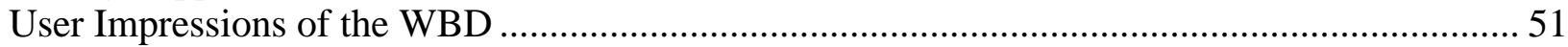

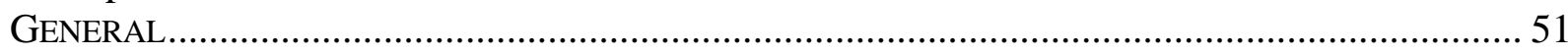

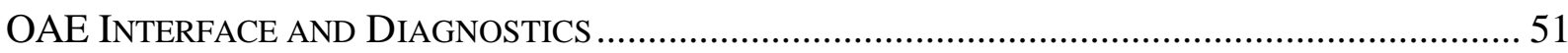

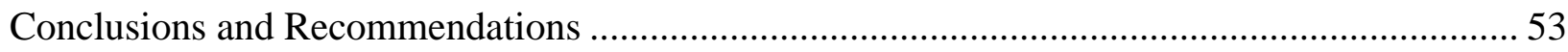

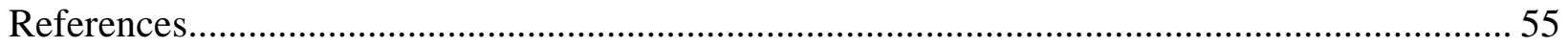

Appendix A: Method for Estimating the Annual Energy Savings .............................................. 1 


\section{Figures}

Figure 1 - Schematic Diagram of the WBD Software ..................................................... 8

Figure 2 - Schematic Diagram of an Air Handler Showing the Sensor Locations .................... 11

Figure 3 - Basic Operating Sequence of an Air-Handling Unit ............................................. 13

Figure 4 - Overview of the OAE Diagnostic Logic Tree Showing Key Decision Processes in

Boxes and Operating States in Ovals......................................................................... 15

Figure 5 - Diagnostic Results Showing Proper and Faulty Operation for an Air Handler with a

Faulty Outdoor-Air Temperature Sensor. The arrow identifies the cell for which more

detailed results are given in Figure 6 and Figure 7 .................................................. 16

Figure 6 - Window Showing a Description of the Diagnosis, the Impacts of the Problem Found,

Potential Causes of the Problem, and Suggested Corrective Actions............................... 16

Figure 7 - "Details" Window Showing a Detailed Description of the Temperature Sensor

Problem Identified in Figure 5 ................................................................................. 17

Figure 8 - An Example OAE display is shown for Air Handler 15 for November 14 through

December 11. A high energy consumption problem is clearly evident throughout this time

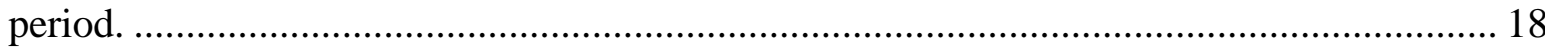

Figure 9 - WBD's Air Handler Configuration Screen for AHU-1 ......................................... 20

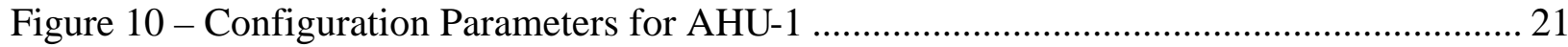

Figure 11 - Display of OAE Diagnostic Results for AHU1 ................................................ 22

Figure 12 - Current Condition Dialogue for the Control Problem at 10 p.m. on Friday, December

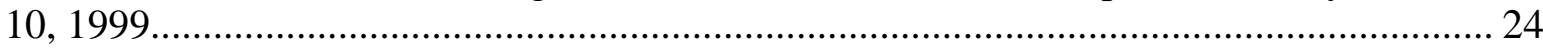

Figure 13 - Details on the Current Condition for the Control Problem .................................. 25

Figure 14 - Current Condition Dialogue for the Excess Ventilation Problem ........................... 25

Figure 15 - Details Dialogue for Excess Ventilation Problem............................................. 26

Figure 16 - WBD Display of Problems after Supply-Air Temperature Sensor was Fixed .......... 27

Figure 17 - Schematic diagram of the On-line Data Collection Process at Symphony Towers .. 29

Figure 18 -WBD Diagnostic Results for AHU1 for a Period from September 27 through October

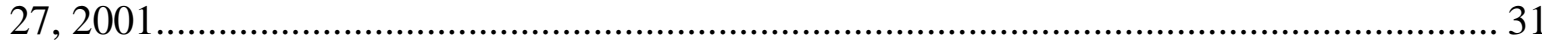

Figure 19 -WBD Diagnostic Results for AHU1 for a Period from December 11, 2001, through

January 10, 2002 .......................................................................................... 32

Figure 20 - WBD Diagnostic Results for AHU-2 for a Period from June 1 through July 1, 2000

Figure 21 - Current Conditions Dialogue for AHU-2 for June 20, 2000, Indicating a

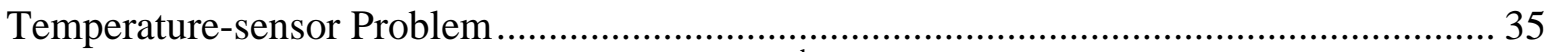

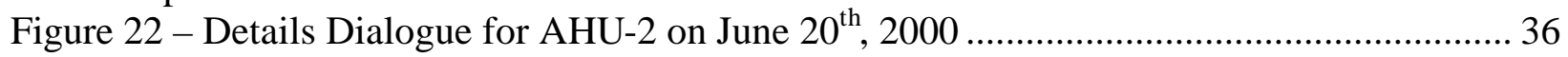

Figure 23 - WBD Diagnostic Results for AHU-2 for the Period from December 11, 2002,

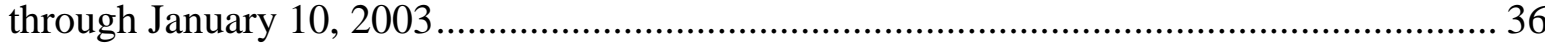

Figure 24 - Measured Values of Mixed-Air Temperature as a Function of Measured Outdoor-Air

Temperature for AHU-2 when the Damper is Fully Open ............................................... 38

Figure 25 - Measured Values of Mixed-Air Temperature as a Function of Measured Values

Return-Air Temperature for AHU-2 when the Damper is Fully Closed ........................... 38

Figure 26 - Comparison of Measured Values of the Outdoor-Air-Temperature Sensors for AHU-

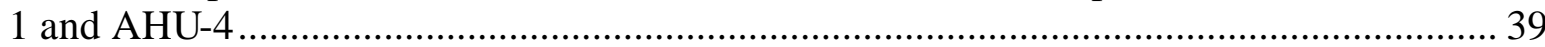

Figure 27 - Measured Values of Mixed-Air Temperature as a Function of Measured Values

Outdoor-Air Temperature for AHU-1 when the Outdoor-Air Damper is Fully Open ......... 40 
Figure 28 - WBD Diagnostic Results for AHU-3 for a Period from June 1 through July 1, 2000

Figure 29 - WBD Diagnostic Results for AHU-3 for a Period from December 10, 2002, through January 9,2003

Figure 30 - Measured Values of Mixed-Air Temperature as a Function of Measured Values

Outdoor-Air Temperature for AHU-3 when the Damper is Fully Open

Figure 31 - Measured Values of Mixed-Air Temperature a Function of Measured Values ReturnAir Temperature for AHU-3 when the Damper is Fully Closed (yellow marker represent conditions when outdoor-air temperature is greater than return-air temperature and blue marker represent conditions when outdoor-air temperature is less than return-air temperature)

Figure 32 - WBD Diagnostic Results for AHU-4 for a Period from December 11, 2001, through January 10,2002 . 45

Figure 33 - WBD Diagnostic Results for AHU-4 for a Period from December 11, 2002, through January 10, 2003

Figure 34 - Measured Values of Mixed-Air Temperature as a Function of Measured Values Outdoor-Air Temperature for AHU-4 when the Damper is Fully Open

Figure 35 - Measured Values of Mixed-Air Temperature as a Function of Measured Values Return-Air Temperature for AHU-4 when the Damper is Fully Closed (yellow marker represent conditions when outdoor-air temperature is greater than return-air temperature and blue marker represent conditions when outdoor-air temperature is less than return-air temperature) 


\section{Tables}

Table 1. Symphony Towers Air Handlers in the Demonstration............................................. 3

Table 2 - Typical Raw 5-Minute Data from AHU-1 ........................................................ 19

Table 3 - Frequency of the Problems for AHU-1 (the color of the various categories match the

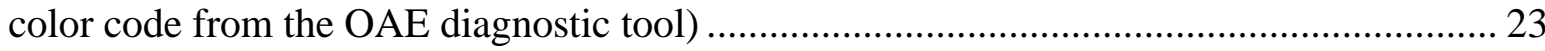

Table 4 - Data Points Collected by Symphony Towers for OAE Diagnostic Module................ 30

Table 5 - Frequency of the Problems for AHU-1 when the Building is Occupied (March 2001

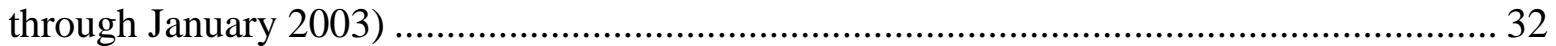

Table 6 - Frequency of the Problems for AHU-2 when the Supply-Fan was Operational (March 2001 through January 2003) .................................................................................... 37

Table 7 - Frequency of the Problems for AHU-3 when the Supply-Fan was Operating (March 2001 through January 2003) ............................................................................................ 42

Table 8 - Frequency of the Problems for AHU-4 when the Supply-Fan was Operating (March

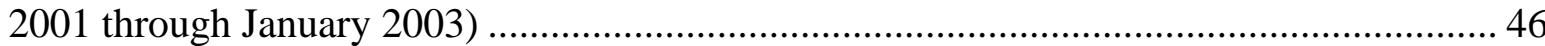

Table 9 - Assumed and Calculated Values of Key Variables for Impact Estimates (see Appendix

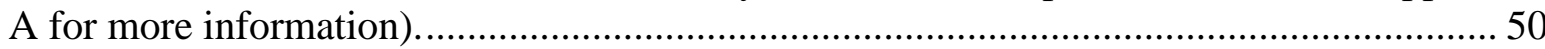




\section{Purpose of This Task Report}

In April 2000, the California Energy Commission (Commission) initiated a project with cofunding from the U.S. Department of Energy (DOE) to evaluate a DOE-developed technology, the Whole-Building Diagnostician (WBD), for automatically and continually diagnosing operational problems in buildings. The Whole-Building Diagnostician is a pre-commercial, production-prototype software package that connects to digital control systems (e.g., energy management systems), utilizing data from the control system's sensors to analyze overall building and system performance. It currently consists of two diagnostic tools, or modules, with a user interface designed to readily identify problems and provide potential solutions to building operators. The Outdoor-Air Economizer module (OAE), the subject of this demonstration, diagnoses whether each air handler in a building is supplying adequate outdoor air for the occupants it is designed to serve, by time of day and day of week. It also determines whether the economizer is providing free cooling with outside air when appropriate and not wasting energy by supplying excess outside air. In addition to the two diagnostic modules, the WBD also has a data module to automatically retrieve data from some building automation systems.

This report documents the results of On-line Test for the Single-Building Operator Demonstration of the Whole-Building Diagnostician. The single-building operator demonstration was conducted at the Symphony Towers building in San Diego. Some characteristics of the building are listed in the next section.

This project is intended to demonstrate the WBD's current automated diagnostic tools in three contexts:

- Single-Building Operator Demonstration - use of the WBD by dedicated operators for a single, Class A office building

- Multi-Building Operator Demonstration - use of the WBD by a set of supervisory operators for a set of commonly managed and operated buildings that share a control system infrastructure

- Service Provider Demonstration - use of the WBD by third-party analysts of a service company providing contracted retrofit and operations and maintenance $(\mathrm{O} \& \mathrm{M})$ services to buildings and facilities.

In each of these three contexts, Project 2.4 is designed to test and demonstrate automated diagnostics using the Whole-Building Diagnostician in actual buildings with actual operators and energy service providers to:

- prove their efficacy in automatically detecting energy efficiency and outdoor-air supply problems in buildings

- test and demonstrate the ability of users to interpret and act upon the information provided by the tools to correct building operational problems 
- develop case studies of the impacts of using the tools in terms of the type and number of problems found, the energy savings and fresh air supply impacts of correcting the problems

- provide early feedback from users, based on their experiences with actual automated diagnostic tools, to guide development and implementation of other tools in the future, including those in the program plan.

This report focuses on the on-line test results for the single-building operator demonstration and is a follow up to an earlier report that described the off-line test results for the same site. After the demonstration site was selected, the demonstrations began with an off-line test of the WBD's Outdoor-Air Economizer diagnostic module. The off-line test was designed to determine the basic suitability of the demonstration site for testing the WBD. The three major criteria to determine the suitability were: accessibility of the control system sensors for data collection, whether the necessary sensors were present and reasonably accurate, and whether the control strategy for the air handlers' outdoor-air economizer systems could be diagnosed by the OAE module. Off-line testing of the OAE module at Symphony Towers was successful because all three major criteria were satisfied.

The results of the on-line demonstration are presented in this report. In the section following this, the need for diagnostics in building systems is briefly discussed, followed by a section on basic information about what the Whole-Building Diagnostician is, how it works, and a detailed description and capabilities of the OAE module. The Symphony Towers building is described next. Technical discussions including installation of the WBD, training of the Symphony Towers staff, the WBD's operation, problems identified by the OAE, potential savings from correcting the problems found, and issues surfaced that have implications for facilities that might wish to use the WBD are also presented. 


\section{Symphony Towers Building}

The single-building operator demonstration took place at the Symphony Towers building in San Diego, California. Crowned the "International Building of the Year" by the Building Owners and Managers Association, (BOMA) in 1994, Symphony Towers is a 34-story 601,000 sq. ft., "Class-A", mixed-use development located at the hub of downtown San Diego's financial corridor. Its net rentable floor space is $528,869 \mathrm{ft}^{2}$, mostly leased to tenants who are legal and accounting firms. There is a private dining facility on the top floor.

Symphony Towers was selected for the demonstration because of its visibility and energy conscious management. In San Diego, Symphony Towers is a superior property, affiliated with numerous associations including the BOMA, The International Facility Managers Association (IFMA), The Association of Energy Engineers (AEE), and the San Diego Building Engineers Association (SDBEA).

The building owner is SPP Investment Management, which has a growing portfolio of 37 buildings in the U.S. In the U.S. Region, Symphony Towers is the "King Pin" project for the owner. Building operation has recently been contracted to StepStone Real Estate Services, but the core of the engineering team remains intact. The team has aggressively pursued optimal equipment performance and has accomplished numerous lighting, mechanical, plumbing, and controls enhancements.

The building's HVAC (heating, ventilating and air-conditioning) system consists of two threestage centrifugal chillers of 550 tons each, and two natural gas hydronic boilers of 3,000 $\mathrm{MBtu} / \mathrm{hr}$ each. The occupied space is served by four variable-air-volume air handlers, equipped with enthalpy-controlled economizers and variable speed drives (see Table 1). The air handlers only supply cooling; no heating coil is present. The control system is manufactured by Johnson Controls Metasys, and provides convenient on-demand access to data by the WBD via a DDE (dynamic data exchange) server.

Table 1. Symphony Towers Air Handlers in the Demonstration

\begin{tabular}{|c|c|}
\hline Air-Handler & $\begin{array}{c}\text { Rated Flow } \\
\left(\mathbf{f t}^{\mathbf{3}} \mathbf{\text { min }}\right)\end{array}$ \\
\hline \hline AHU-1 & 80,000 \\
\hline AHU-2 & 144,000 \\
\hline AHU-3 & 144,000 \\
\hline AHU-4 & 126,000 \\
\hline
\end{tabular}

At the start of the demonstration (March 2000), the primary contact at Symphony Towers was Jim Ford, Chief Engineer and Energy Manager. Jim Ford left Symphony Towers and was replaced by Richard Dishman in 2000. Initially Jim Ford and later Richard Dishman was the primary administrator of the WBD at Symphony Towers (The Administrator has the highest- 
level permissions to change the configuration of the WBD to reflect changes to controls, add diagnosticians, rename buildings and components, reprocess data, etc.)

Symphony Towers is the second test of the WBD at a private-sector building; the first was done at a large hotel in San Francisco. This demonstration is a continuation of an earlier demonstration funded by the U.S. Department of Energy as part of the WBD development effort. The earlier demonstration began in December of 1999 and continued through Fiscal Year ${ }^{1}$ (FY) 2000, when it became part of this project. During that time significant improvements were made to the WBD, and these were tested in this demonstration.

\footnotetext{
${ }^{1}$ The federal fiscal year runs for October 1 through September 30. For example, FY2000 ran from October 1, 1999, through September 30, 2000.
} 


\section{The Need for Diagnostics in Building Systems}

Automated commissioning and diagnostic technologies are designed to ensure the ongoing performance of buildings at the highest possible levels of efficiency. Evidence of extensive performance problems in buildings shows that an efficient building stock will not result from solely designing efficient buildings and installing efficient equipment in them (Lunneberg 1999; also check the commissioning resources at http://www.peci.org).

These performance problems are not inherent with efficiency technologies themselves, but instead result from errors in installation and operation of complex building heating/cooling systems and their controls. It is also significant that these systems are becoming increasingly more sophisticated to obtain ever higher levels of energy efficiency, adding to the complexity and subtlety of problems that reduce the net efficiency acquired. Such problems are even more common in existing buildings because they arise over time from operational changes and lack of maintenance (Claridge et al. 2000; also check the commissioning resources at http://www.peci.org). They often result in problems with comfort control and indoor-air quality, which affect occupant health and productivity (Daisey and Angell 1998).

Assuring efficient performance by commissioning of new buildings followed by regularlyscheduled preventative maintenance is clearly insufficient to address this issue. Manually commissioning ${ }^{2}$ buildings is valuable in terms of both finding problems and developing the techniques for doing so, but, it is expensive. With only 1 to $2 \%$ of total construction costs devoted to commissioning (see the commissioning resources at http://www.peci.org) and the few experts available to provide such services in high demand, commissioning is not done adequately for most commercial buildings. Commissioning is difficult to sell in a low-bid construction environment, where variations in the effort allocated to commissioning can be the difference between winning and losing bids and where building owners (rightfully) feel they should not have to pay extra to get buildings to work properly. Further, commissioning is often shortchanged because it largely occurs at the end of the construction process, when time-to-occupancy is critical and cost overruns drive last minute budget cuts in remaining items.

Effective, on-going maintenance of building systems as usually performed is notably ineffective, being almost exclusively complaint-driven and "quick fix" oriented. This is especially true for problems affecting air quality and efficiency because they are "silent killers" that go unnoticed until complete system failure occurs.

By embedding the expertise required to detect and diagnose operation problems in software tools that leverage existing sensors and control systems, detection and diagnosis can be conducted automatically and comprehensively without the ongoing cost of expensive human expertise. Further, this oversight remains as a legacy in buildings after they are constructed, protecting the

\footnotetext{
${ }^{2}$ Commissioning is the process of systematically putting a building "through its paces," checking that it performs as expected in terms of sensor and actuator connectivity and calibration, system modes, control sequences, and equipment capacities and conversion efficiencies. The term derives from the traditional acceptance process for naval ships, which must undergo a shakedown cruise to prove their speed, range, stability, maneuverability, communications, etc., to meet design specifications before they are accepted into service.
} 
building systems against slow mechanical degradation, as well as faults inadvertently introduced by operators seeking to resolve complaints without finding root causes. The principal technical challenges are the construction of diagnostic techniques that 1) can be automated, 2) comprehensively diagnose the range and diversity of building systems and equipment, 3) make use of a minimal set of additional sensors beyond those used for control, and 4) are applicable for building commissioning, as well as on-going diagnostics.

Currently, most building owners are not aware of the power of automated commissioning and diagnostic technology to provide them more cost effective, comfortable, and productive buildings. The technology is in its infancy and not yet well know in practice. Finally, energy service companies who may eventually offer commissioning and diagnostic services are slow to expand their business practices beyond their current focus on lighting and cooling equipment retrofits. Despite this current state, automated diagnostic technology offers promise of a future with improved facility operation, better indoor environments, and enhanced and higher-quality offerings by service companies. 


\section{Background on the WBD}

Developed by the Pacific Northwest National Laboratory (PNNL) ${ }^{3}$ under funding from the Office of Energy Efficiency and Renewable Energy of the U.S. Department of Energy, with Honeywell, Inc. and the University of Colorado as subcontractors, the Whole-Building Diagnostician is a production-prototype software package with two modules providing automated diagnostics for buildings based on data collected by direct-digital control (DDC) systems. These tools are deployed in the WBD's user interface and data and process management infrastructure.

The WBD's Outdoor-Air Economizer module diagnoses whether each air handler in a building is supplying adequate outdoor air for the occupants it is designed to serve, by time of day and day of week. It also determines whether the economizer is providing free cooling with outdoor air when appropriate, and is not wasting energy by supplying excess outdoor air. Few, if any, sensors other than those used to control most economizers are required, making the OAE practical in near-term markets because of its low cost. Early experience with the OAE in new and existing buildings in Washington and California has confirmed the broadly held suspicion that problems with outdoor-air ventilation control and economizing are endemic. The OAE has discovered problems in all but 1 of the roughly 35 air handlers examined to date, in existing and newly commissioned buildings.

The WBD also contains a Whole-Building Efficiency module that monitors whole-building and major subsystem (end-use) performance. It does this by tracking actual energy consumption and comparing it to estimated expected consumption as a function of time of day, day of week, and weather conditions. Using these data, it automatically constructs a model based on actual past system performance for a baseline period, and then alerts the user when performance is no longer as good as or, in the case of retrofits or operations and maintenance programs, is better than past performance. The tool bootstraps itself to provide feedback during the initial training period after a period of about 4 to 6 weeks. Electricity or gas consumption sensors typically must be connected to the building's direct digital control system to obtain the consumption data. This, however, is not an absolute requirement.

Both modules provide information to users in simple, graphical displays that indicate the presence or absence of problems at a glance. They also provide cost estimates of detected energy waste to provide feedback to users on the relative importance of the problems detected. These tools are available for commercialization through special use licenses from PNNL. The WBD's infrastructure is an open-protocol, public-domain framework designed to support the ready incorporation of new diagnostic tools from other developers in the future.

\section{The WBD Infrastructure}

The WBD currently consists of four primary modules: the two diagnostic modules, the user interface, and a database that stores measured data, as well as diagnostic results. These are connected by an infrastructure that provides data transfer, data management, and process control, as shown in Figure 1. Boxes represent major components; lines represent flows of data. Data is

\footnotetext{
${ }^{3}$ Operated for the U.S. Department of Energy by Battelle Memorial Institute under Contract DE-AC06-76RL01830.
} 
automatically obtained at a user-specified sub-hourly frequency and averaged to create hourly values. As new hourly values become available in the database, the diagnostic modules automatically process them and produce diagnostic results that are also placed in the database. The user can then open the WBD user interface at any time to see the latest diagnostic results, and can also browse historical results.

Raw data (e.g., sensor measurements) may be obtained from a variety of data sources: a data logger or building management system, another database, or some other analytic software tool. The system also requires one-time entry of setup data that customizes the WBD modules to each specific building and heating/cooling/ventilation system. The system is written in the $\mathrm{C}++$ language and uses an SQL database. The term DDE in Figure 1 refers to Microsoft's Dynamic Data Exchange protocol.

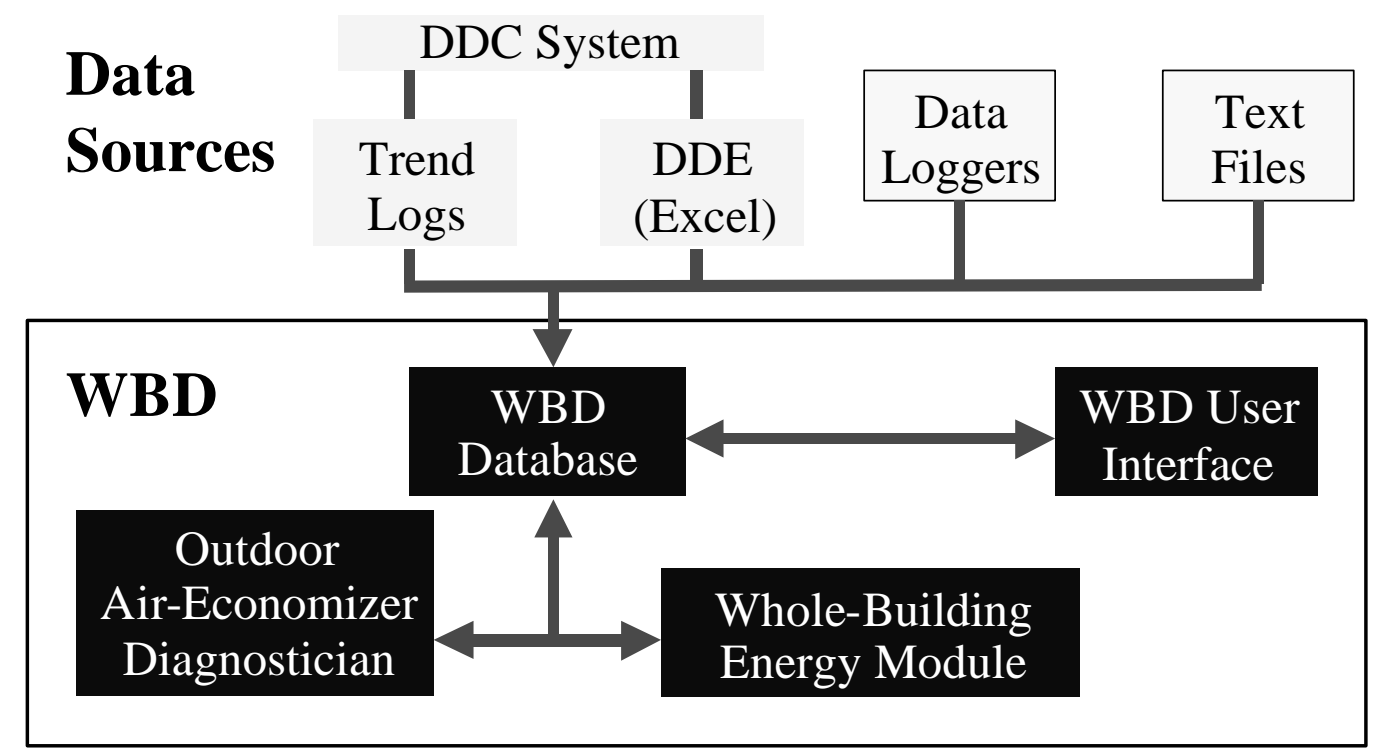

Figure 1 - Schematic Diagram of the WBD Software 


\section{The Outside-Air Economizer (OAE) Diagnostic Module}

This section provides a brief overview of the Outside-Air Economizer (OAE) module. Additional information about the WBD and the OAE can be found in Brambley et al. (1998) and Katipamula et al. (1999). The OAE continuously monitors the performance of air handlers and can detect basic operation problems or faults with outside-air control and economizer operation. The current version detects about 25 different basic operational problems and over 100 variations of them [for details refer to Brambley et al. (1998) or Katipamula et al. (1999)]. It uses color coding to alert the building operator when problems occur and then provides assistance in identifying the causes of problems and advice for correcting them. It, however, does not detect problems with the water-side or the refrigerant side of the air handler; it only detects problems on the air side, i.e., economizer operation and ventilation. If the air handler does not have an economizer, the OAE module can still detect problems with the outdoor-air ventilation.

\section{Types of Economizer Controls Supported}

The OAE module can diagnose abnormal operations or problems with several different types of economizer controls including: differential dry-bulb temperature-based, differential enthalpybased, high-limit dry-bulb temperature-based and high-limit enthalpy-based.

With differential control strategies, the outside-air condition is compared with the return-air condition. As long as the outside-air condition is more favorable (for example, with dry-bulb temperature control, the outside-air dry-bulb temperature is less than the return-air temperature), outside air is used to meet all or part of the cooling demand. If the outside air alone cannot satisfy the cooling demand, mechanical cooling is used to provide the remainder of the cooling load.

With high-limit control strategies, the outside-air condition is compared to a single or fixed set point (usually referred to as a high limit). If the outside-air condition is below the set point, outside air is used to meet all or part of the cooling demand. Any remaining cooling load is provided by mechanical cooling.

In addition to these economizer control strategies, the OAE supports fault detection with both integrated and nonintegrated economizers. An integrated economizer, as its name implies, is fully integrated with the mechanical cooling system such that it can either provide all of the building's cooling requirements if outdoor conditions allow, or it can supplement mechanical cooling when outdoor conditions are not sufficiently favorable to handle the entire cooling load. An economizer often has the ability to throttle outdoor-air intake rates between minimum and maximum levels to prevent the delivered air from being cooler than the supply-air set point.

Conversely a nonintegrated economizer does not operate when the mechanical cooling system is operating. If outdoor conditions are not sufficiently favorable to allow $100 \%$ economizing, no economizing is used. A two-stage thermostat often controls a nonintegrated economizer. The first stage opens the economizer; the second stage locks out the economizer and turns on the mechanical cooling. 


\section{Types of Air-Handling Systems Supported}

The OAE tool supports the following types of single-duct air handlers:

- Constant-air-volume systems

- Variable-air-volume (VAV) systems with no volume compensation (i.e., outside-air intake is a constant fraction of the supply-air flow rate rather than changing it to maintain a constant outside-air volume).

Air handlers that the OAE tool does not support include:

- VAV systems that maintain constant outside-air volume flow through volumetric flow measurements (commonly using air-monitoring stations consisting of pitot-tube arrays)

- VAV systems that attempt to approximately provide constant outside-air volumetric flow by increasing the outside-air fraction (e.g., by opening the outside-air damper system) as the fan speed decreases

- Systems that utilize $\mathrm{CO}_{2}$-based outside-air control strategies

- Dual-duct air-handling systems.

\section{Metered Data Requirements for the OAE Module}

The OAE requires seven periodically measured/collected (currently at sub-hourly increments) variables, as shown in Figure 2 (bold labels in the figure identify required data). In addition to the seven variables, the damper-position signal is also required for air handlers with damperposition-signal control, i.e., if the damper-position signal is controlled directly to maintain the ventilation or to control the supply- or mixed-air temperatures when the air handler is economizing. For economizers with enthalpy-based control, outside- and return-air relative humidities (only for differential enthalpy control) or dew-point temperatures are required. If the supply- or mixed-air temperature set point is reset, the reset value at each hour is also needed.

\section{Setup Data Requirements}

The OAE module requires several one-time (setup or configuration) data inputs to characterize the existing systems and define how they are controlled. In addition to the setup data, the OAE also requires at least seven metered data points (same as variables called out in Figure 2). The engineering units for all inputs (both setup and measured) are assumed to be in Inch-Pound units unless otherwise specified. 


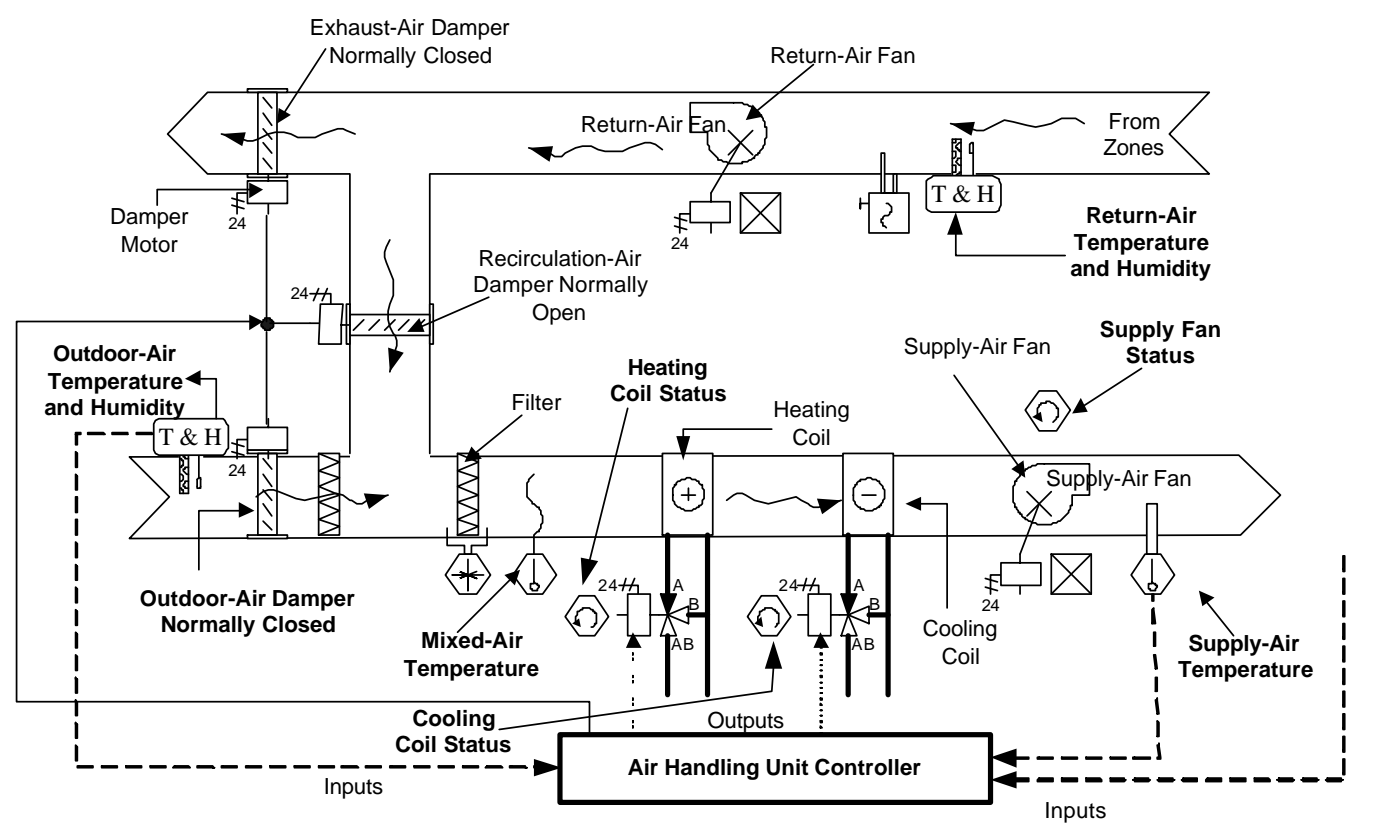

\section{Figure 2 - Schematic Diagram of an Air Handler Showing the Sensor Locations}

The OAE is capable of detecting and diagnosing faults with most commonly found air handlers using almost all outside-air and economizer control strategies. However, the user must describe the control strategies used to the OAE with the setup information. In addition, the OAE is designed to be flexible in accepting status inputs. For example, the WBD can accept any one of four different types of signals to indicate whether the supply fan is ON. Once the OAE module is configured, the detection and diagnosis is fully automated.

The setup data are required for all air-handler systems with economizers. These data describe:

1. the basic air-handling system

2. the minimum, maximum, and required (building fully-occupied) outdoor-air fractions

3. the occupancy schedule, defining when the required outdoor air must be supplied

4. data needed to estimate energy and cost impacts of problems.

There are 17 items of setup data that must be supplied by the user for every air-handler system. In addition, there are a number of additional setup data inputs, along with the types of air handler and economizer controls to which they are applied. As few as 3 to as many as 15 additional inputs may be required to describe any given system type. For a typical system with an outdoorair-fraction-based differential temperature economizer with low-limit control, nine of these setup items are required. Almost all of these inputs are provided with defaults that enable the OAE module to be initialized without the user providing them; however, it will not provide correct diagnoses unless the setup values are correct. Potential errors in the setup data are sometimes identified by the OAE as candidate causes of problems it detects with the air-handler operation. Generally, these then need to be reconciled by the building operator and setup data changed to correct any differences between the actual and default values. 


\section{Basic Operating Sequence of Air Handlers}

The OAE module uses a logic tree to determine the operational "state" of outdoor-air ventilation and economizer systems at each point in time for which measured data are available. The logic tree is based on the basic air-handler operating sequence, as described below.

An air handler typically has two main controllers: 1) to control the outdoor-air intake and 2) to control the supply-air temperature (in some cases mixed-air temperature is controlled rather than supply-air temperature). The basic operation of the air handler is to draw in outdoor air and mix it with return air from the zones and, if necessary, condition it before supplying the air back to the zones, as shown in Figure 2.

An air handler typically has four primary modes of operation during a building's occupied periods, for maintaining ventilation (fresh-air intake) and comfort (the supply-air temperature at the set point), as shown in Figure 3. The operating sequence determines the mode of operation and is based on the ventilation requirements, the internal and external thermal loads, and indoor and outdoor conditions.

When indoor conditions call for heating, the heating-coil valve is modulated (i.e., controlled) to maintain the supply-air temperature at its set point (heating mode in Figure 3). When the air handler is in the heating mode, the cooling-coil valve is fully closed, and the outdoor-air damper is positioned to provide the minimum outdoor air required to satisfy the ventilation requirements. As heat gains increase in the zone and the need for cooling increases, the air handler transitions from heating to cooling. Before mechanical cooling is provided, the outdoor-air dampers are opened fully to use the favorable outdoor conditions to provide 100\% cooling (economizer mode in Figure 3). In this mode, the heating- and the cooling-coil valves are fully closed and the outdoor-air dampers are modulated to meet all the cooling requirements.

As the heat gains in the zone continue to increase, the outdoor air alone cannot provide all the cooling necessary, and the air handler changes modes by initiating mechanical cooling (cooling and economizing mode in Figure 3) to supplement the economizer. In this mode, the outdoor damper is fully open, the heating-coil valve is fully closed, and the cooling-coil valve is modulated to maintain the supply-air temperature. As the outdoor conditions become unfavorable (i.e., too hot and humid) for economizing, the air handler changes mode again. This time the outdoor-air dampers are modulated to the minimum position to provide the minimum outdoor air required to satisfy the outdoor-air ventilation needs, the heating-coil valve continues to be fully closed, and the cooling-coil valve is modulated to maintain the supply-air temperature at its set point.

If an air handler does not have an economizer, there are two basic modes of operation (heating and mechanical cooling). If the economizer is not integrated with mechanical cooling (i.e., it cannot economize and provide mechanical cooling simultaneously), there are three basic modes of operation (heating, economizing, and mechanical cooling). 


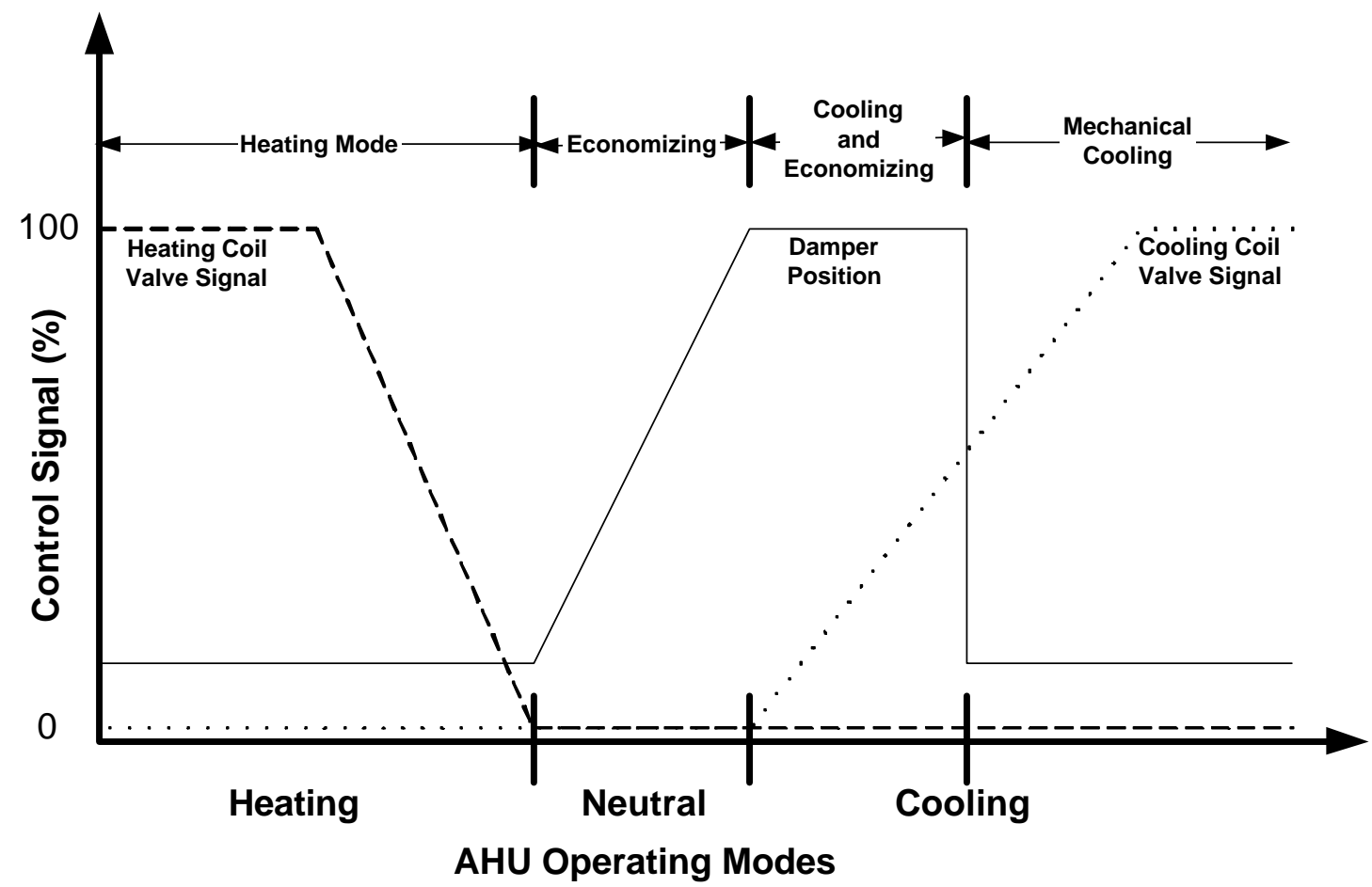

Figure 3 - Basic Operating Sequence of an Air-Handling Unit

\section{Diagnostic Approach}

The OAE uses rules derived from engineering models and understanding of proper and improper air-handler performance to diagnose operating conditions. The rules are implemented in a decision tree structure in the software. The OAE diagnostician uses periodically measured conditions (temperature or enthalpy) of the various air-flow streams, measured outdoor conditions, and status information (e.g., fan on/off status) to navigate the decision tree and reach conclusions regarding the operating state of the air handler. At each point in the tree, a rule is evaluated based on the data, and the result determines which branch the diagnosis follows. A conclusion is reached regarding the operational state of the air handler when the end of a branch is reached. Tolerances are assigned to each data point, and uncertainty is propagated through all calculations.

Many of the states correspond to normal operation and are dubbed "OK states." For example, one OK state is described as "ventilation and economizer $\mathrm{OK}$; the economizer is correctly operating (fully open), and ventilation is more than adequate." For this case, the system is apparently operating correctly with the outdoor-air damper fully open to benefit to the maximum extent possible from cool outdoor-air used for free cooling. Ventilation rates for the occupants are also being met by the current outdoor-air ventilation rate. Other states correspond to something operationally wrong with the system and are referred to as "problem states." An example problem state might be described as "economizer should not be off; cooling energy is being wasted because the economizer is not operating; it should be fully open to utilize cool outside air; ventilation is adequate." As with the previous state, conditions are such that the outside-air damper should be fully open to benefit from free cooling; however, in this case the economizer is incorrectly off, yet the outdoor-air ventilation is still adequate to meet occupant needs. Thus, the building is experiencing an energy penalty from not using the economizer. 
Other states (both OK and problem) may be tagged as incomplete diagnoses, if critical data are missing or results are too uncertain to reasonably reach a conclusion.

Each problem state known by the OAE module has an associated list of possible failures that could have caused the state; these are identified as possible causes. In the example above, a stuck outdoor-air damper, an economizer controller failure, or perhaps a misconfigured setup could cause the economizer to be off. Thus, at each metered time period, a list of possible causes is generated.

An overview of the logic tree used to identify operational states and to build the lists of possible failures is illustrated in Figure 4. The boxes represent major sub-processes necessary to determine the operating state of the air handler; diamonds represent tests (decisions), and ovals represent end states and contain brief descriptions of OK and problem states. Only selected end states are shown in this overview, and the details of processes and decisions are excluded because of space constraints.

\section{Basic OAE Functionality}

The OAE user interface uses color coding to alert the building operator when problems occur. It then provides assistance in identifying the causes of the problems detected and in correcting them. Figure 5, for example, shows a representative OAE diagnostician window. On the left pane of the window is a directory tree showing the various systems implemented in this particular WBD system. The tree can be used to navigate among the diagnostic results for various systems. In this case, results for air handler 12 (AHU-12) are highlighted in the tree. In the right pane is a color map, which shows the OAE diagnostic results for this air handler. Each cell in the map represents an hour. The color of the cell indicates the type of state. White cells identify OK states, for which no problems were detected. Other colors represent problem states. "Clicking" the computer mouse on any shaded cell brings up the specific detailed diagnostic results for that hour.

Figure 6 and Figure 7 show pop-up windows providing a short description of a problem, a more detailed explanation of the problem, energy impacts of the problem, potential causes, and suggested actions to correct each cause. The second window (Figure 7) labeled "Details" is revealed by "clicking" on the "Details" button in the first window (Figure 6). In this case, the problem investigated is a sensor problem. The current version of this OAE diagnostician cannot, by itself, isolate the specific sensor that has failed, but instead it suggests manual inspection and testing of the sensors and their wiring to identify the specific problem. Yet another example of OAE is shown in Figure 8, where a high energy consumption problem is evident. 


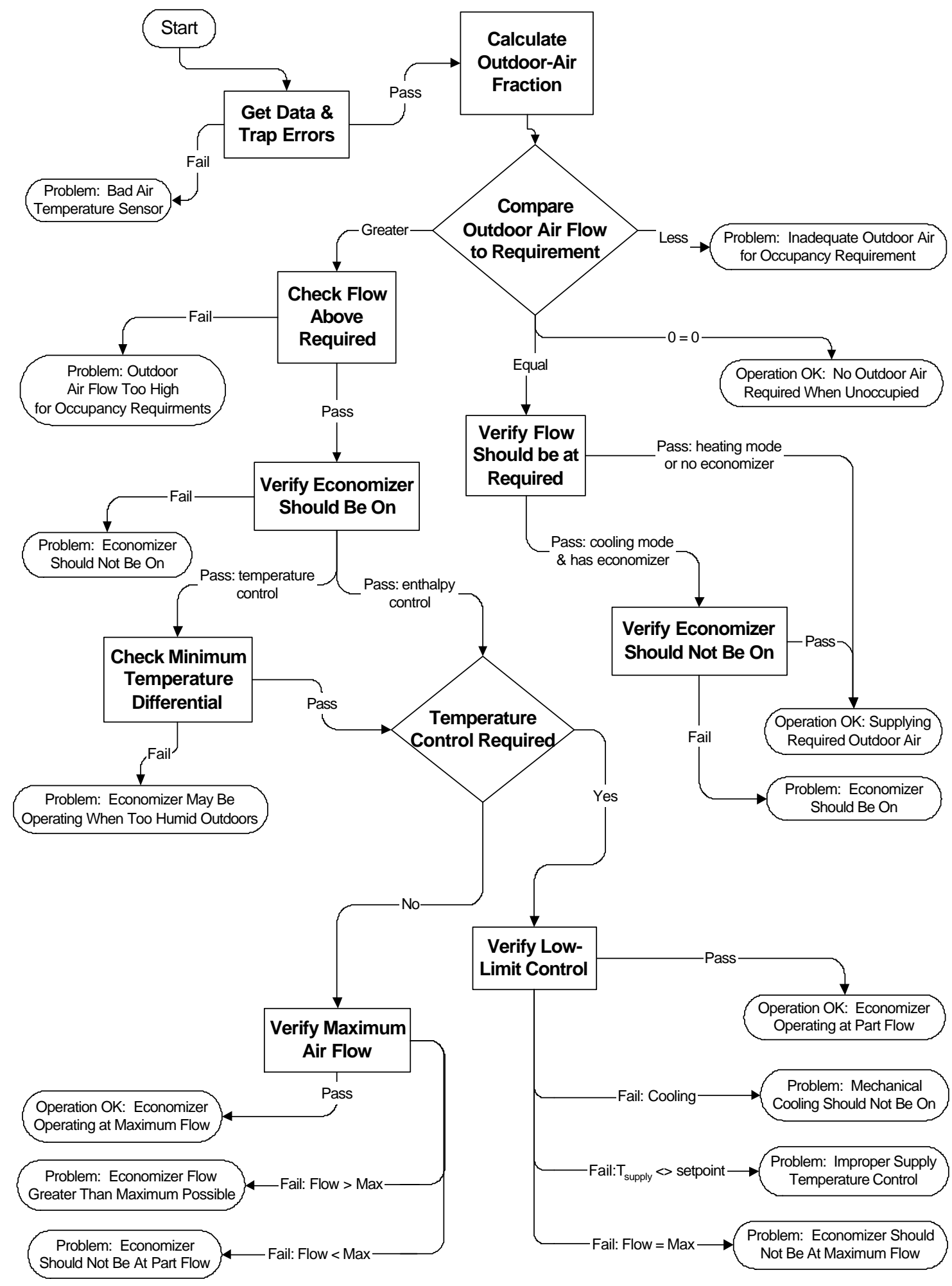

Figure 4 - Overview of the OAE Diagnostic Logic Tree Showing Key Decision Processes in Boxes and Operating States in Ovals 


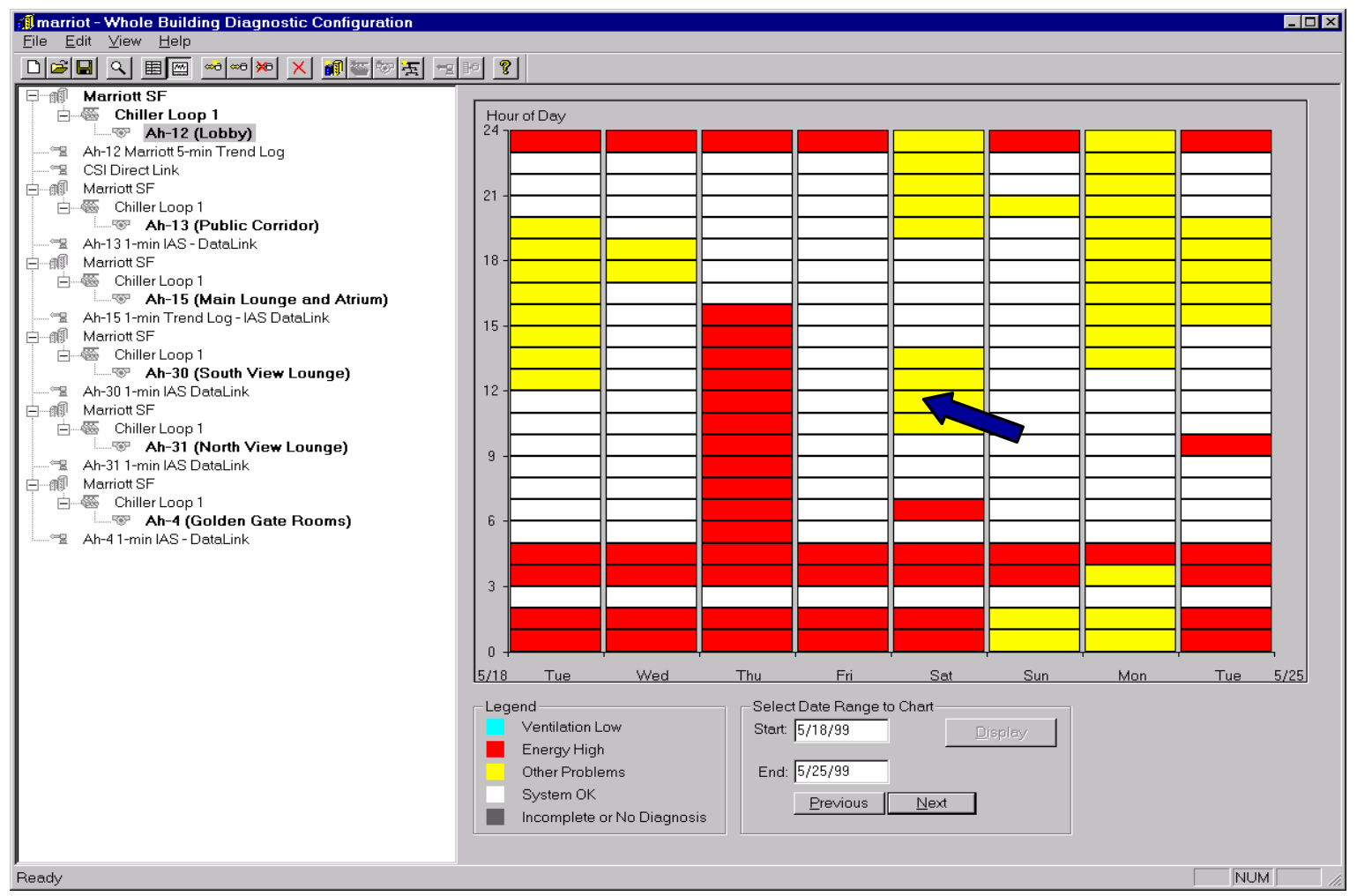

Figure 5 - Diagnostic Results Showing Proper and Faulty Operation for an Air Handler with a Faulty Outdoor-Air Temperature Sensor. The arrow identifies the cell for which more detailed results are given in Figure 6 and Figure 7

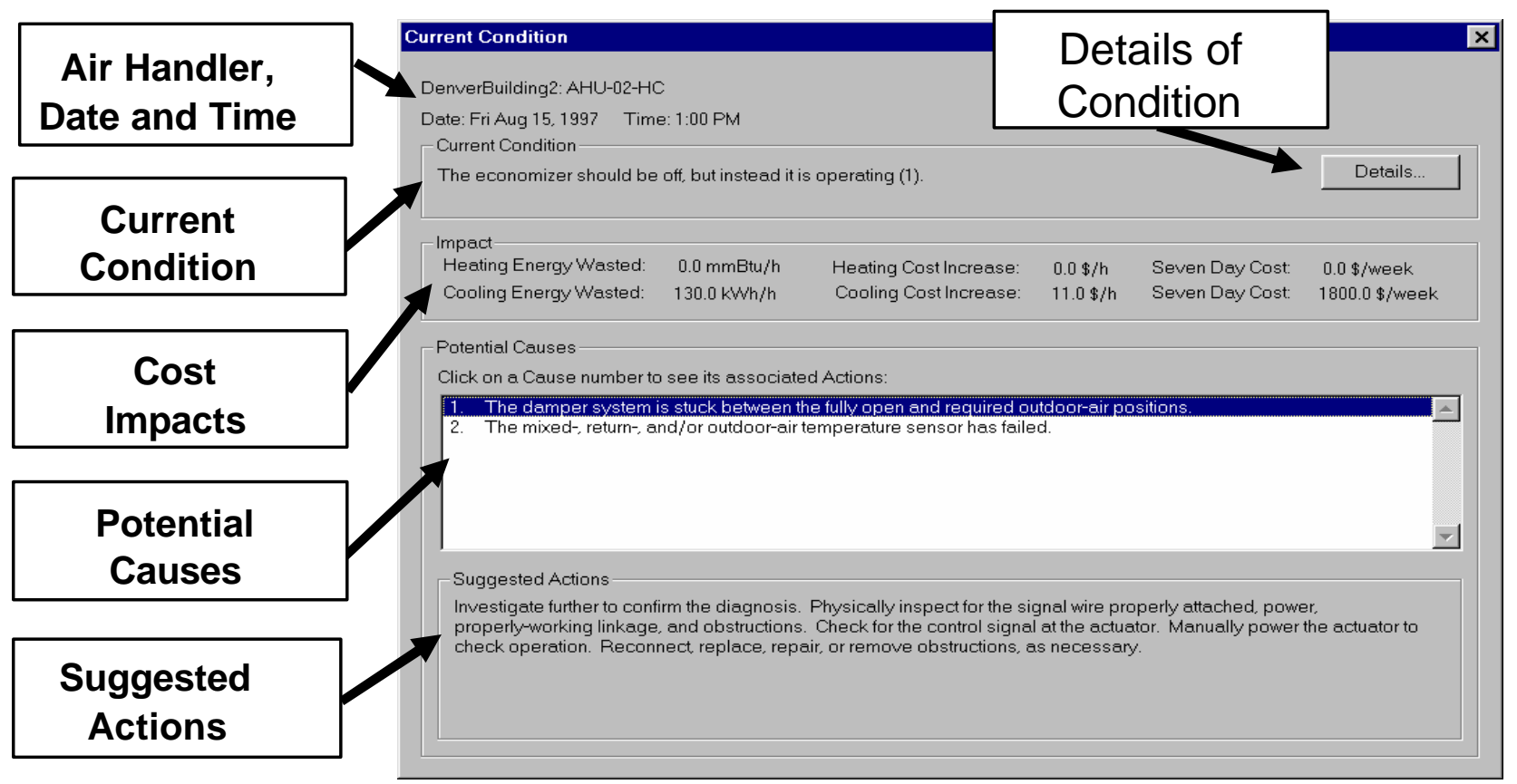

Figure 6 - Window Showing a Description of the Diagnosis, the I mpacts of the Problem Found, Potential Causes of the Problem, and Suggested Corrective Actions. 


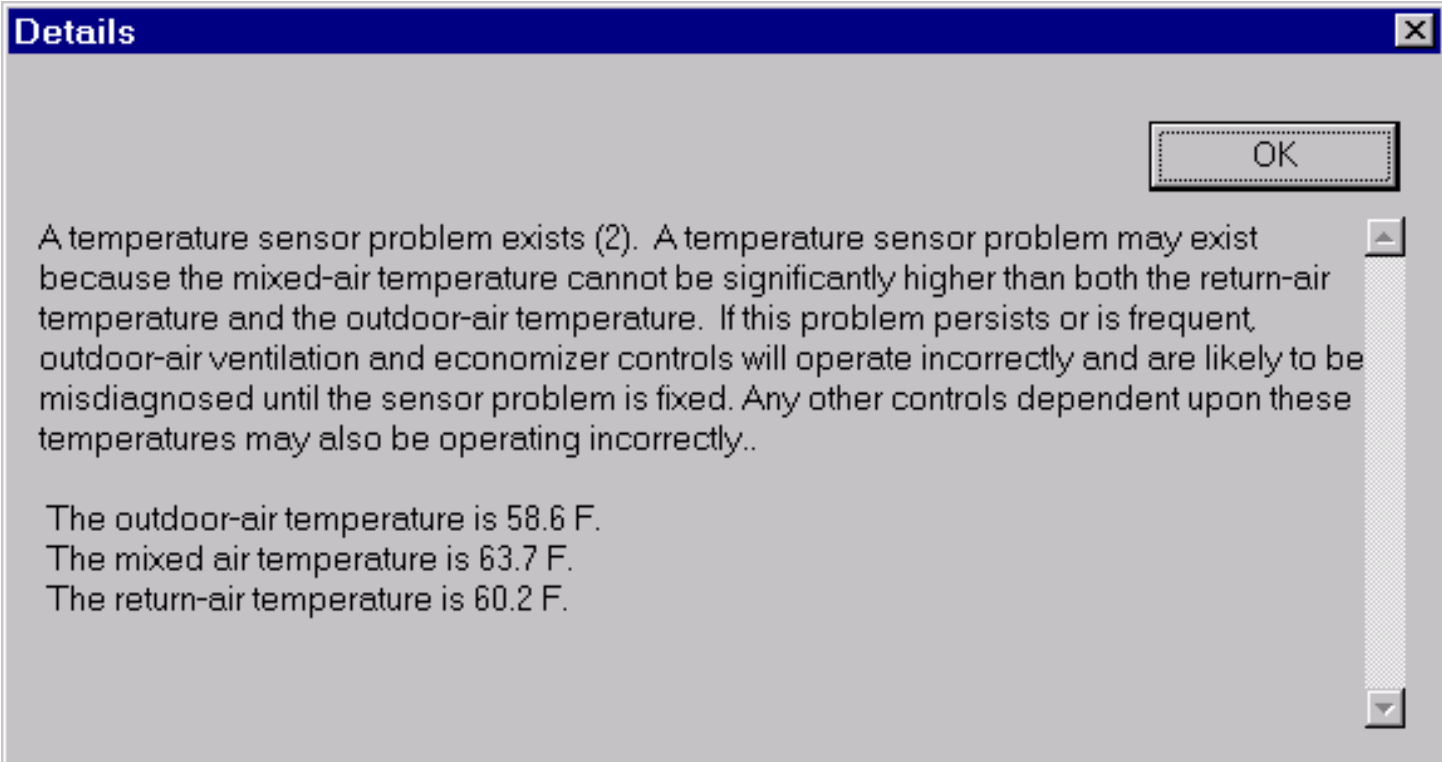

\section{Figure 7 - "Details" Window Showing a Detailed Description of the Temperature Sensor Problem I dentified in Figure 5}

\section{Requirements for Using the WBD and OAE}

The WBD and its diagnostic modules were developed for a personal computer running any Microsoft Windows operating system (98/ME/NT/2000/XP) ${ }^{4}$. The WBD can be run in a fully automated/unattended mode or can be used to batch process the data. To run the WBD in a fully automated (unattended) mode, the data collection from the air handlers to the WBD database must be fully automated. A companion data collection module can be used to collect the data from air handlers that are controlled by central building automation systems. To use this data collection module, the site needs a networked computer operating under Windows 98/NT/2000 (preferably NT or 2000 to avoid problems with the computer's clock) and a building automation system (BAS) that supports Microsoft DDE protocols. There are other methods available for data collection; however, several of the current methods may require increased levels of human intervention (see Figure 1).

Although the underlying methodology used by the OAE is independent of the time interval at which data are collected, the user interface can only display results at hourly intervals.

Therefore, all data should be at least at an hourly resolution. The data collection module can process data that is more frequent (5-minute intervals, for example) and average it to hourly values. Instantaneous values obtained on 5-minute intervals or less, and averaged to form hourly data, are recommended. It is preferable to have all measured data either instantaneous or averaged. Mixing instantaneous and averaged data may introduce false alarms and therefore is not recommended.

\footnotetext{
${ }^{4}$ Although the initial version of the WBD and its components were developed and tested under the Windows 95 operating system, this operating systems is not currently supported.
} 


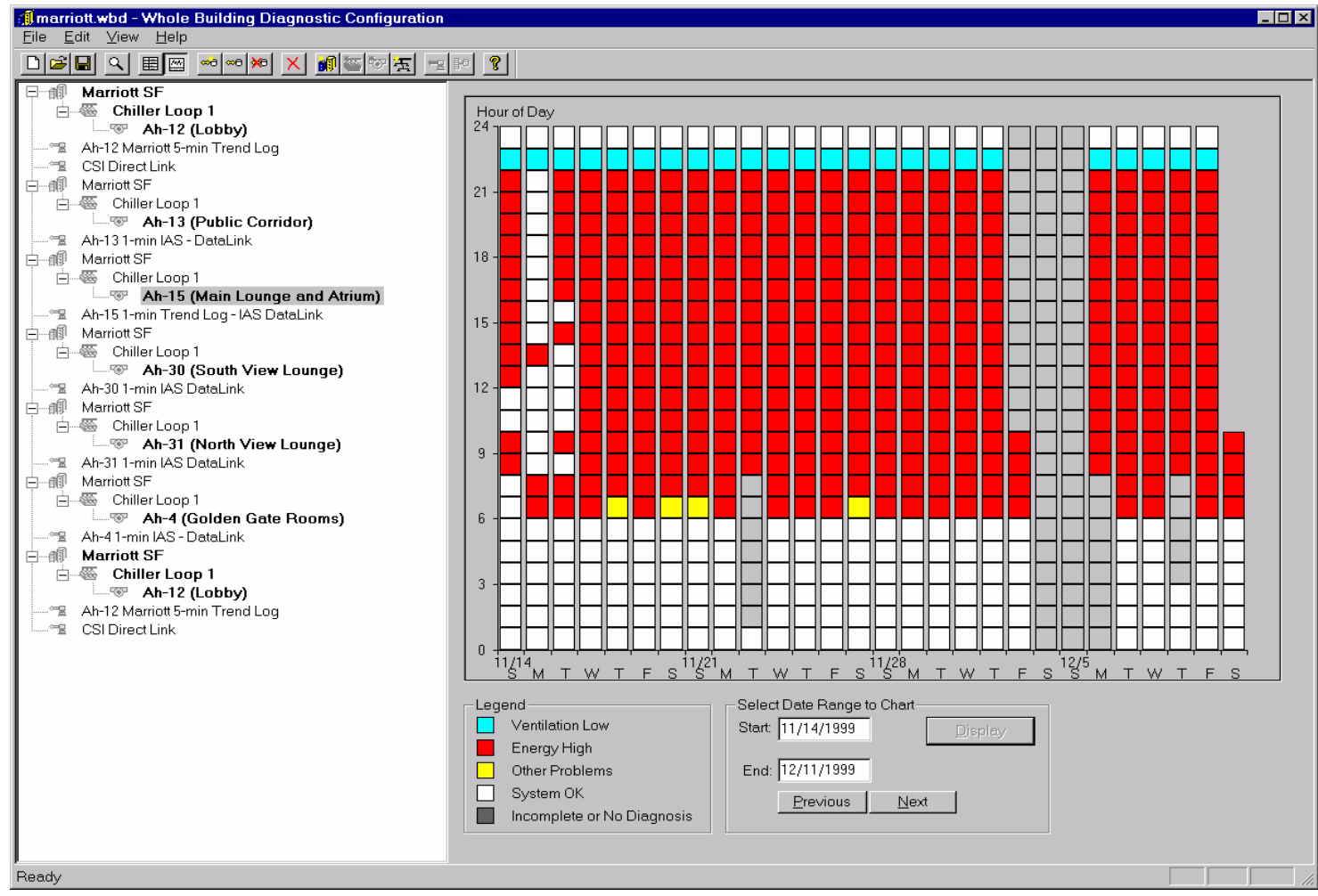

Figure 8 - An Example OAE display is shown for Air Handler 15 for November 14 through December 11. A high energy consumption problem is clearly evident throughout this time period. 


\section{Summary of Off-line Results for Symphony Towers}

The data for the off-line tests for all four air handlers were collected using the trending feature of existing building automation system in Symphony Towers. The data were from December 10, 1999 through January 13, 2001 collected on 10-minute intervals, with only a couple 1- or 2-hour gaps (3 p.m. to 4 p.m. on February 8, 2001 and 12 p.m. to 1 p.m. on February 16, 2001). A typical section of the data after it was assembled into a single file is shown in Table 2 . The column names are the sensor and control point names used in the Metasys control system. The data for the other three air handlers were similar.

The only problem with the data delivered for the off-line test was that the return-air enthalpy (computed by the control system) was provided in lieu of the return-air relative humidity that was requested. This was simply an oversight in setting up the trend logs for the test.

Fortunately, the relative humidity could be computed from the enthalpy and temperature of the air using an Excel macro. This manual step completed the data set and allowed the off-line test to proceed normally.

Table 2 - Typical Raw 5-Minute Data from AHU-1

\begin{tabular}{|c|c|c|c|c|c|c|c|c|c|c|c|c|c|}
\hline Day & Date & me & -FAN\%। & CHWV & -2 & - RA & -MAT & SA- & -RAE & A-EN & -ECON & -RAl & A-RH \\
\hline Mon & $12 / 13 / 1999$ & $9: 10$ & 82.5 & 100.0 & 63.3 & 76.1 & 56.8 & 54.9 & 23.6 & 20.1 & 100.0 & 25.7 & 67.5 \\
\hline Mon & $12 /$ & 9:20 & 82.7 & 100.0 & 63.5 & 76.3 & 56.1 & 55.2 & 23.7 & 20.2 & .0 & 25.8 & 67.5 \\
\hline Mon & 99 & $9: 30$ & 2.8 & .0 & 63.6 & 76.2 & 56.8 & 55.2 & 23.7 & 0.4 & & 26.0 & 7.5 \\
\hline Mon & & $9: 40$ & 82.9 & & 64.1 & 76.4 & 57.4 & 56.0 & 24.0 & 20.7 & & 26.8 & 67.5 \\
\hline Mon & 12 & 9:50 & 83.6 & 1 & 64.4 & 76.5 & 58.0 & 56.3 & 24.0 & 20.8 & & 26.7 & 67.6 \\
\hline Mon & 12/13/1999 & $10: 00$ & 84.4 & 100.0 & 64.8 & 76.6 & 58.1 & 56.7 & 24.1 & 21.0 & 100.0 & 26.8 & 67.5 \\
\hline
\end{tabular}

Table 2 Heading definitions:

-FAN\% is the percentage of full fan operation at the current time

-CHWV is the percentage open for the chilled-water valve

-DAT is the discharge-air temperature for the air downstream of the cooling coil and supply fan

-MAT is the mixed-air temperature

-OSA-T is the outdoor-air temperature

-RAE is the return-air enthalpy

-OSA-EN is the outdoor-air enthalpy

-ECON is the percentage of fully open for the current outdoor-air damper position (100 corresponds to the maximum economizing possible)

- $\mathrm{RAH}$ is the return-air relative humidity

-OSA-RH is the outdoor-air relative humidity.

\section{Configuring the Diagnostician}

The next step in conducting the off-line analysis was to specify the air handler's configuration for the WBD's OAE diagnostic module. There are two aspects of the air handler's operation that must be specified for the OAE: the control strategy for the outdoor-air and economizer, and the schedule (times of day and days of week) for which the minimum outdoor air must be supplied for the occupants.

The configuration screen of the WBD's user interface is shown in Figure 9. The left side is the hierarchical "configuration tree" specified by the Administrator for this WBD installation. In this case there is the Symphony Towers building and a data collection network, which is repeated 
four times at the highest level. This is because data for each air handler is stored in a separate database for convenience. Beneath the building is a heating/cooling plant, and the plant serves the air handlers. In the off-line test only one air handler (AHU-1) is configured. When the user selects AHU-1 and the configuration tab on the toolbar is pushed, as shown, the configuration for AHU-1 is displayed as shown.

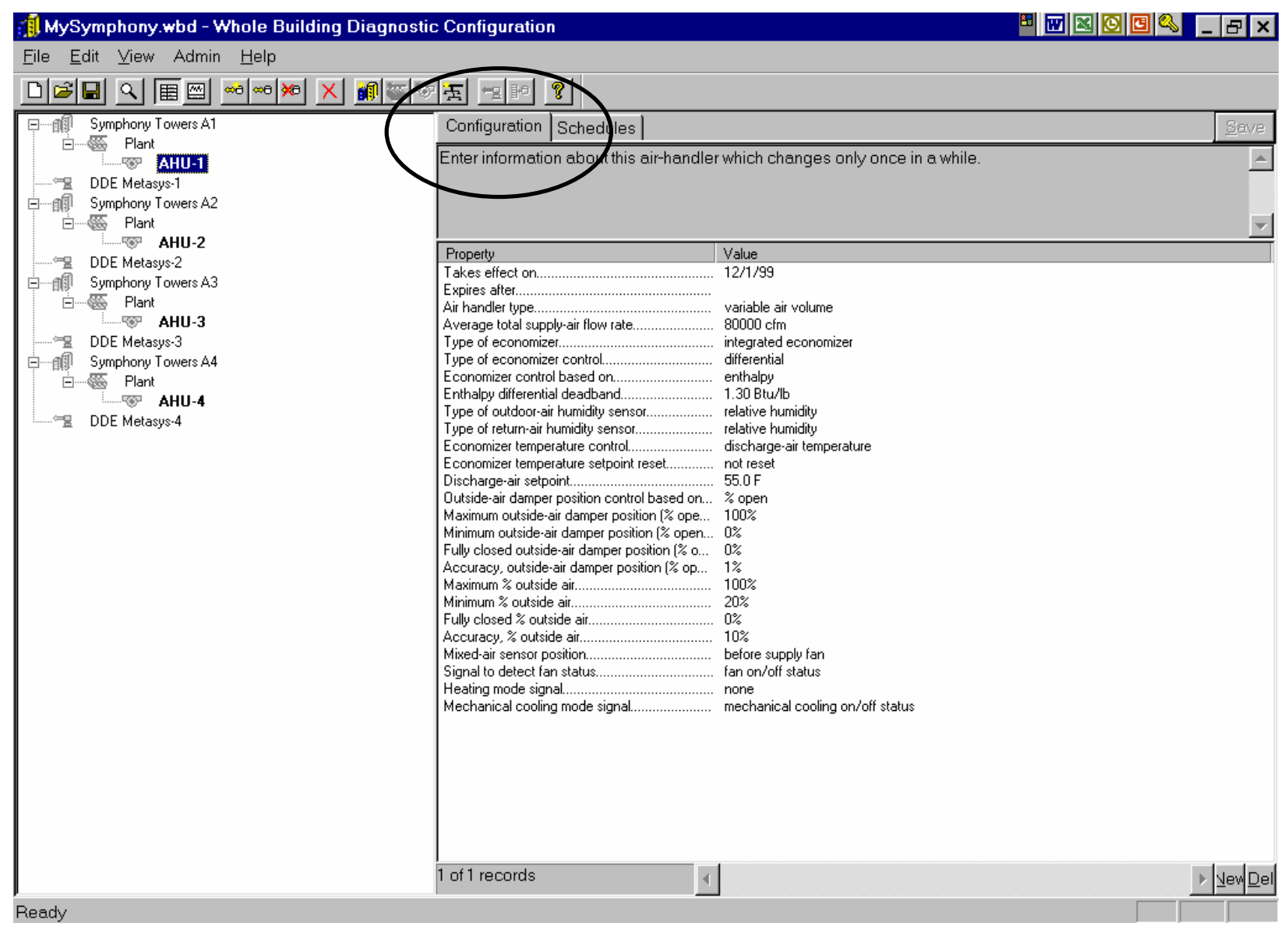

Figure 9 - WBD's Air Handler Configuration Screen for AHU-1

\section{Air Handler Configuration Parameters}

The configuration parameters for AHU-1 are shown in Figure 10. The AHU is a variable-airvolume type with a maximum air flow rate of about $80,000 \mathrm{ft}^{3} / \mathrm{min}$. It has an integrated economizer with control based on the differential between the return- and outdoor-air enthalpies, computed from dry-bulb temperature and relative humidity measurements. The dead band for economizer operation is $1.3 \mathrm{Btu} / \mathrm{lb}^{5}$. AHU-1 has a constant discharge-air temperature set point of $55^{\circ} \mathrm{F}$.

\footnotetext{
${ }^{5}$ Dead bands are usually specified in the control system to avoid excessive cycling for the outdoor-, return- and exhaust-air dampers. For temperature-based economizers, it is typically between $1^{\circ} \mathrm{F}$ and $2^{\circ} \mathrm{F}$; for enthalpy economizers, it is between 1 and $2 \mathrm{Btu} / \mathrm{lb}$.
} 


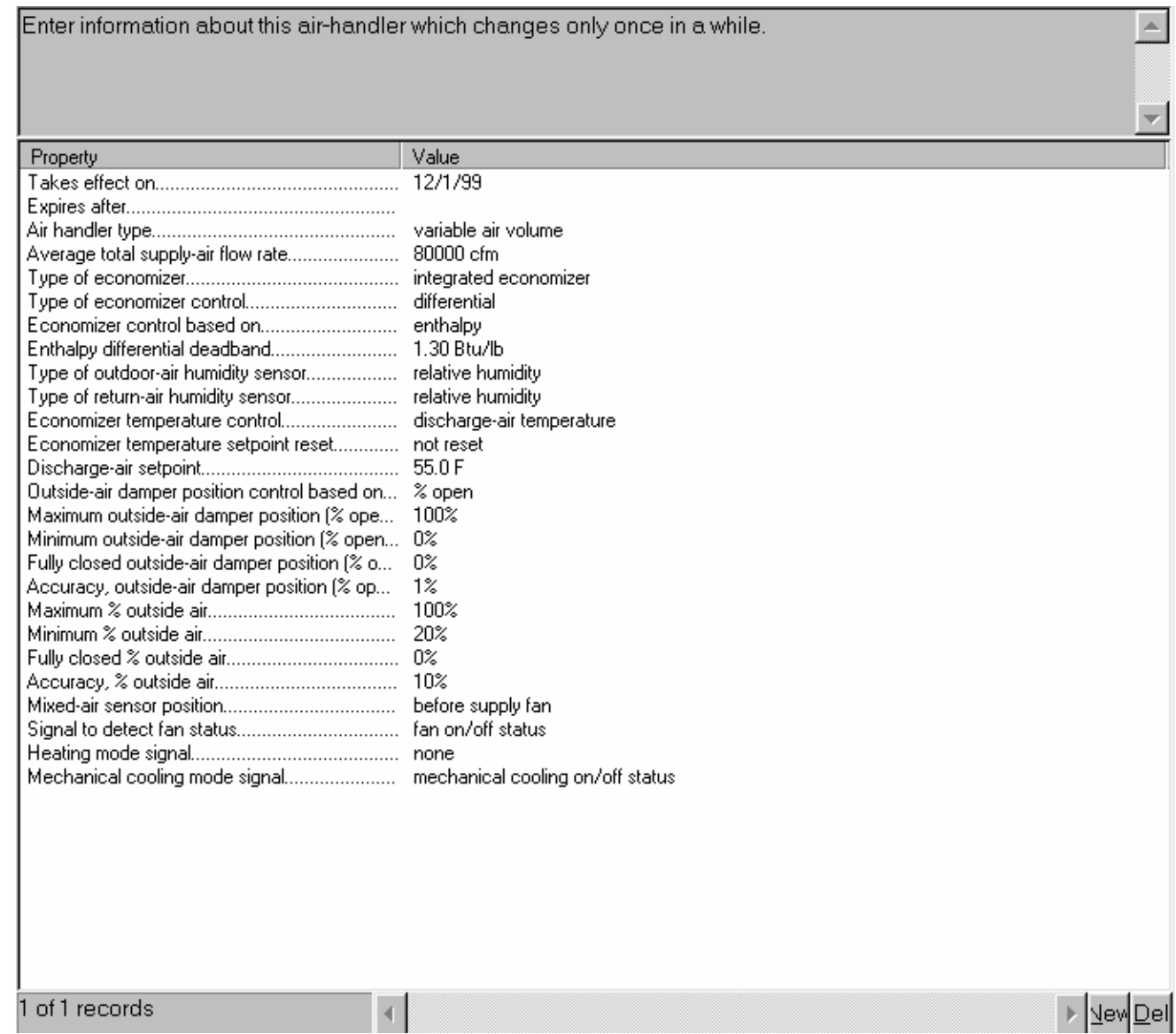

Figure 10 - Configuration Parameters for AHU-1

The outdoor-air damper system is controlled based on a specification of damper position (\% open), with a minimum position the same as the fully-closed position $(0 \%)$ and a maximum position of $100 \%$ during economizer operation. The minimum outdoor-air fraction is expected to be about $20 \%$ when the fan is operating because one bank of outdoor-air dampers is intentionally disconnected from the actuator and left in the open position to ensure minimum outdoor air is always supplied. The damper position is assumed accurate to within 1\%. The maximum damper position was specified as corresponding to an outdoor-air fraction of $100 \%$. The resulting outdoor-air fractions computed by the OAE diagnostic module from the air temperatures were observed to be accurate to within about $10 \%$.

The remaining parameters specify the types of signals and thresholds used to determine whether the supply fan and heating and cooling modes for the air handler are on at a given time. The other air handlers at Symphony Towers are configured similarly.

\section{Off-line Test Results}

The OAE diagnostic results for the first 28 days of the off-line analysis are shown in Figure 11. This view is displayed when the user selects AHU-1 on the configuration tree on the left side of the screen and pushes the View diagnostic results button on the toolbar. Each square of the "checkerboard" displays the diagnostic result for an hour, and each column of squares provides 
results for all hours in 1 day. Each square is color coded to indicate the general category of problem identified that hour, if any. As indicated in the legend in the lower part of the display, white squares indicate normal operation without problems (more strictly, no fault was detected). This was seldom the case for AHU-1 during this time. Gray squares indicate that full diagnosis could not be completed, generally when outdoor- and return-air temperatures are too close for an accurate outdoor-air fraction to be computed. Gray squares also are used to indicate missing data.

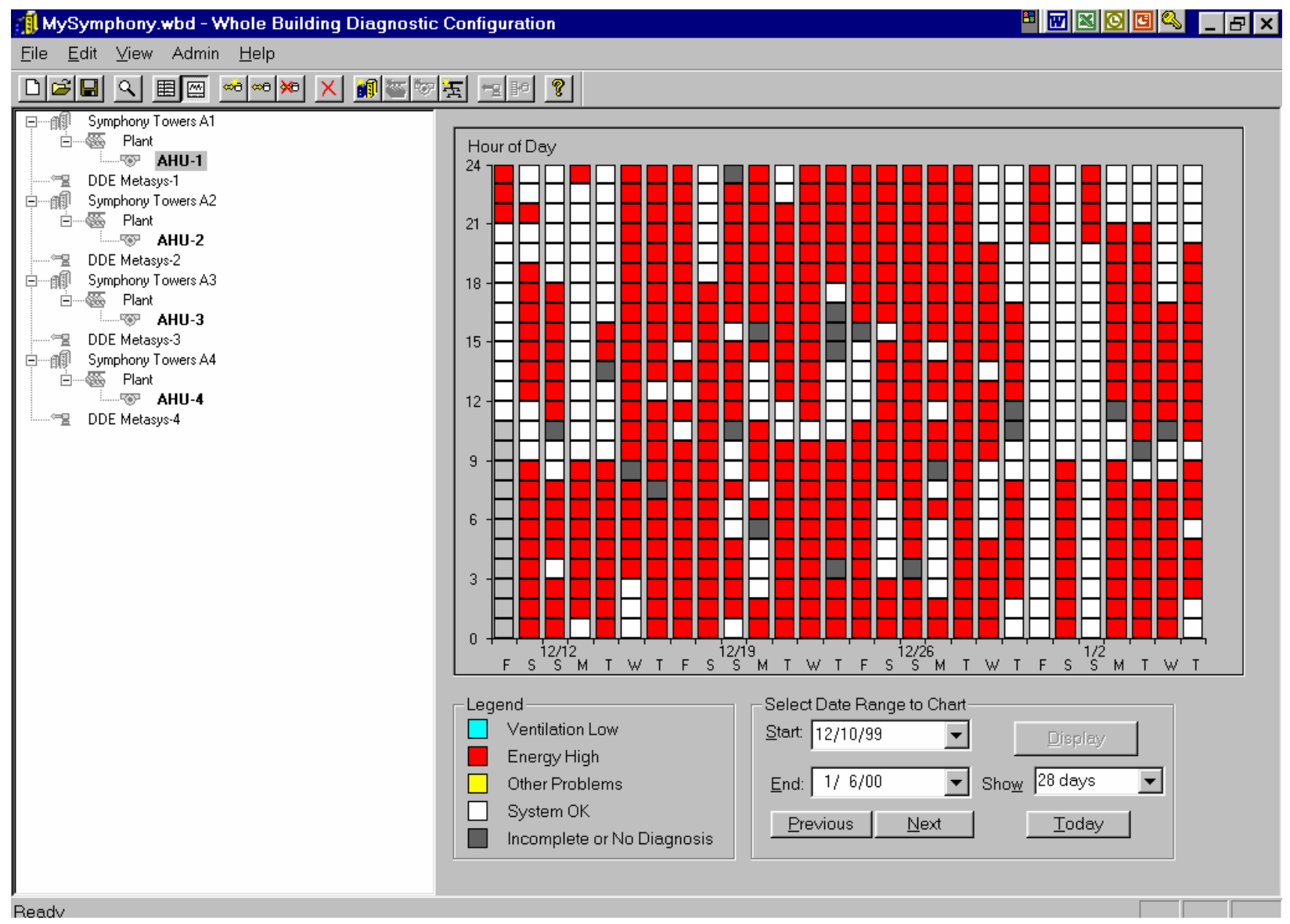

Figure 11 - Display of OAE Diagnostic Results for AHU1

Colored cells indicate abnormal or faulty operation. Blue squares indicate inadequate outside ventilation air is being supplied for the occupants; no problems of this type were detected during the period of the analysis.

The numerous red squares indicate problems that wasted energy. As indicated in Table 3, there are two general problems that occurred over $60 \%$ of the time during the period analyzed. They are investigated in further detail here. The information given in Table 3 is not displayed by the OAE, but a user can get a sense for the frequency of problem detection by sampling the cells in the OAE display. Last column in Table 3 represents the reliability score, which is cumulative uncertainty calculated from propagating the measurement uncertainty of measured values and user defined values. 
Table 3 - Frequency of the Problems for AHU-1 (the color of the various categories match the color code from the OAE diagnostic tool)

\begin{tabular}{|l|c|c|c|}
\hline $\begin{array}{c}\text { Category of Operational } \\
\text { States }\end{array}$ & $\begin{array}{c}\text { Number of } \\
\text { Occurrences }\end{array}$ & $\begin{array}{c}\text { Percent of } \\
\text { Total } \\
\text { Occupied } \\
\text { Hours (\%) }\end{array}$ & $\begin{array}{c}\text { Reliability } \\
\text { Score }\end{array}$ \\
\hline Control Problems & 0 & $0 \%$ & $\mathrm{NA}$ \\
\hline Excess Ventilation & 315 & $39 \%$ & $86 \%$ \\
\hline Low Economizer Flow & 32 & $4 \%$ & $93 \%$ \\
\hline Control Problems & 166 & $20 \%$ & $95 \%$ \\
\hline Inadequate Ventilation & 0 & $0 \%$ & $\mathrm{NA}$ \\
\hline OK but incomplete diagnosis & 24 & $3 \%$ & $93 \%$ \\
\hline Operation OK & 273 & $34 \%$ & $53 \%$ \\
\hline
\end{tabular}

Clicking on the first red cell (hour 22 [10 p.m.] on Friday December 10, 1999) displays the Current Condition dialogue shown in Figure 12. The problem is indicated as mechanical cooling is on but should be off. By browsing the other red squares, it was found that this message is common to many of them. This is a control problem that wastes energy (red control problem in Table 3), and it occurs $20 \%$ of the time during this period, as shown in Table 3. The cost impact estimate for this hour is modest, an estimated $\$ 5 /$ hour for excess cooling at an average electricity price (including demand charges) of $\$ 0.15 / \mathrm{kWh}$. A number of possible causes for this problem are presented; clicking on one of them (as shown) produces guidance to the operator in the form of suggested action(s) that might be taken to verify and correct the problem.

Clicking on the Details button provides additional information on the nature of the problem, as shown in Figure 13. This provides a more detailed description of the problem, and some key data that led to identification of this problem (and potentially for an experienced investigator to help interpret it). The economizer is operating only fully open, because the mixed-air temperature is about equal to the outdoor-air temperature. But mechanical cooling is on, even though the mixed-air temperature was quite cool at $54^{\circ} \mathrm{F}$, below the supply-air temperature set point of $55^{\circ} \mathrm{F}$ and should have been cool enough for the economizer to provide all the necessary cooling. The cause of this problem was not isolated (four possible causes are given), and the operation and maintenance staff would need to visually check all potential causes to isolate the actual cause. As we show in Section 7.4, additional information could be obtained by examining trends in the raw data (but the OAE diagnostician does not yet automate the process to this depth).

Browsing the red squares also showed another type of problem was even more prevalent during the period (39\% of the time) of the off-line analysis. Clicking on one of the red squares occurring during the afternoons (hour 16 [4 p.m.] on Sunday December 12, 1999) provides the Current Condition shown in Figure 14 and the Details shown in Figure 15. These displays indicate that even though the damper position is correct, the resulting outdoor-air fraction is too high. This excess outdoor air has a large cost impact: \$76/hour for the hour being examined, 
which projects to $\$ 13,000$ per week if those operating conditions persisted for every hour during that week.

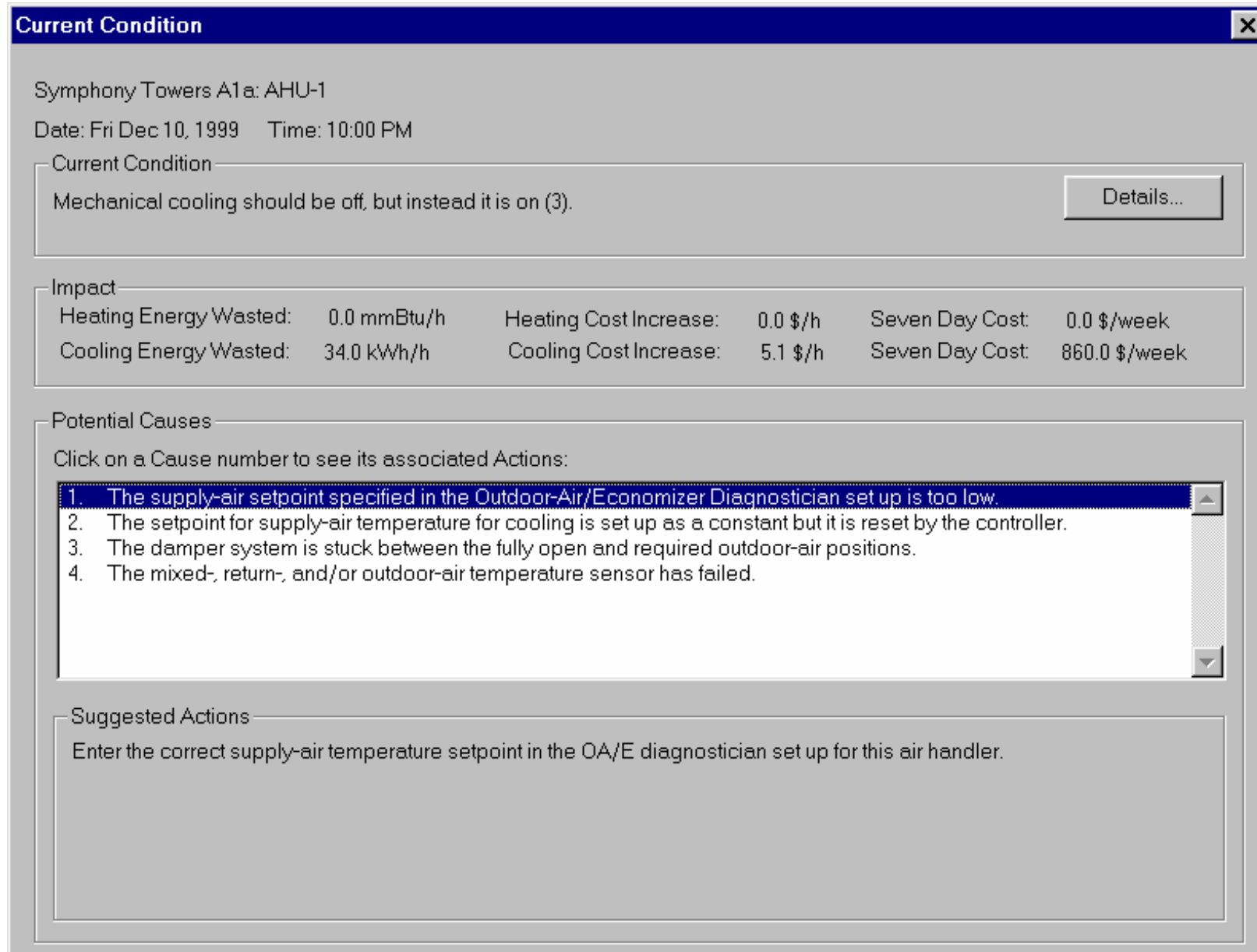

Figure 12 - Current Condition Dialogue for the Control Problem at 10 p.m. on Friday, December 10, 1999. 
Mechanical cooling should be off, but instead it is on (3). Mechanical cooling should not be on. Cooling with the economizer alone should be sufficient to maintain the supply-air temperature at the setpoint specified in the component description for this air handler. Also, the economizer should be partly closed when the outdoor air is cooler than the setpoint for the supply-air temperature to properly limit low supply-air temperatures.

The outdoor-air temperature is $52.9 \mathrm{~F}$.

The mixed air temperature is $53.8 \mathrm{~F}$.

The return-air temperature is $75.2 \mathrm{~F}$.

The supply air temperature is $61.8 \mathrm{~F}$.

Figure 13 - Details on the Current Condition for the Control Problem

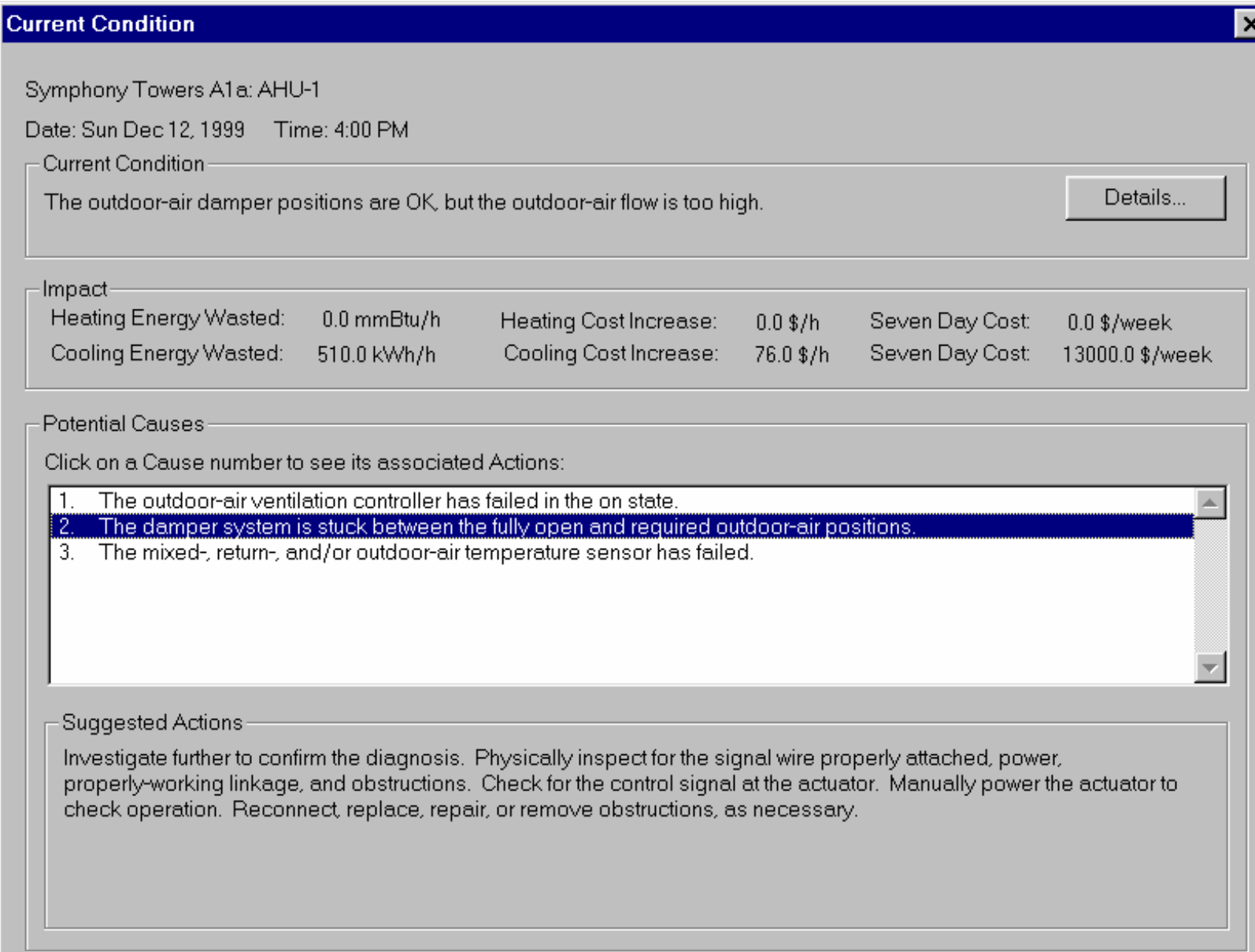

Figure 14 - Current Condition Dialogue for the Excess Ventilation Problem 


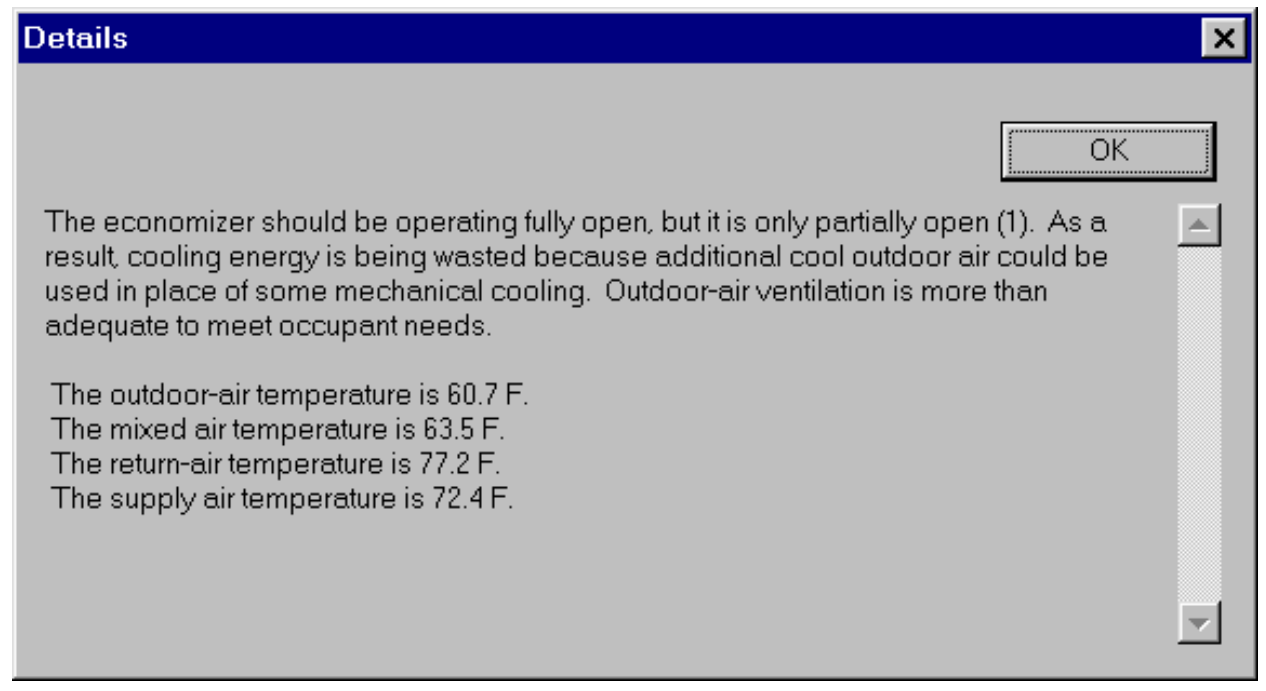

\section{Figure 15 - Details Dialogue for Excess Ventilation Problem}

\section{Analysis of Trend Data}

The user of the WBD is encouraged to examine the equipment or to utilize the control system's capabilities to investigate problems further when their exact cause or impact of a problem is unclear (i.e., a single cause is not isolated). In the off-line analysis for this project, our version of this is to look at the raw data, which in fact is identical with trend-log data obtained from the control system, to try to extract information beyond that provided by the OAE.

Examining the trend data showed that when the economizer was not running and the outdoor-air dampers were at their minimum position $(0 \%)$, the outdoor-air fractions were in the range of $50 \%$ to $60 \%$. Thus, it appears that too large a portion of the damper was disengaged from the actuator to maintain the desired $20 \%$ outdoor-air fraction and is allowing much more outdoor air than that to enter. Alternatively, it may be that the remainder of the damper system leaks more than expected or is not controlled properly to fully close (and this must be determined by visual inspection).

Examining the trend data also showed that when the control problems were indicated, the supply-air temperature exceeded its set point of $55^{\circ} \mathrm{F}$, and the chilled-water valve was continually at $100 \%$ in an attempt to maintain it. The reason for this was not clear until the pattern of supply-air temperature was examined in conjunction with Symphony Towers' controls consultant. The supply-air temperatures were consistently about $8^{\circ} \mathrm{F}$ to $10^{\circ} \mathrm{F}$ higher than the mixed-air temperature. Because the mixed-air temperature is checked by the OAE diagnostic module for consistency with the outside- and return-air temperatures, it was considered reliable. The supply-air temperature was then checked manually and found to be inaccurate. It was recalibrated. This adjusted its reading by about $8^{\circ} \mathrm{F}$ higher than previously.

The whole HVAC system immediately began to unload as soon as this change was made. The control system data showed the chilled water valves immediately closed, and the fan speed increased as the terminal unit (VAV box) dampers opened, no longer trying to restrict entry of unwanted cool air. Undoubtedly significant reheating of this air was occurring in the terminal 
units. The WBD's display of problems after this correction is shown in Figure 16. Note that the frequency of problems is greatly reduced.

This problem is not the focus of the OAE diagnostic module because it is a more general air handler problem outside the OAE's scope. Nevertheless, the problem was detected by the OAE diagnostician under conditions when it affected the economizer function. Its actual impacts are difficult to assess and are the subject of a supplementary analysis being conducted. The case, however, is a good example of how the OAE can identify problems and their potential causes. Building staff can then follow up to examine these problems carefully, isolate the causes, and correct them to capture energy savings and improve building performance.

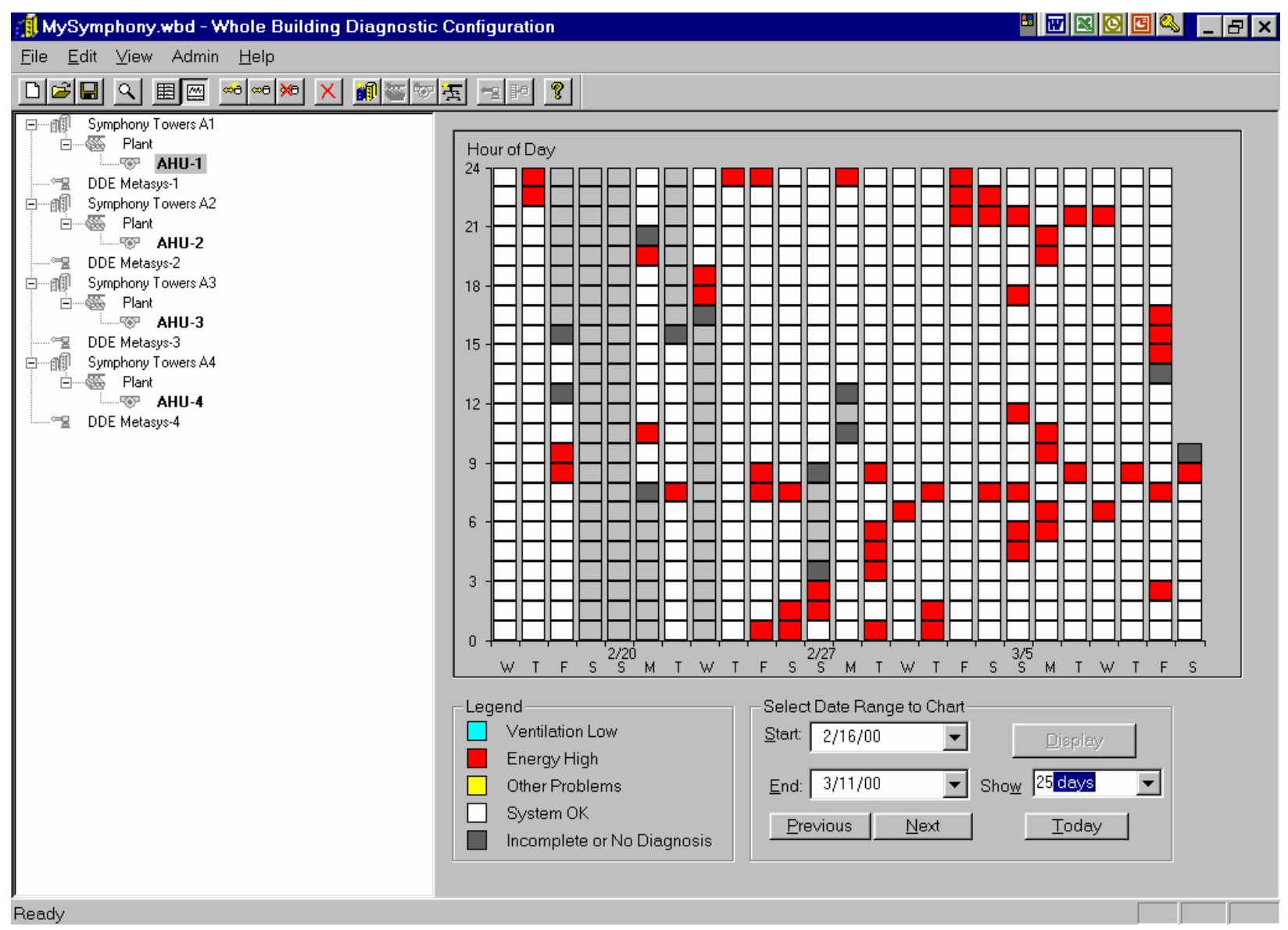

Figure 16 - WBD Display of Problems after Supply-Air Temperature Sensor was Fixed

\section{Conclusions from Off-line Tests}

Two problems were found in the operation of AHU-1 in Symphony Towers. One, unnecessary cooling as a result of the uncalibrated supply-air temperature sensor, was fixed immediately after the off-line analysis was completed. The second problem, the outdoor-air flow rates at the minimum occupied level being too high, should be corrected by adjusting the flow rates downward to save energy while still providing sufficient outdoor air to maintain indoor-air quality. This second problem is only an issue during the heating season or times when it is too hot for the economizer to open. Fortunately, San Diego's mild climate minimizes the impact of this problem. 
No problems were detected with the primary temperature sensors (return-, outside-, and mixedair). This suggests that the sensors are providing reasonably-accurate data. Symphony Towers had recalibrated these sensors before the WBD demonstration. The supply-air sensor did not receive this calibration, however, and was to be found faulty. 


\section{On-line Data Collection and Testing}

Continuous data collection and testing started immediately after the off-line test was completed and the WBD configured for all four AHUs in April 2000 and continued through the end of the demonstration project March 2003.

\section{Data Collection}

The automated on-line data collection uses the Dynamic Data Exchange (DDE) protocol, an industry standard protocol developed by Microsoft, for exchanging data between two applications. The DDE server application developed by the control manufacturer [in this case Johnson Controls Inc. (JCI)] only runs on an operator's workstation; therefore, a part of the WBD's data collection software also had to run on the workstation. Although the entire WBD software can run on the operator's workstation, at Symphony Tower most of the WBD software was on a separate workstation, as shown in Figure 17.

The WBD periodically requests data from the BAS through the operator's workstation using the TCP/IP network. Requests from the WBD are acknowledged by the WBD's data acquisition module that runs on the operator workstation, which in turn passes those requests to the BAS through an intermediate application (Metalink from JCI). Metalink gets the data from sensors or control devices and passes it to the WBD, which stores them in a Microsoft Access database for processing. The data requests can be made at any frequency. At Symphony Towers, the data was requested at 5-minute intervals and integrated over the hour before being processed by the diagnostic module.

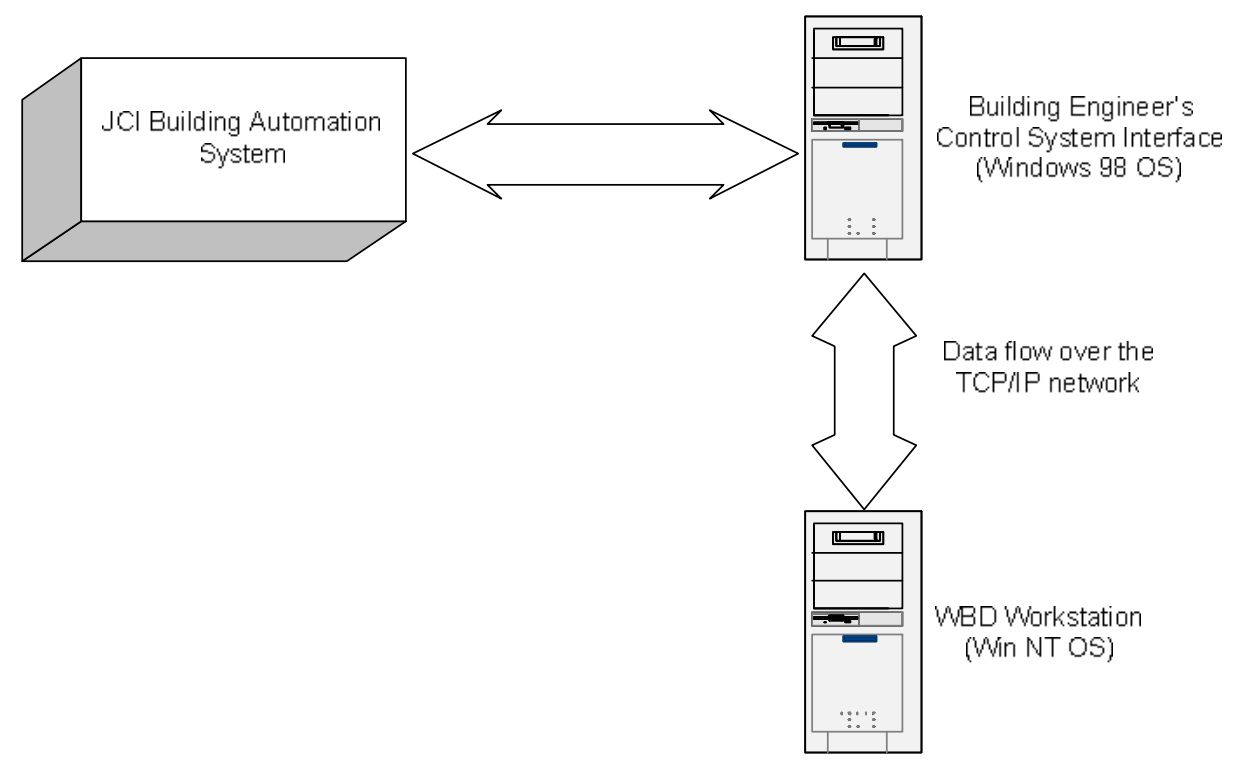

Figure 17 - Schematic diagram of the On-line Data Collection Process at Symphony Towers

The list of data points for each of the four AHUs at the Symphony Towers is shown in Table 4. Integration of most channels is conditioned on whether the fan is on, as shown in Table 4. 
As noted earlier, the automated on-line data collection started in April 2000 for all four AHUs. The data collection module on the operator's workstation and all modules for the WBD on the WBD workstation were put in the startup folder of the respective workstations so that when the computers were rebooted, all necessary software was automatically initiated. However, if applications are manually terminated, the data collection process stops until the application is manually restarted or until the workstation is restarted. There were several occasions where the data acquisition module on the operator's workstation was manually terminated and it went undetected for several weeks. Although several weeks of data were lost as a result of this problem, more than 1 year of data was collected for all four AHUs.

Table 4 - Data Points Collected by Symphony Towers for OAE Diagnostic Module

\begin{tabular}{|c|c|c|c|}
\hline Type of Data & Data Item & Units & Integration \\
\hline time stamp & time stamp (end of hour) & Date Time & none \\
\hline fan on-time & fan on-time & Fraction & average hourly \\
\hline \multirow{4}{*}{ air temperatures } & outdoor-air (dry-bulb) temperature & \multirow{4}{*}{${ }^{\circ} \mathrm{F}$} & \multirow{4}{*}{$\begin{array}{l}\text { average hourly } \\
\text { when fan on }\end{array}$} \\
\hline & return-air (dry-bulb) temperature & & \\
\hline & mixed-air (dry-bulb) temperature & & \\
\hline & supply-air temperature (dry-bulb) & & \\
\hline \multirow{2}{*}{ air humidities } & outdoor-air relative humidity & \multirow{2}{*}{$\%$} & \multirow{2}{*}{$\begin{array}{l}\text { average hourly } \\
\text { when fan on }\end{array}$} \\
\hline & return-air relative humidity & & \\
\hline damper position & outdoor-air damper position command & $\%$ open & $\begin{array}{l}\text { average hourly } \\
\text { when fan on }\end{array}$ \\
\hline status of $\mathrm{AHU}$ & chilled-water valve position (fraction open) & $\%$ open & $\begin{array}{l}\text { average hourly } \\
\text { when fan on }\end{array}$ \\
\hline
\end{tabular}

\section{Results for AHU-1}

Initially, when the off-line data from AHU-1 was processed, most of the cells were red, indicating energy waste (Figure 11). The OAE diagnostician identified that the problem was related to the supply-air temperature. During a site visit, the diagnosis was confirmed and the supply-air temperature recalibrated. After the recalibration, the number of red cells decreased considerably (Figure 16) but were not totally eliminated. Red cells remained because the AHU is drawing in more outdoor air than required to meet the ventilation requirement when conditions are not favorable for economizing and when the AHU is in the heating mode.

By design, the OAE diagnostician's single-state diagnostic process terminates and reports a finding that the AHU is improperly operating when it finds the first problem (for a particular hour). Although the process could be modified to track multiple problems simultaneously, the computational overhead of doing so would certainly be higher than for the single-state process that the OAE currently uses. If the AHU has multiple problems, like AHU-1, the process only identifies the first predominant problem encountered. However, if the first problem is corrected and new data are then analyzed, the OAE will identify the next predominant problem encountered or will indicate no problems if all problems have been fixed. Identifying faults sequentially may take slightly more time, but it is still better than letting the AHU operate inefficiently or in faulty condition without the operation staff knowing. 
The second problem (excess outdoor-air) for AHU-1 continued through the on-line monitoring period, as seen in Figure 18 and Figure 19. It is important to note the number of red cells in Figure 18 is greater than in Figure 19. This is caused by differences in outdoor conditions during the two periods. In September and October, outdoor conditions are less favorable for economizing compared to conditions in December and January (in San Diego). When the AHU is not economizing, the damper is at the minimum position, and it is during these conditions that this fault manifests itself.

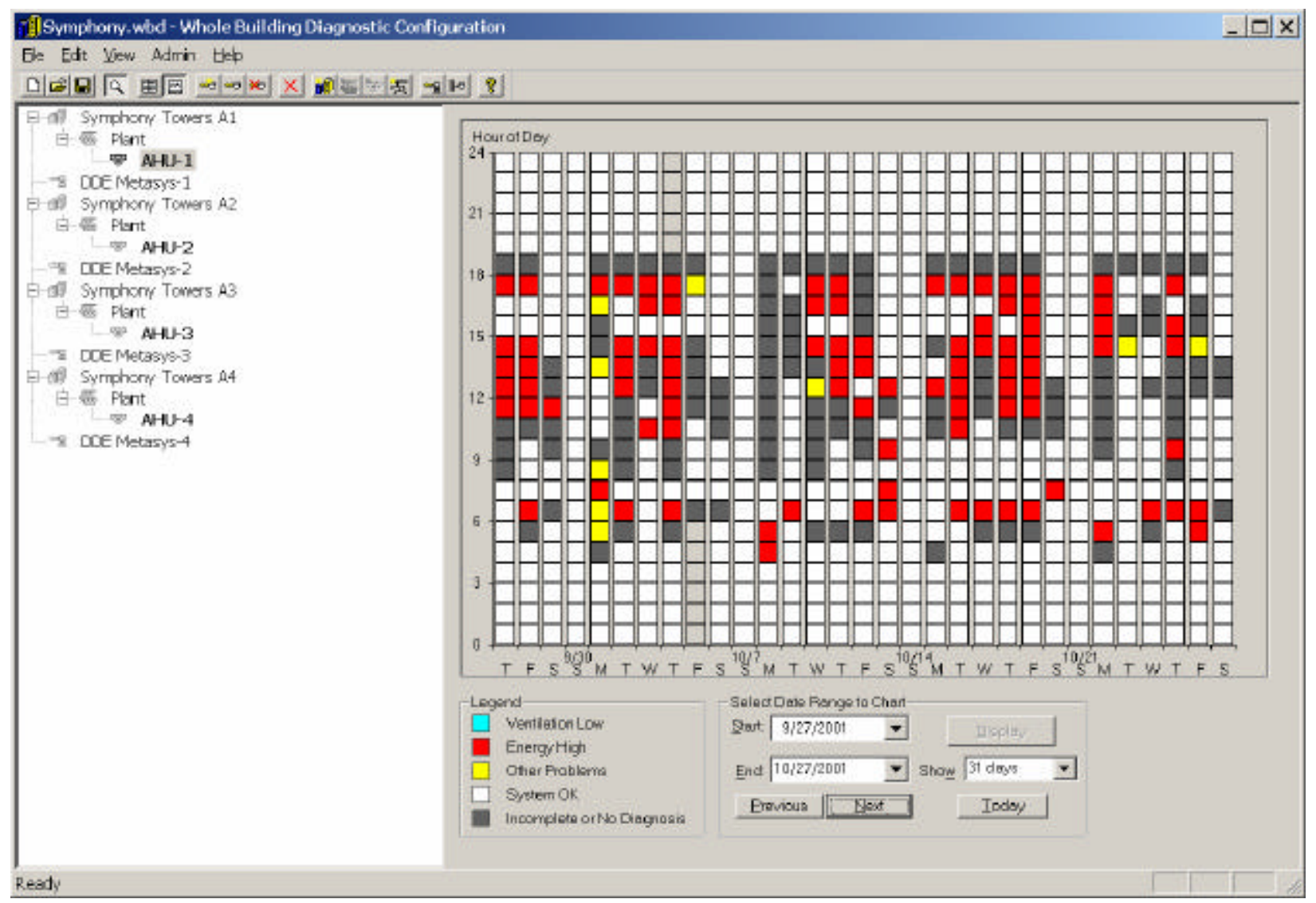

Figure 18 -WBD Diagnostic Results for AHU1 for a Period from September 27 through October 27, 2001 


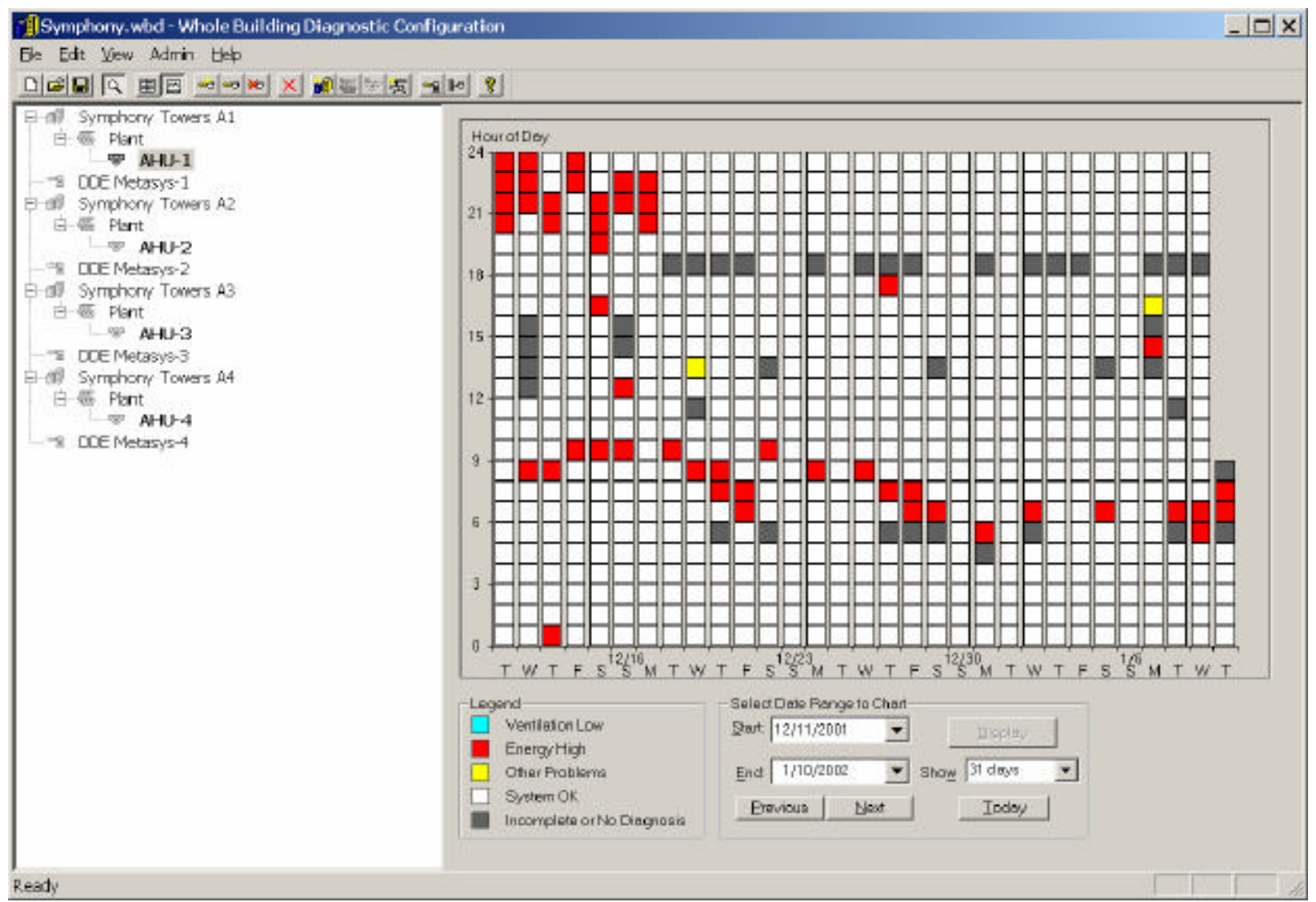

Figure 19 - WBD Diagnostic Results for AHU1 for a Period from December 11, 2001, through J anuary 10, 2002

The frequency of problems reported during the on-line test (March 2001 through January 2003) after the correction of the first problem (supply-air temperature sensor calibration) is shown in Table 5. Compared to frequency the distribution prior to correcting the first problem identified (Table 3), the percentages of excess ventilation and control problems have decreased, while the percentage of hours when the diagnosis was incomplete has increased substantially.

Table 5 - Frequency of the Problems for AHU-1 when the Building is Occupied (March 2001 through J anuary 2003)

\begin{tabular}{|l|r|r|r|}
\hline Category of Operational States & \multicolumn{1}{|c|}{$\begin{array}{c}\text { Reliability } \\
\text { Score }\end{array}$} & \multicolumn{1}{c|}{$\begin{array}{c}\text { Number of } \\
\text { Occurrences }\end{array}$} & \multicolumn{1}{c|}{$\begin{array}{c}\text { Percent of Total } \\
\text { Hours (\%) }\end{array}$} \\
\hline Control Problem & 0.933 & 119 & 2.5 \\
\hline Control Problem - Excess Energy & 0.946 & 156 & 3.3 \\
\hline Excess Ventilation & 0.863 & 862 & 18.2 \\
\hline Low Economizer Flow & 0.934 & 175 & 3.7 \\
\hline Inadequate Ventilation & 0.855 & 2 & 0.0 \\
\hline OK but incomplete diagnosis & 0.934 & 890 & 18.8 \\
\hline Operation OK & 0.562 & 2522 & 53.4 \\
\hline \multicolumn{1}{|c|}{ Total } & & $\mathbf{4 , 7 2 6}$ & $\mathbf{1 0 0}$ \\
\hline
\end{tabular}




\section{Results for AHU-2}

In April 2000, the WBD was set up to automatically collect and process data from AHU-2 continuously through the end of the demonstration period. Like AHU-1, there were several gaps in data from AHU-2, again, primarily caused by manual termination of data collection software on the operator's workstation.

The results from the WBD indicate that AHU-2, like AHU-1, is operated improperly. The screen shot of the processed results for the time period between June 1 and July 1, 2000, is shown in Figure 20. A significant number of cells during occupied hours (6 a.m. to 9 p.m.) are yellow, followed in frequency by grey and blue. Yellow and blue cells, in most cases, indicate a problem with the temperature sensors (outdoor-air, return-air or mixed-air). Clicking on one of the yellow cells (hour 13 on June 20, 2000) displays the Current Conditions Dialogue shown in Figure 21. This indicates the presence of a temperature-sensor problem. By browsing the other yellow cells, this message was found to be common to almost all of them. The cost impact shown in Figure 21 is meaningless because it was based on a faulty sensor value. The OAE diagnostician cannot accurately estimate energy and cost impacts from fault temperature data.

Clicking on the Details button (shown in Figure 21) provides additional information on the nature of the problem, as shown in Figure 22. This provides a more detailed description of the problem, and some key data upon which detection of the problem is based. This data can also help understand the problem better. The mixed-air temperature $\left(78.4{ }^{\circ} \mathrm{F}\right)$ is higher than both the return-air $\left(76.4^{\circ} \mathrm{F}\right)$ and outdoor-air $\left(71.2^{\circ} \mathrm{F}\right)$ temperatures. Although the OAE diagnostician has detected a problem with the temperature-sensor data, it cannot isolate which of the three sensors is faulty. Examination of the trend data, however, may provide additional information that may allow for isolation of the fault (but this is not yet implemented in the OAE).

The most current results (at the time of writing this report) are shown in Figure 23; they are similar to the results shown in Figure 21. Although there are more red cells compared to the earlier time period, browsing the cells reveals the potential cause is still same, a temperaturesensor problem.

The frequency of problems reported for AHU-2 is shown in Table 6 (March 2001 and January 2003). The AHU-2 operates almost $30 \%$ of the occupied period with a control problem, $11 \%$ with inadequate ventilation and $9 \%$ with low economizer flow (economizer not fully open). Although the temperature-sensor problem exists at all times, it only manifests about $50 \%$ of the time, during the occupied hours. 


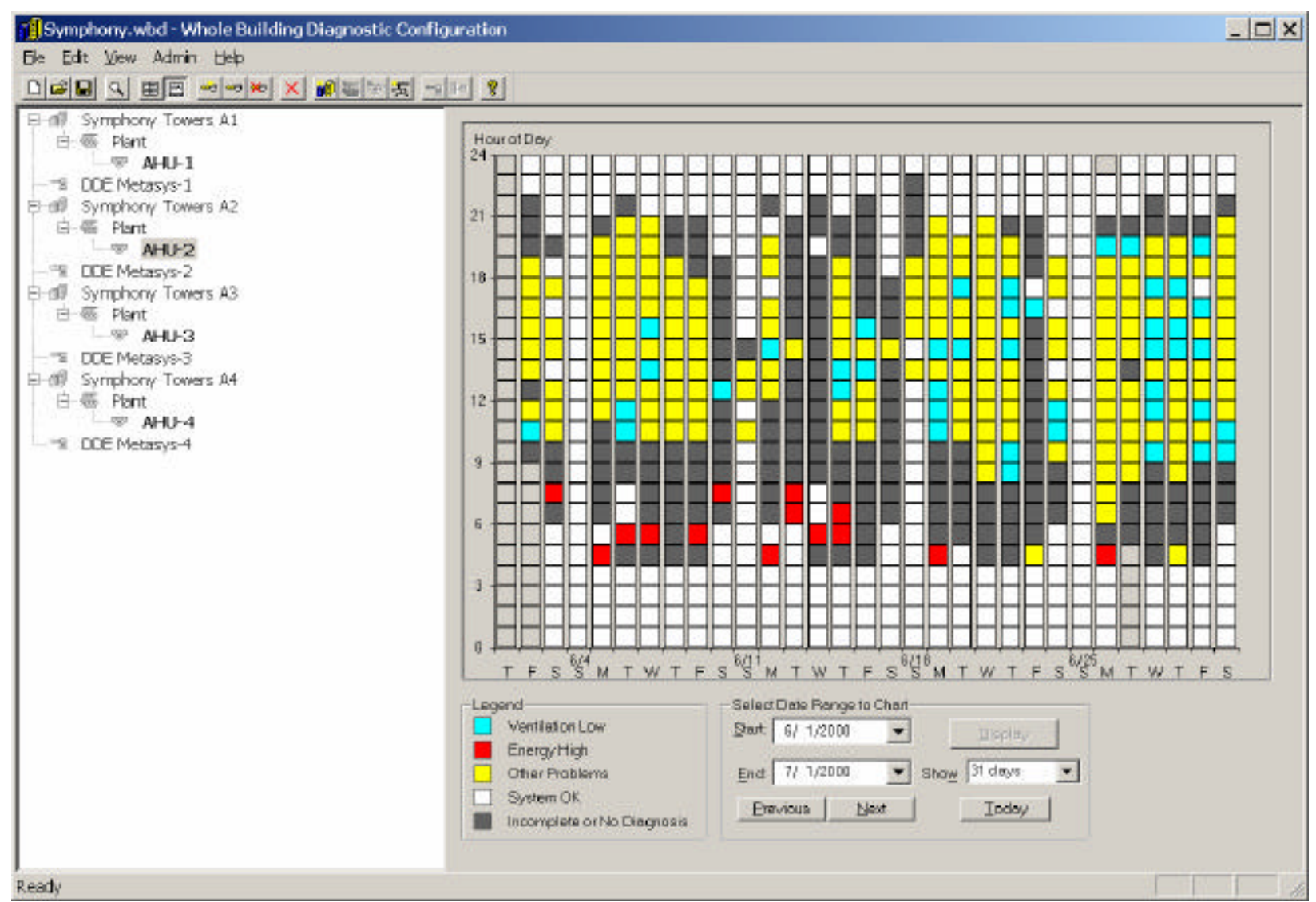

Figure 20 - WBD Diagnostic Results for AHU-2 for a Period from J une 1 through J uly 1, 2000 


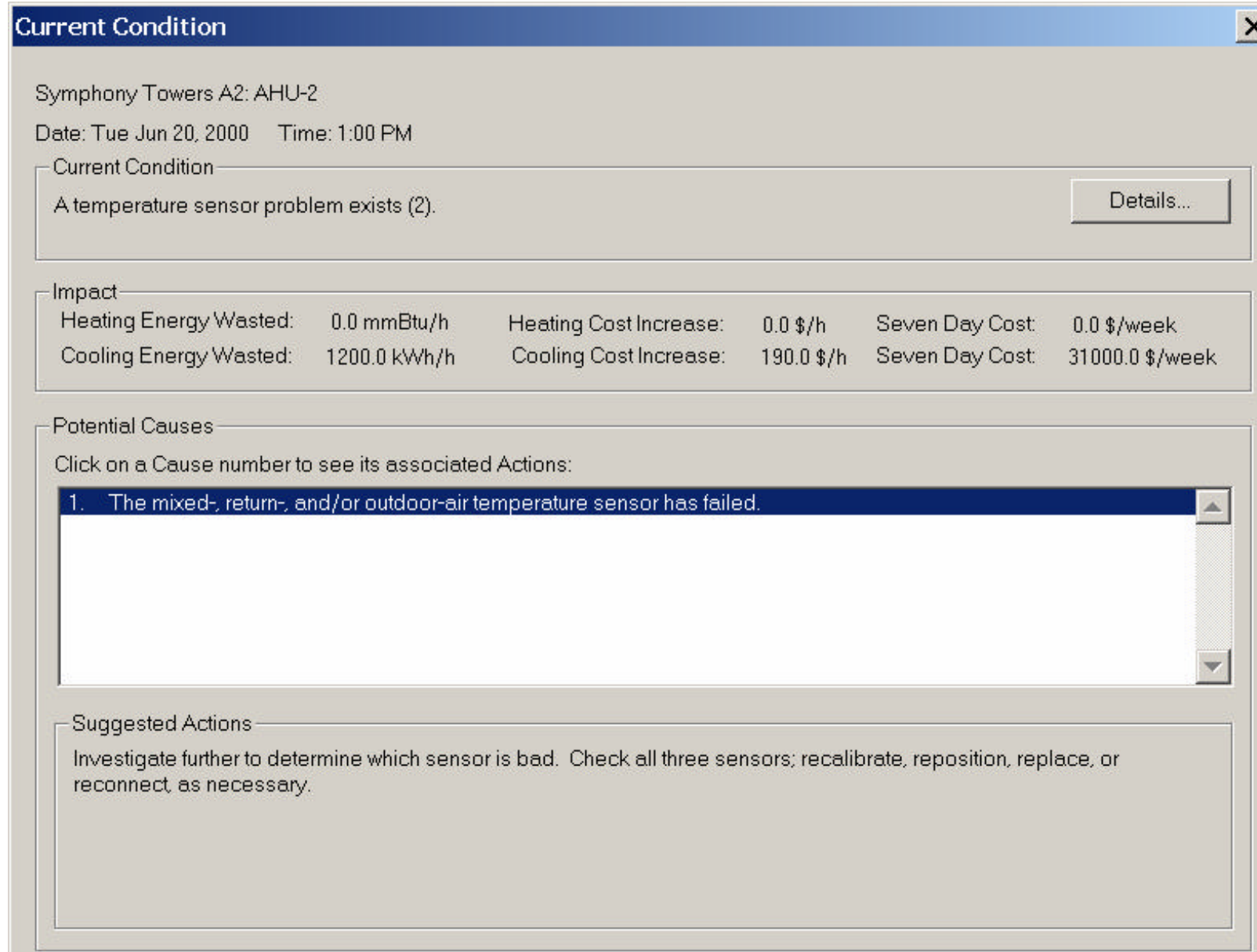

Figure 21 - Current Conditions Dialogue for AHU-2 for J une 20, 2000, Indicating a Temperature-sensor Problem 


\section{Details}

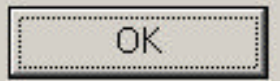

A temperature sensor problem exists (2). A temperature sensor problem may exist because the mixed-air temperature cannot be significantly higher than both the return-air temperature and the outdoor-air temperature. If this problem persists or is frequent, outdoor-air ventilation and economizer controls will operate incorrectly and are likely to be misdiagnosed until the sensor problem is fixed. Any other controls dependent upon these temperatures may also be operating incorrectly.

The outdoor-air temperature is $71.2 \mathrm{~F}$.

The mixed air temperature is $78.4 \mathrm{~F}$.

The return-air temperature is $76.4 \mathrm{~F}$.

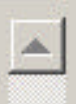


Table 6 - Frequency of the Problems for AHU-2 when the Supply-Fan was Operational (March 2001 through J anuary 2003)

\begin{tabular}{|l|r|r|r|}
\hline Category of Operational States & \multicolumn{1}{|c|}{$\begin{array}{c}\text { Reliability } \\
\text { Score }\end{array}$} & $\begin{array}{c}\text { Number of } \\
\text { Occurrences }\end{array}$ & \multicolumn{1}{c|}{$\begin{array}{c}\text { Percent of Total } \\
\text { Hours (\%) }\end{array}$} \\
\hline Control Problem & 0.872 & 998 & 26.5 \\
\hline Control Problem - Excess Energy & 0.950 & 99 & 2.6 \\
\hline Excess Ventilation & 0.859 & 43 & 1.1 \\
\hline Low Economizer Flow & 0.800 & 323 & 8.6 \\
\hline Inadequate Ventilation & 0.885 & 404 & 10.7 \\
\hline OK but incomplete diagnosis & 0.940 & 1,343 & 35.7 \\
\hline Operation OK & 0.614 & 549 & 14.6 \\
\hline \multicolumn{1}{|c|}{ Total } & & $\mathbf{3 , 7 5 9}$ & $\mathbf{1 0 0}$ \\
\hline
\end{tabular}

\section{Additional Analysis of Data from AHU-2}

The analysis presented in this section is not provided by the OAE, but could be undertaken by an engineer experienced in this sort of analysis. It is not expected that most users will undertake such analysis, but they will rather inspect the sensors directly to determine the sources of the problems found by the OAE diagnostician. The analysis is presented here (and in Sections 8.7 and 8.9 ) to provide more insight into the specific underlying problems that led to the findings of the OAE.

The OAE diagnostician detected a temperature-sensor problem but was unable to diagnose which of the three sensors was faulty. Additional graphical analysis presented in this section may provide addition information regarding which sensor is faulty. This graphical analysis is not part of the OAE module. In Figure 24 the mixed-air temperature is plotted as a function of the outdoor-air temperature when the outdoor-air damper position signal is at $100 \%$ (i.e., the outdoor-air damper is fully open). When the outdoor-air damper is fully open, the mixed-air temperature should be nearly equal to the outdoor-air temperature. However, in the case of AHU-2, the mixed-air temperature is greater than outdoor-air temperature by $2^{\circ} \mathrm{F}$ to $15^{\circ} \mathrm{F}$. If the mixed-air and outdoor-air temperatures are nearly equal, they should be close to the solid line (say within $\pm 2^{\circ} \mathrm{F}$ ).

Another plot, mixed-air temperature as a function of the return-air temperature when the outdoor-air damper position signal is at its minimum position, is shown in Figure 25. Considering that the zone set-point temperatures are around $75^{\circ} \mathrm{F}$, the return-air temperature appears to be in the acceptable range $\left(73^{\circ} \mathrm{F}\right.$ to $\left.80^{\circ} \mathrm{F}\right)$. When the outdoor-air damper is at the minimum position and outdoor-air temperature is higher than return-air temperature, the mixedair temperature should be greater than the return-air (i.e., above the solid line in Figure 25). Likewise, when the outdoor-air temperature is lower than return-air temperature, the mixed-air temperature should be lower than the return-air temperature (i.e., below the solid line in Figure 25). However, the mixed-air temperature is always higher than the return-air temperature (i.e., above the solid line). By comparing the results from Figure 24 and Figure 25, it appears that the mixed-air temperature sensor is probably faulty. 


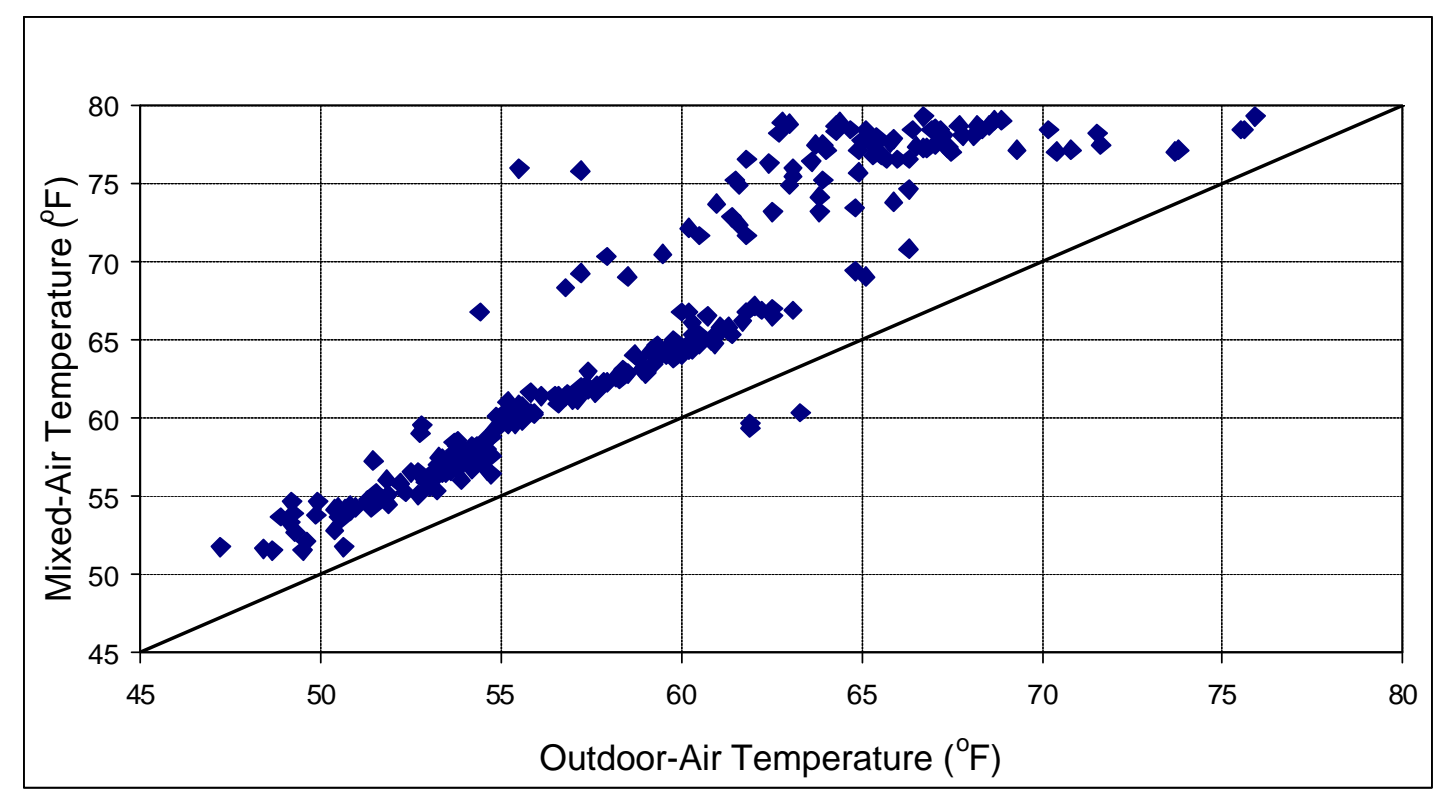

Figure 24 - Measured Values of Mixed-Air Temperature as a Function of Measured Outdoor-Air Temperature for AHU-2 when the Damper is Fully Open

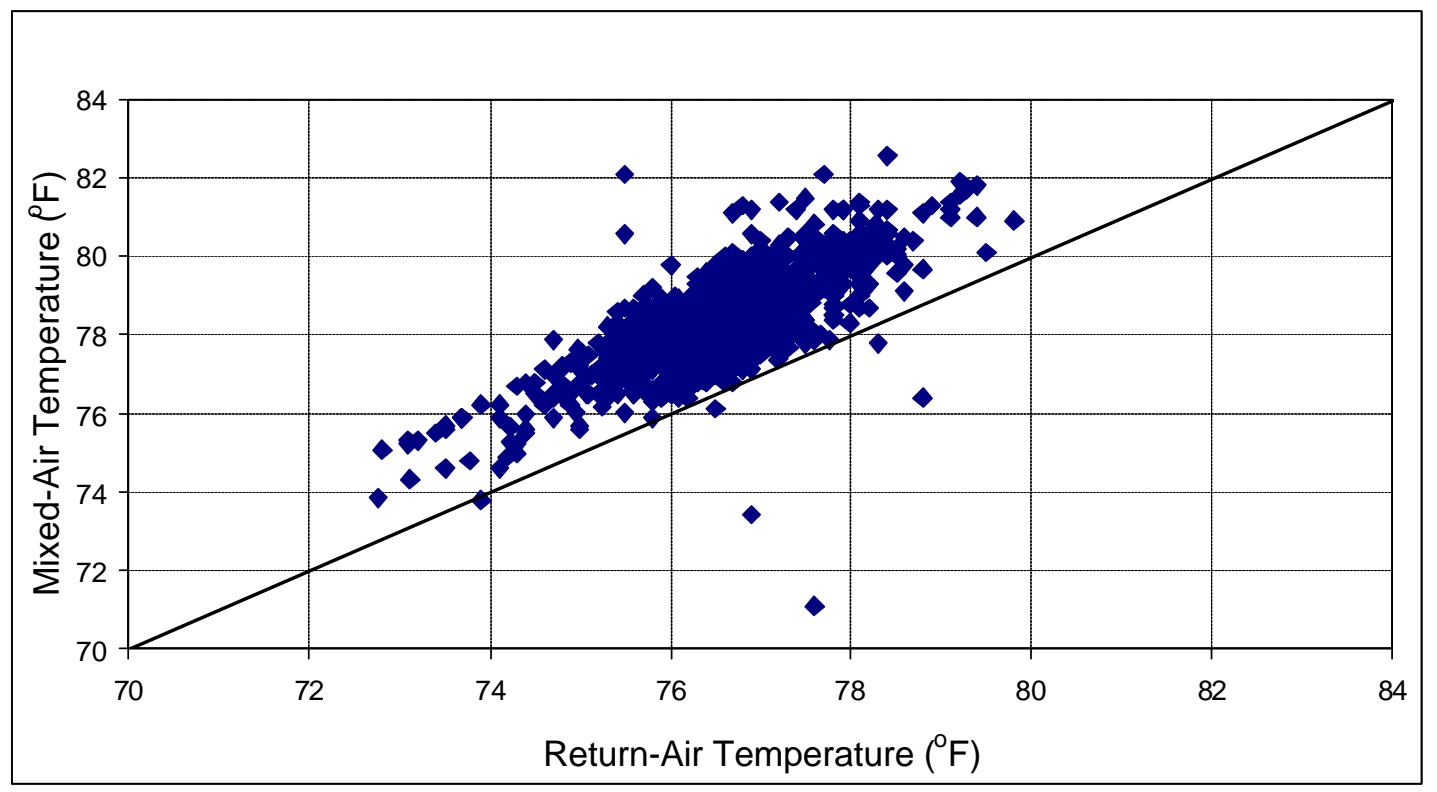

Figure 25 - Measured Values of Mixed-Air Temperature as a Function of Measured Values Return-Air Temperature for AHU-2 when the Damper is Fully Closed

At Symphony Towers there are two outdoor-air temperature sensors serving the four AHUs. AHU-1, AHU-2 and AHU-3 share the same outdoor-air temperature sensor, while AHU-4 has its own outdoor-air temperature sensor. As another check we can compare the values simultaneously indicated by the two outdoor-air temperature sensors. If they are both operating 
correctly, the values should be nearly equal ${ }^{6}$ (Figure 26). Although for the most part, the values from the two outdoor-air temperature sensors are equal, there are major differences as well. So, this test is inconclusive.

Because the results from AHU-1 did not indicate any temperature-sensor problem, the outdoorair temperature and mixed-air temperature from AHU-1 can be compared when the outdoor-air damper is fully open (Figure 27). The mixed-air temperature is nearly equal to the outdoor-air temperature, although there is a small bias with the mixed-air temperature slightly exceeding the outdoor-air temperature for outdoor-air temperatures below $55^{\circ} \mathrm{F}$ and being slightly below it for outdoor-air temperatures above $60^{\circ} \mathrm{F}$. The difference in mixed-air and outdoor-air temperature measurements for AHU-1 is within the manufacturer specified accuracies for the two sensors. Therefore, it can be concluded that the outdoor-air temperature sensor being used for AHU-1 is good; as a result, the sensor for AHU-2 also is probably not faulty. The mixed-air temperature sensor for AHU-2 is probably faulty; however, site inspection is still required to confirm this diagnosis.

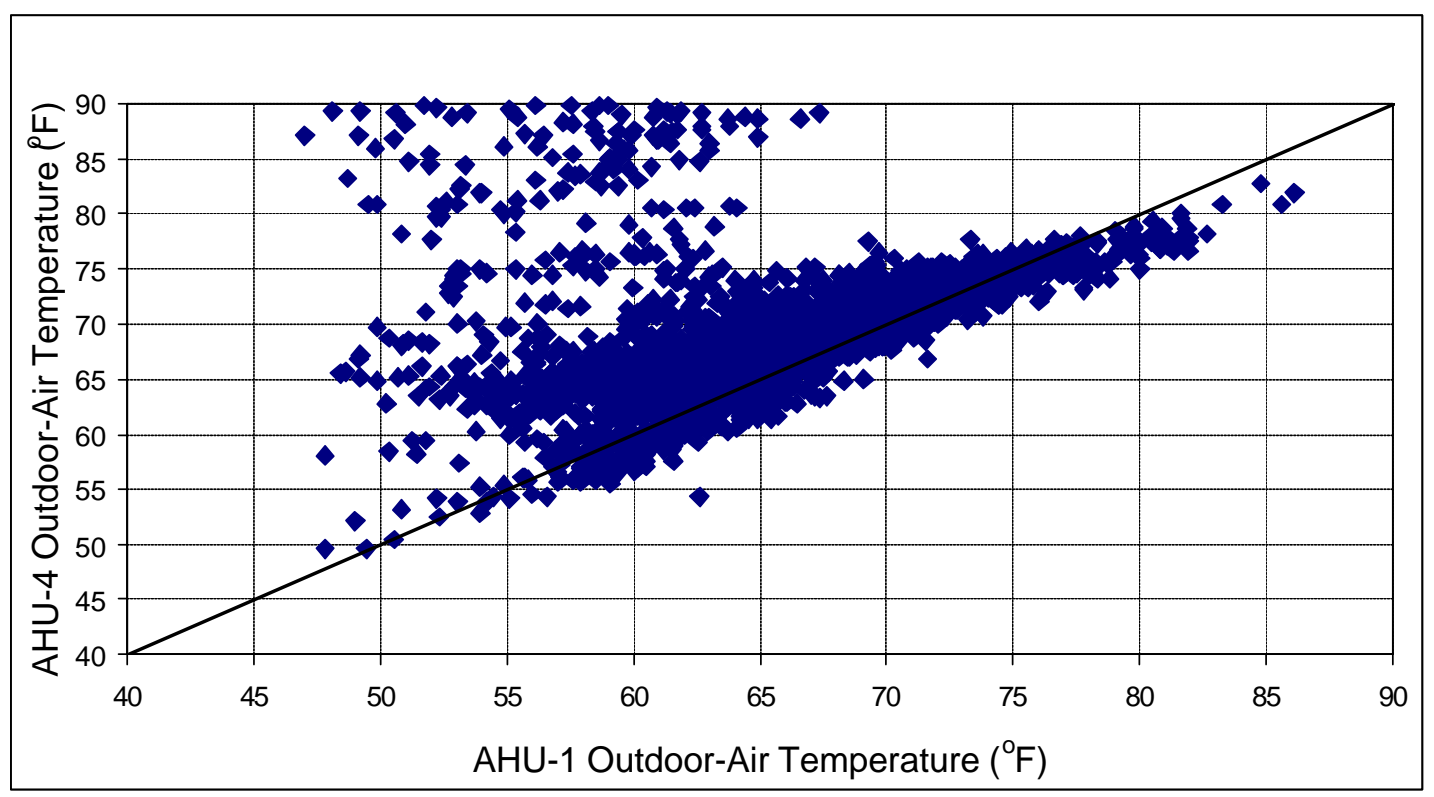

Figure 26 - Comparison of Measured Values of the Outdoor-Air-Temperature Sensors for AHU-1 and AHU-4

\footnotetext{
${ }^{6}$ This does not guarantee that the sensors are correct, only that they are consistent with one another; however, the two sensors being identically incorrect is improbable.
} 


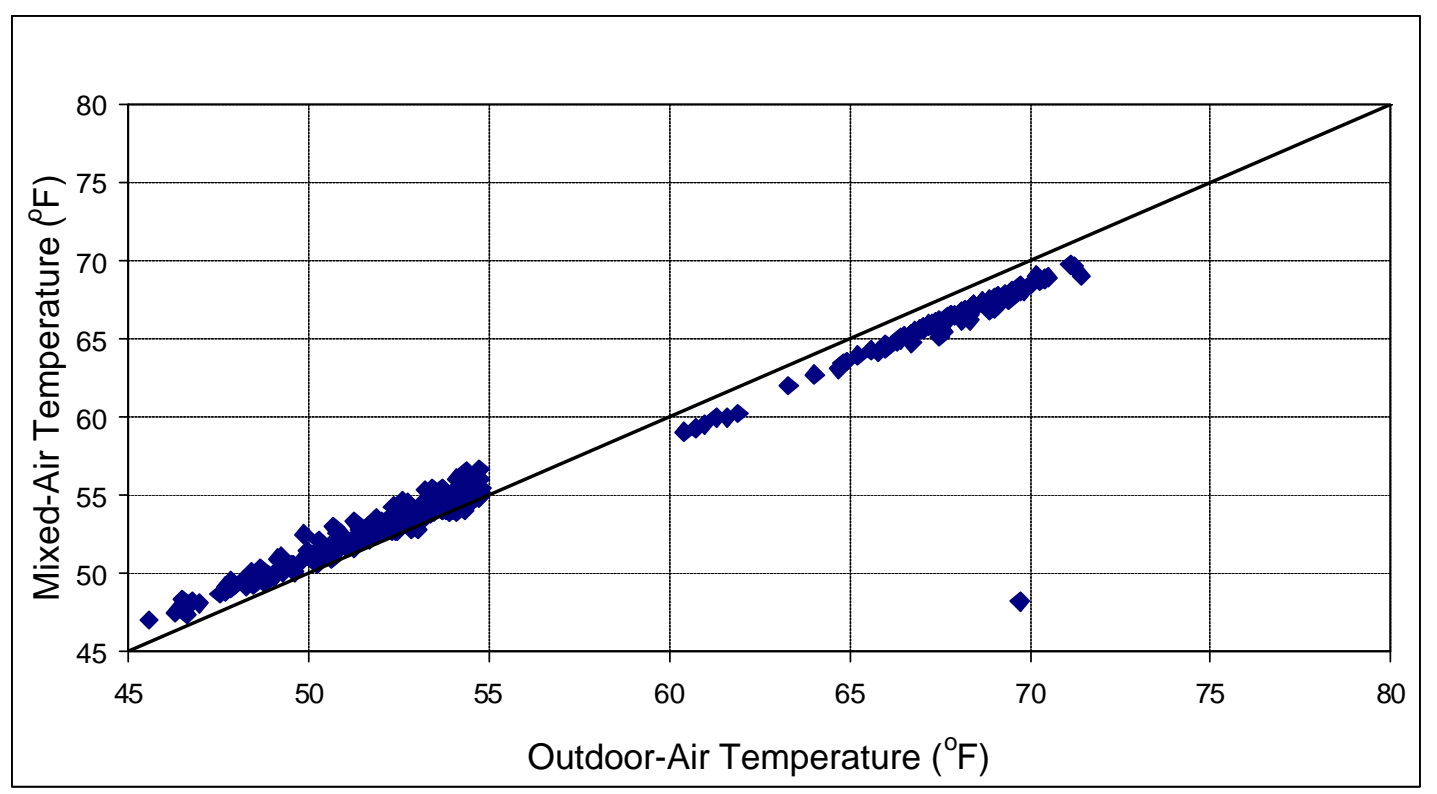

Figure 27 - Measured Values of Mixed-Air Temperature as a Function of Measured Values Outdoor-Air Temperature for AHU-1 when the Outdoor-Air Damper is Fully Open

\section{Results for AHU-3}

In April 2000, the WBD was set up to automatically collect and process data from AHU-3 though the end of the demonstration period. Like AHU-1 and AHU-2, there were several gaps in data from AHU-3, again, primarily as a result of manual termination of the data collection software on the operator's workstation.

The results from the WBD indicate that AHU-3, like AHU-1 and AHU-2, is being operated improperly. A screen shot of the processed results for the time period between June 1 and July 1 , 2000, is shown in Figure 28. A significant number of cells for occupied hours (6 a.m. to 9 p.m.) are yellow, followed in frequency by grey, blue and red. When there are a number of yellow and blue cells, in most cases, this indicates a problem with the temperature sensors (outdoor-air, return-air or mixed-air). Browsing a number of non-white and non-grey cells indicates a temperature-sensor problem in almost all cases. 


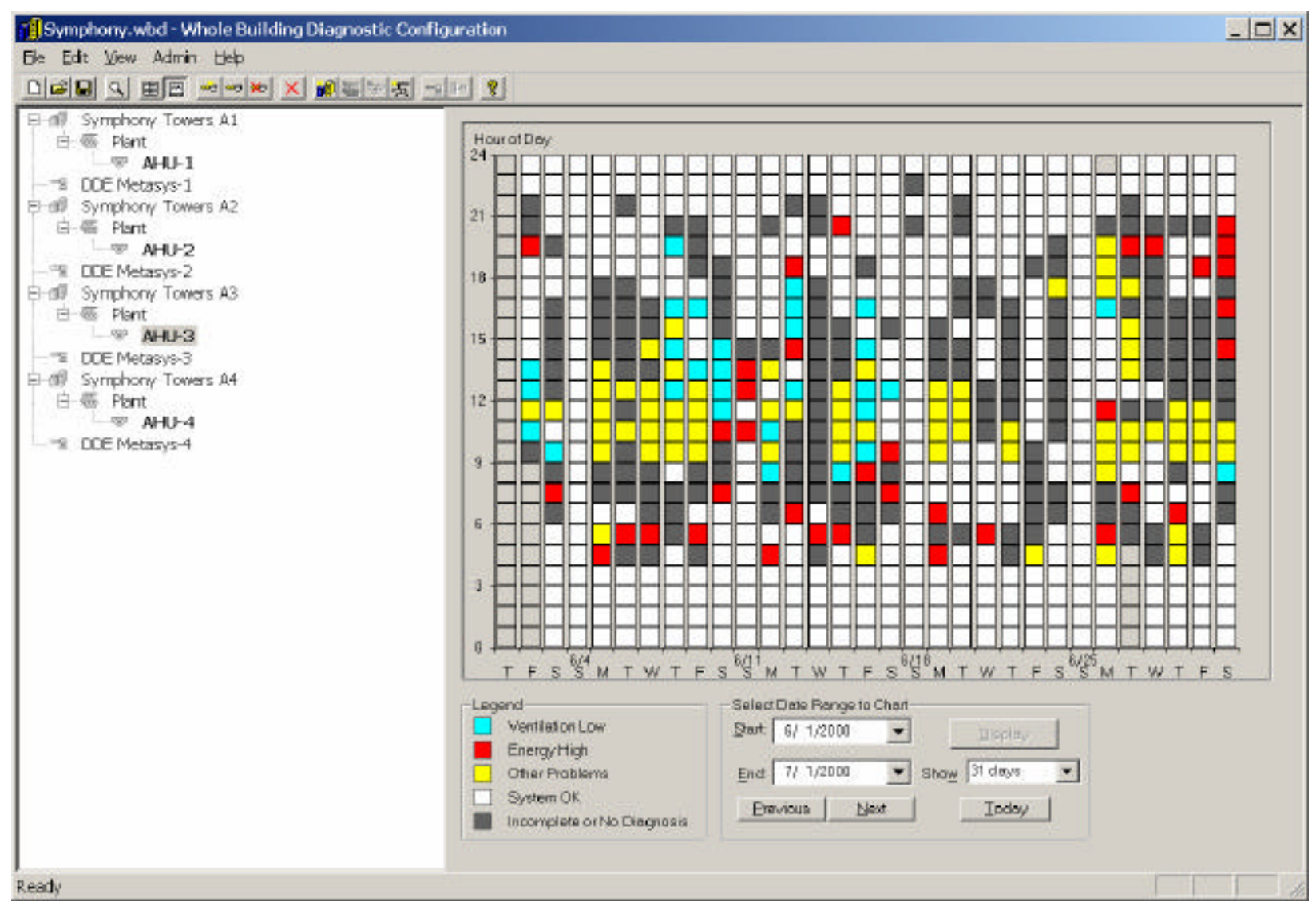

Figure 28 - WBD Diagnostic Results for AHU-3 for a Period from J une 1 through J uly 1, 2000

The most current data (at the time of writing this report) is shown in Figure 29. The display appears similar to the one shown in Figure 28, although there are more red cells than any other non-white cells.

The frequency of problems (March 2001 and January 2003) reported for AHU-3 is shown in Table 7 . The results indicate that AHU-3 operates about $10 \%$ of the occupied period with a control problem, $6 \%$ with inadequate ventilation, and $6 \%$ with low economizer flow (economizer not fully open). Although a temperature-sensor problem exists at all times, it only manifests itself about $30 \%$ of the time, during occupied hours. 


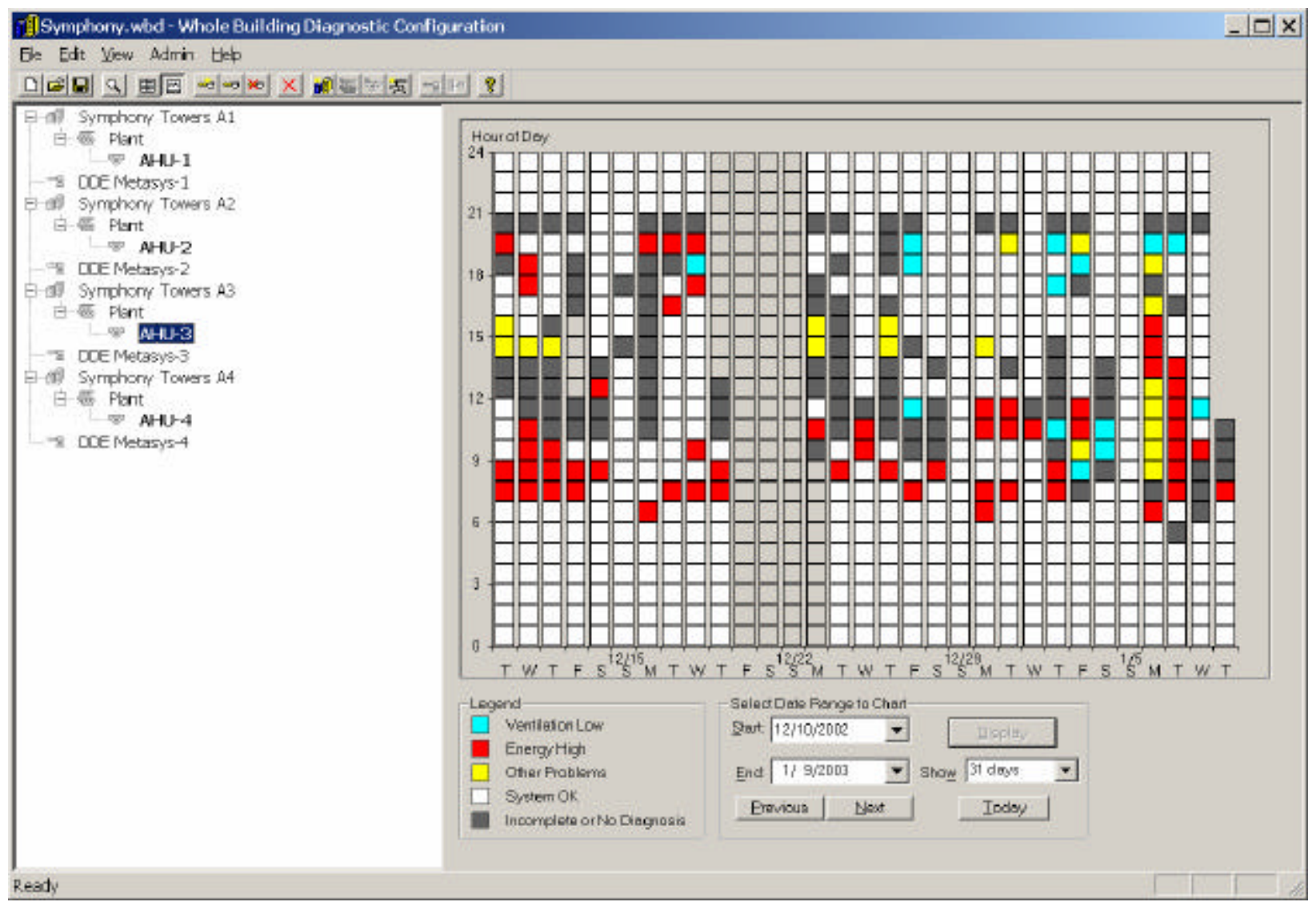

Figure 29 - WBD Diagnostic Results for AHU-3 for a Period from December 10, 2002, through J anuary 9, 2003

Table 7 - Frequency of the Problems for AHU-3 when the Supply-Fan was Operating (March 2001 through J anuary 2003)

\begin{tabular}{|l|c|c|c|}
\hline Category of Operational States & $\begin{array}{c}\text { Average } \\
\text { Reliability Score }\end{array}$ & $\begin{array}{c}\text { Number of } \\
\text { Occurrences }\end{array}$ & $\begin{array}{c}\text { Percent of Total } \\
\text { Occupied Hours } \\
(\%)\end{array}$ \\
\hline Control Problem & 0.874 & 427 & 10.0 \\
\hline $\begin{array}{l}\text { Control Problem - Excess } \\
\text { Energy }\end{array}$ & 0.948 & 99 & 2.3 \\
\hline Excess Ventilation & 0.860 & 219 & 5.2 \\
\hline Low Economizer Flow & 0.854 & 252 & 5.9 \\
\hline Inadequate Ventilation & 0.869 & 263 & 6.2 \\
\hline OK but incomplete diagnosis & 0.912 & 1,510 & 35.5 \\
\hline Operation OK & 0.731 & 1,481 & 34.8 \\
\hline \multicolumn{1}{|c|}{ Total } & & $\mathbf{4 , 2 5 1}$ & $\mathbf{1 0 0}$ \\
\hline
\end{tabular}

\section{Additional Analysis of Data from AHU-3}

The OAE diagnostician identified a temperature-sensor problem but was unable to diagnose which of the three sensors was faulty. Additional analysis beyond the normal WBD analysis is 
presented in this section to provide insight into the cause of this problem. First, Figure 30 shows the plot of the measured mixed-air temperature as a function of the measured outdoor-air temperature when the outdoor-air damper position signal is at $100 \%$ (i.e., outdoor-air damper is fully open). When the outdoor-air damper is fully open, the mixed-air temperature should be nearly equal to the outdoor-air temperature. However, for AHU-3 the difference between the mixed-air temperature and outdoor-air temperature is about $-2^{\circ} \mathrm{F}$ to $+7^{\circ} \mathrm{F}$. If the mixed-air and outdoor-air temperatures are nearly equal, the data points should all be close to the solid line (within $\pm 2{ }^{\circ} \mathrm{F}$ ). Although the difference between the outdoor-air and mixed-air temperature is not as large as it was with AHU-2, it is significantly greater than the accuracies specified by the manufacturer, so we can conclude that these two sensors don't adequately agree.

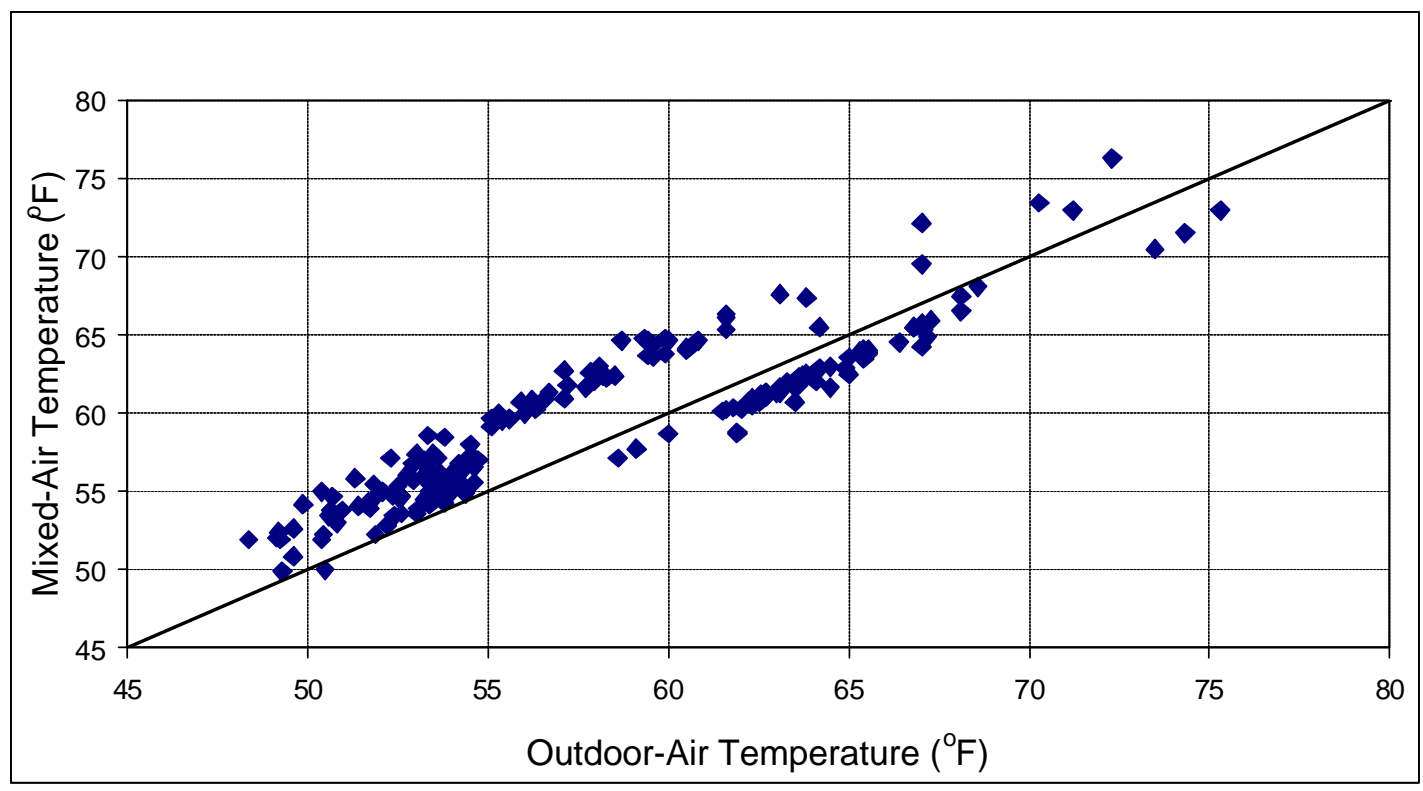

\section{Figure 30 - Measured Values of Mixed-Air Temperature as a Function of Measured Values Outdoor-Air Temperature for AHU-3 when the Damper is Fully Open}

Another plot of the mixed-air temperature as a function of the return-air temperature is shown in Figure 31. These data correspond to times when the outdoor-air damper position signal is at the minimum position (i.e., fully closed). Considering that the zone temperature set points are around $75^{\circ} \mathrm{F}$, the range of return-air temperatures appears to be acceptable (most between $71^{\circ} \mathrm{F}$ and $75^{\circ} \mathrm{F}$ ). When the outdoor-air damper is in the minimum position and the outdoor-air temperature is higher than the return-air temperature, the mixed-air temperature should be slightly greater than the return-air temperature (or should be above the solid line). Likewise, when the outdoor-air temperature is lower than return-air temperature the mixed-air temperature should be lower than the return-air (or should be below the solid line). The mixed-air temperature does show such a pattern, i.e., above and below the solid line, but there are also several hours when that is not true.

The previous analysis of AHU-2 data concluded that the outdoor-air temperature sensor was fine. AHU-3 shares an outdoor-air temperature sensor with AHU-1 and AHU-2; therefore, we can assume that its outdoor-air temperature sensor is operating properly. The problem can then be 
isolated to a faulty mixed-air temperature sensor or to a difference between the actual outdoor-air temperature at the intake of AHU-3 and the outdoor-air temperature that is being sensed at AHU1 (the outdoor-air temperature sensor is positioned close to AHU-1). Building staff should independently (possibly using a hand-held temperature measuring instrument) determine which of these problems exists.

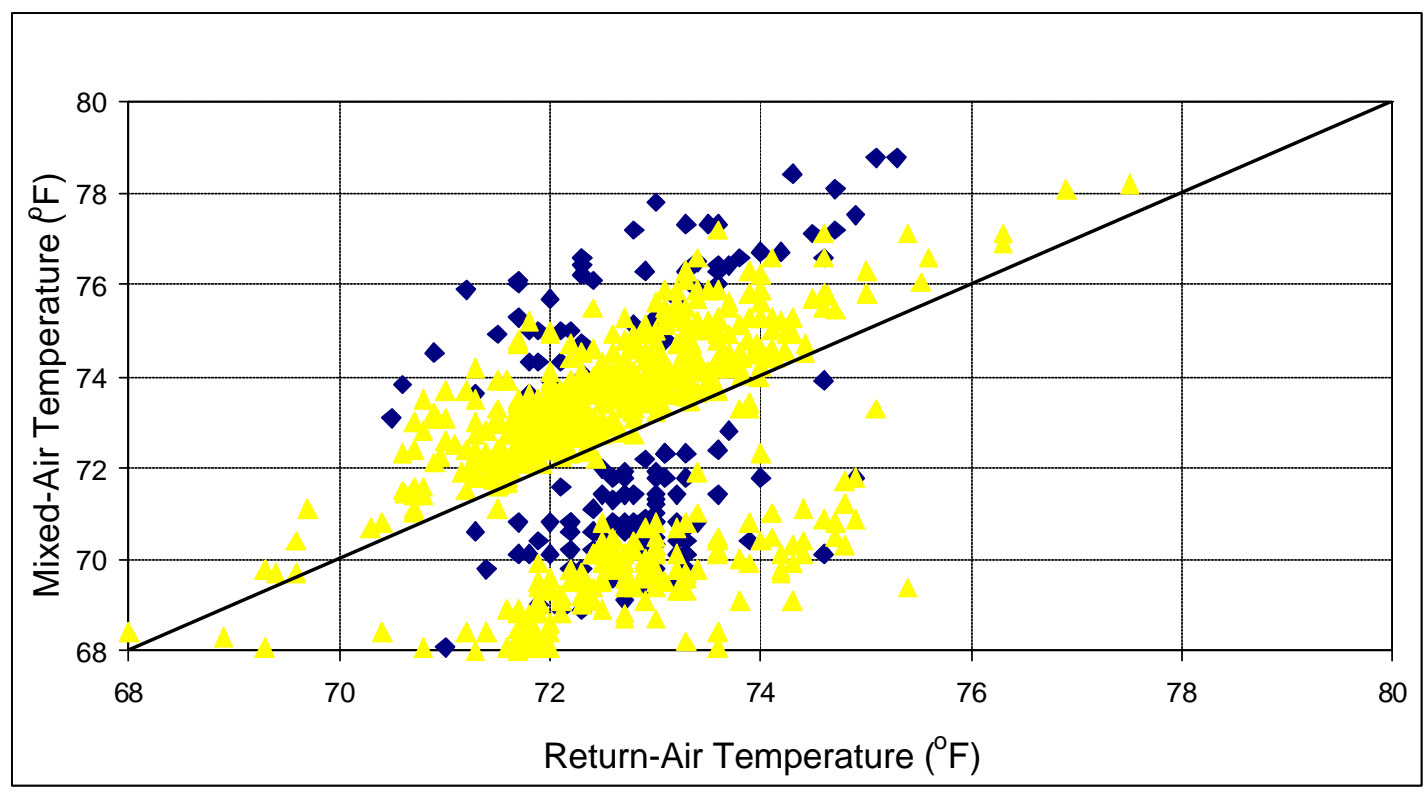

Figure 31 - Measured Values of Mixed-Air Temperature a Function of Measured Values Return-Air Temperature for AHU-3 when the Damper is Fully Closed (yellow marker represent conditions when outdoor-air temperature is greater than return-air temperature and blue marker represent conditions when outdoor-air temperature is less than return-air temperature)

\section{Results for AHU-4}

In April 2000, the WBD was set up to automatically collect and process data from AHU-4 though the end of the demonstration period. Like the other AHUs, there were several gaps in the data from AHU-4, again, primarily because of manual termination of the data collection software on the operator's workstation.

The results from the WBD indicate that AHU-4, like the other AHUs, is operating improperly. A screen shot of the processed results for the time period between December 11, 2001, and January 10, 2002, is shown in Figure 32. Almost all cells during occupied hours (6 a.m. to 9 p.m.) are yellow, with a few blue and grey cells. When there are a significant number of yellow and blue cells, this generally indicates a problem with the temperature sensors (outdoor-air, return-air or mixed-air). Browsing a number of yellow cells indicates a temperature-sensor problem in almost all cases. 
The most current data (at the time of writing the report) is shown in Figure 33. The screen shot appears to be similar to that shown in Figure 32, although there are more red cells.

The frequency of problems (March 2001 and January 2003) reported for AHU-4 is shown in Table 8 . The AHU-4 operates almost $26 \%$ of the occupied period with a control problem, $3 \%$ with inadequate ventilation, $3 \%$ excess ventilation and $3 \%$ with low economizer flow (economizer not fully open). Although the temperature-sensor problem exists at all times, it only manifests about $36 \%$ of the time, during the occupied hours. Based on this information, the building staff could investigate further, possible using a hand-held temperature instrument, to determine which of these three sensors is faulty.

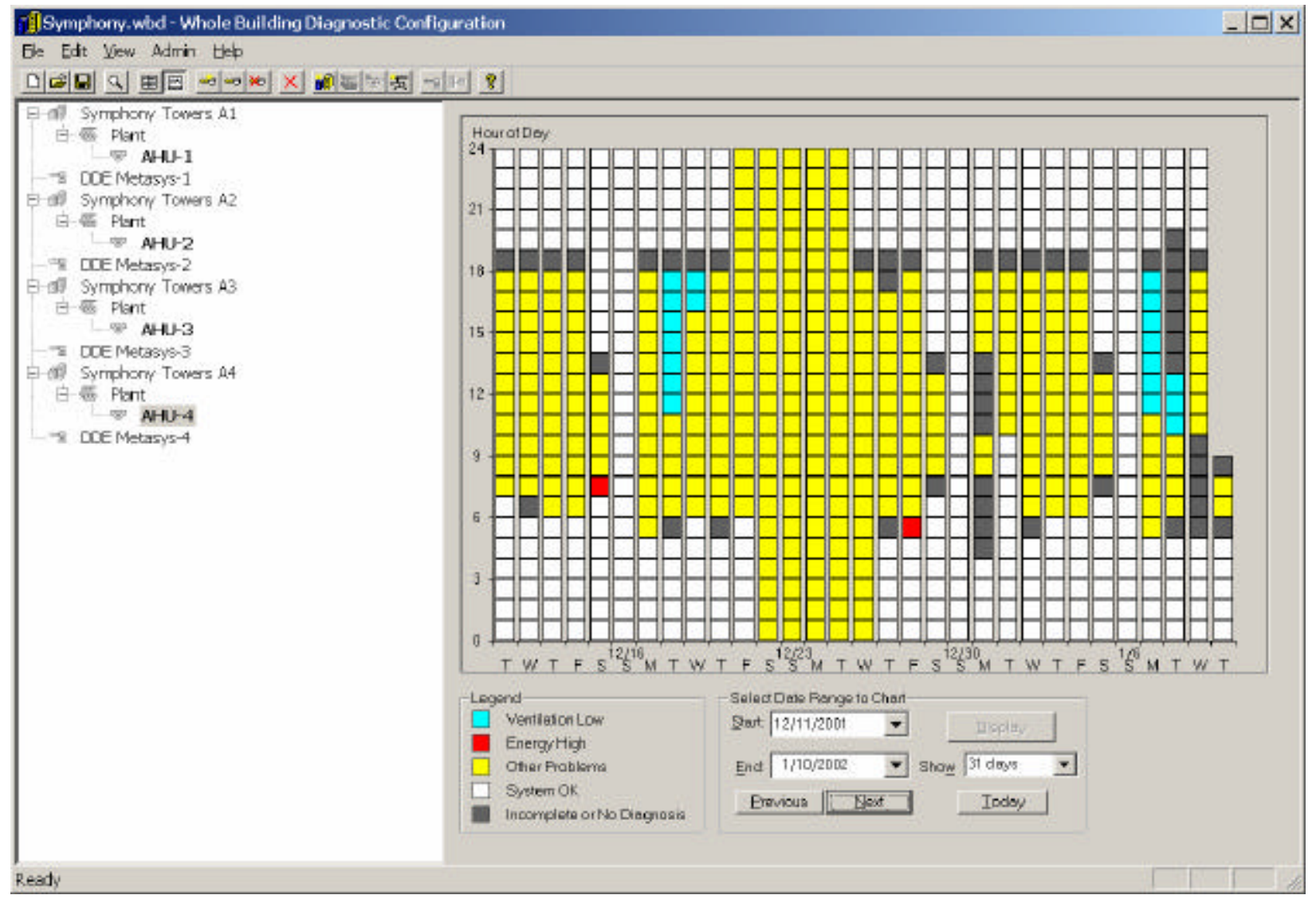

Figure 32 - WBD Diagnostic Results for AHU-4 for a Period from December 11, 2001, through J anuary 10, 2002

\section{Additional Analysis of Data from AHU-4}

The OAE diagnostician identified a temperature-sensor problem but was unable to diagnose which of the three sensors was faulty. Additional analysis beyond the normal WBD analysis is presented in this section to provide further insight into the cause of this problem. Figure 34 shows the measured mixed-air temperature as a function of the measured outdoor-air temperature for conditions when the outdoor-air damper position signal is at $100 \%$ (i.e., outdoor-air damper is fully open). When the outdoor-air damper is fully open, the mixed-air temperature should be nearly equal to the outdoor-air temperature. For AHU-4, however, the mixed-air temperature is significantly lower than the outdoor-air temperature in most cases (up to $90^{\circ} \mathrm{F}$ lower). In only a 
few cases is the measured mixed-air temperature greater than the measured outdoor-air temperature. It is clear from Figure 34 that the outdoor-air temperature measurement is faulty because it has values far greater than expected in the San Diego climate (as high as $140^{\circ} \mathrm{F}$ ).

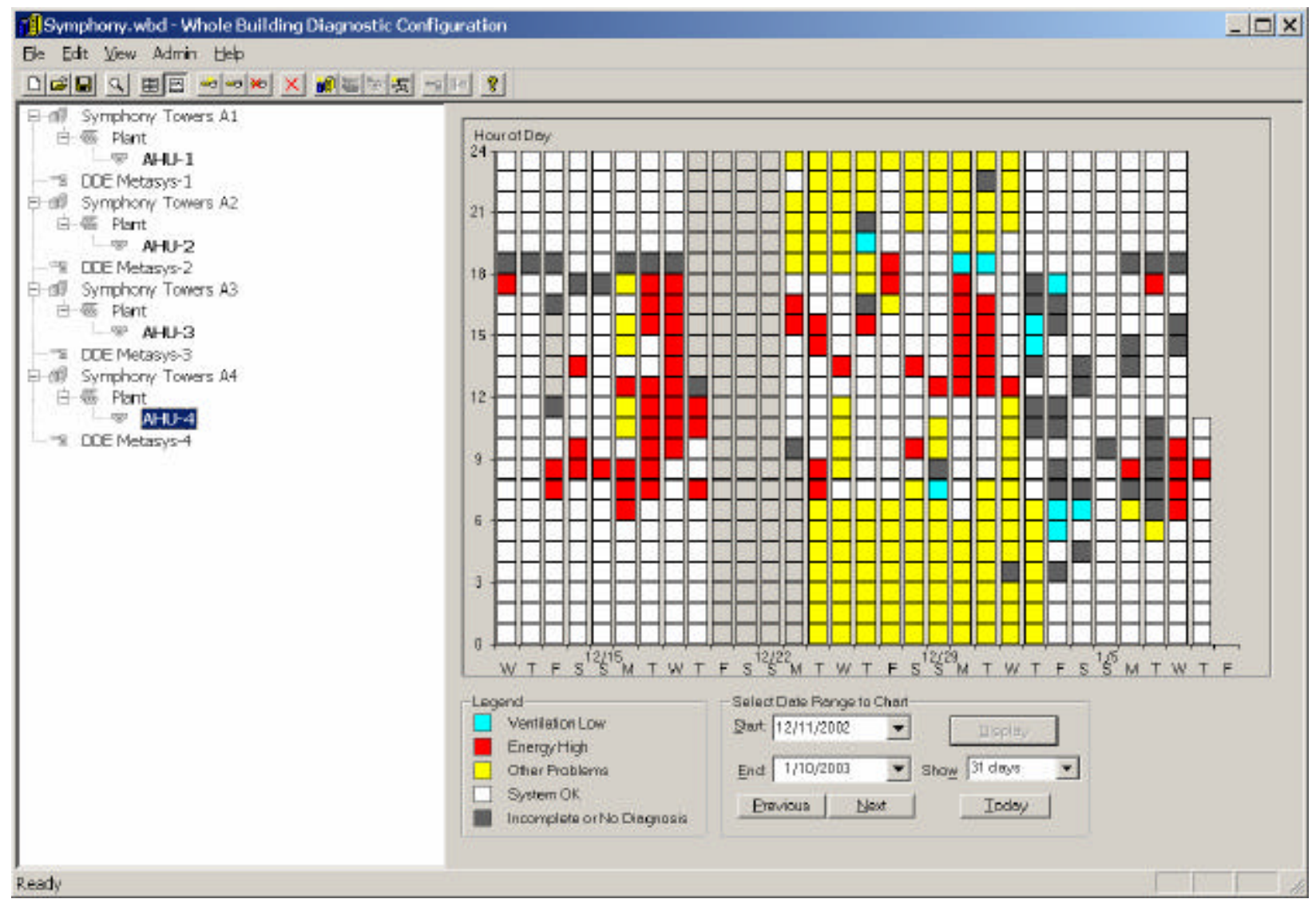

Figure 33 - WBD Diagnostic Results for AHU-4 for a Period from December 11, 2002, through J anuary 10, 2003

Table 8 - Frequency of the Problems for AHU-4 when the Supply-Fan was Operating (March 2001 through J anuary 2003)

\begin{tabular}{|c|c|c|c|}
\hline Category of Operational States & $\begin{array}{c}\text { Average } \\
\text { Reliability Score }\end{array}$ & $\begin{array}{l}\text { Number of } \\
\text { Occurrences }\end{array}$ & $\begin{array}{l}\text { Percent of Total } \\
\text { Hours }(\%)\end{array}$ \\
\hline Control Problem & 0.967 & 1,010 & 25.5 \\
\hline Control Problem - Excess Energy & 0.954 & 3 & 0.1 \\
\hline Excess Ventilation & 0.876 & 126 & 3.2 \\
\hline Low Economizer Flow & 0.896 & 134 & 3.4 \\
\hline Inadequate Ventilation & 0.877 & 133 & 3.4 \\
\hline OK but incomplete & 0.888 & 1,115 & 28.1 \\
\hline Operation $\mathrm{OK}$ & 0.748 & 1,447 & 36.5 \\
\hline Total & & 3,968 & 100 \\
\hline
\end{tabular}

A plot showing the measured mixed-air temperature as a function of the measured return-air temperature is shown in Figure 35 for conditions when the outdoor-air damper position signal is 
at the minimum position. Considering that the zone temperature set point is around $75^{\circ} \mathrm{F}$, the return-air temperature appears to be in the acceptable range (a little less than $73^{\circ} \mathrm{F}$ to little greater than $79^{\circ} \mathrm{F}$ ). When the outdoor-air damper is in the minimum position and the outdoor-air temperature is higher than the return-air temperature, the mixed-air temperature should be slightly greater than the return-air temperature (or should be above the solid line). Likewise, when the outdoor-air temperature is lower than return-air temperature, the mixed-air temperature should be lower than the return-air temperature (or should be below the solid line). The mixedair temperature spans across the solid line and mostly follows the expected trend, but there are few hours when the trend does not hold.

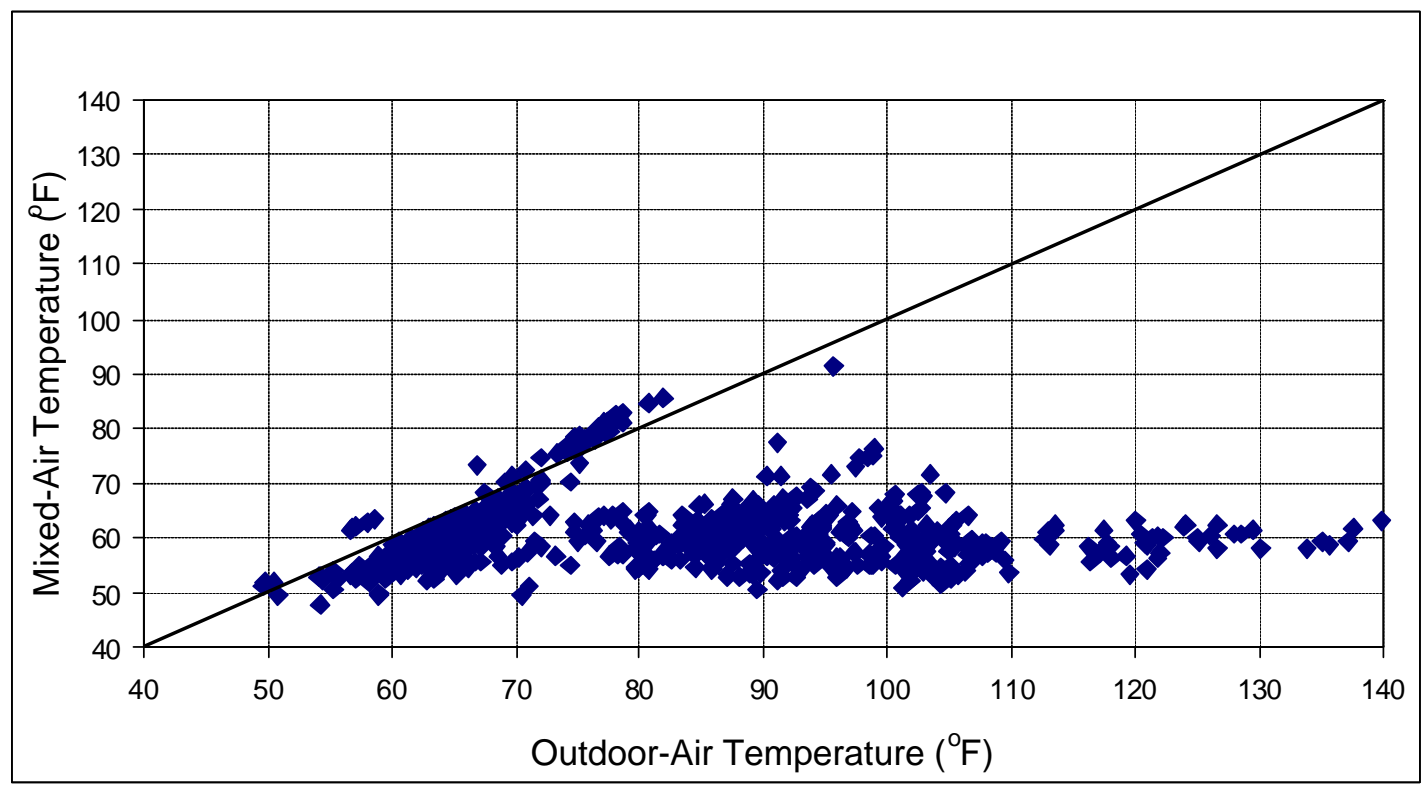

Figure 34 - Measured Values of Mixed-Air Temperature as a Function of Measured Values Outdoor-Air Temperature for AHU-4 when the Damper is Fully Open 


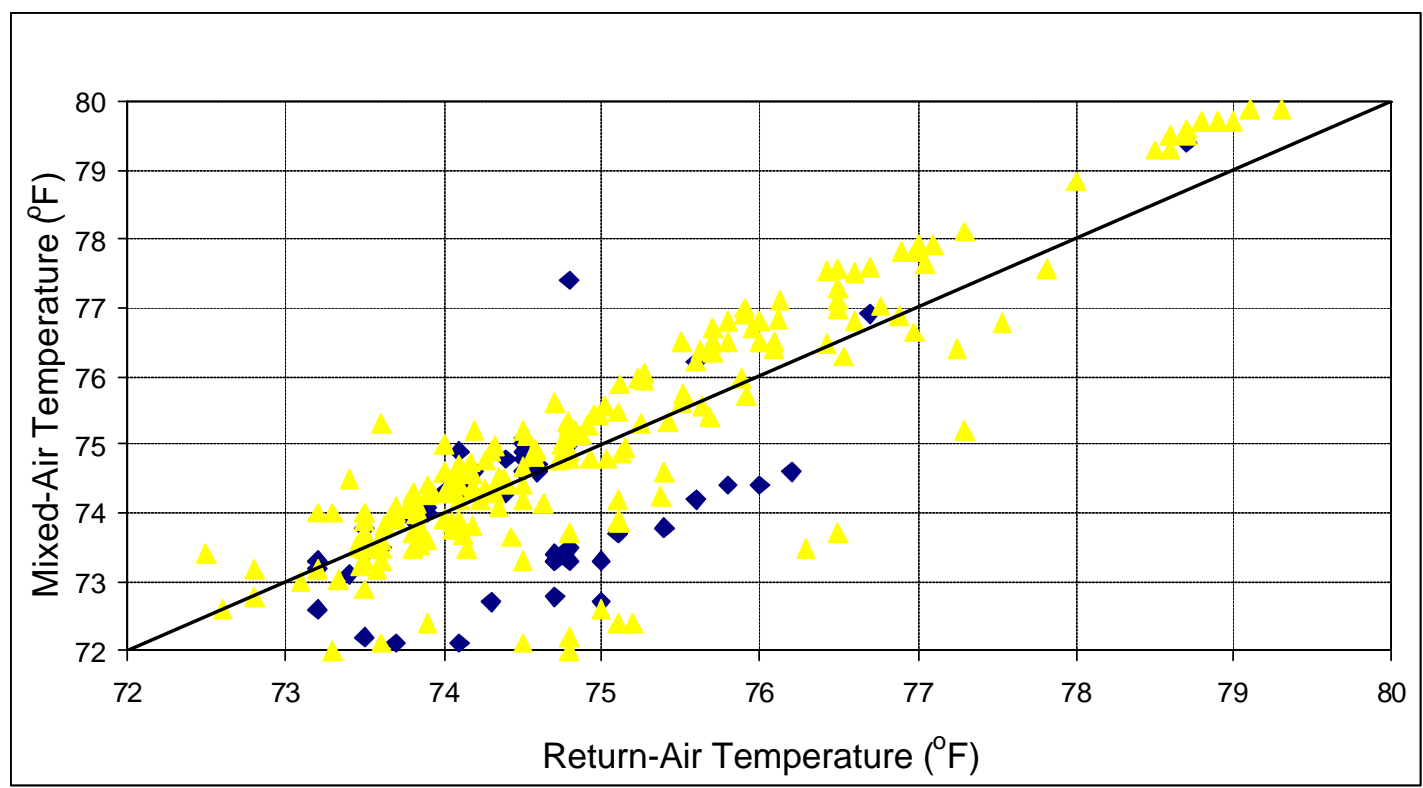

Figure 35 - Measured Values of Mixed-Air Temperature as a Function of Measured Values Return-Air Temperature for AHU-4 when the Damper is Fully Closed (yellow marker represent conditions when outdoor-air temperature is greater than return-air temperature and blue marker represent conditions when outdoor-air temperature is less than return-air temperature) 


\section{Savings Opportunities for AHU-1}

Correcting the energy-wasting problems identified by the OAE will produce reductions in energy consumption and savings on energy expenditures. In this section, we present the estimated savings from correcting the problem with AHU-1 identified by the OAE during on-line use of the WBD. For this air handler, the minimum outdoor-air damper setting was greater than the minimum required to provide adequate ventilation with outdoor air, and as a result energy was being wasted (see Sections 0).

The other three air-handling units (AHU-2, AHU-3, and AHU-4) were found to have faulty temperature sensors. Faulty readings from those sensors prevent us from estimating savings that would result from correcting those problems because we have no (reliable) data upon which to base estimates of savings. This also makes the energy and cost estimates provided by the OAE meaningless for those air handlers. Sensor problems present a quandary in this respect. If building staff do not correct or replace faulty sensors, control of the affected building systems will be wrong - the building equipment will not behave as desired - but the energy and cost impacts of the bad sensors cannot be determined because no good measured data are available upon which to base calculations of deviations from desired behavior. Therefore, the severity of the problems resulting for the bad sensors cannot be assessed. Building staff must decide whether they want to control their building or not. If the answer is affirmative, they replace the sensors; if not, the affected equipment continues to operate out of control in response to bad measurements from the failed sensors.

The savings associated with correcting the problem with AHU-1 were estimated using the simplified methodology described in Appendix A: Method for Estimating the Annual Energy Savings. The impact estimates are based on both the measured data and user-specified inputs [e.g., the system coefficient of performance (COP) and cost of energy]. Because measured values are used in estimating the impacts, the sensors must be fault free. If the AHU has a faulty sensor (especially, the outdoor-air, return-air or mixed-air temperature), the estimates are not accurate and cannot be relied upon. The sensors for AHU-1 were found to be good and, therefore, savings opportunities could be estimated. Major assumptions used in calculating the savings are shown in Table 9.

The estimated annual cooling energy savings from correcting the problem were $81,000 \mathrm{kWh}$ with a corresponding value of about $\$ 12,200$. The estimated energy and cost impacts are conservatively low because only the impacts on cooling energy were determined. The estimate does not impact heating energy. Heating is provided by reheat of the supply air before it enters the building spaces, and no information is currently collected by the WBD on terminal-box reheat. In addition, other operation problems may have been present for AHU-1, but the presence of the problem found may have masked these other problems. Before the single-fault nature of the logic implemented in the OAE, it only identified one prominent fault at a time (see Section 0). As a result, addition opportunities to improve the performance of AHU-1 may be available, as well as the associated savings. The OAE will reveal other problems after the one identified here is corrected. 
Table 9 - Assumed and Calculated Values of Key Variables for I mpact Estimates (see Appendix A for more information).

\begin{tabular}{|l|r|}
\hline $\begin{array}{l}\text { Coefficient of performance of the chilled water system (including chillers, pumps, } \\
\text { cooling towers) }\end{array}$ & 2.5 \\
\hline Marginal cost of electric energy including demand & $0.15 \$ / \mathrm{kWh}$ \\
\hline Average return-air temperature & $76^{\circ} \mathrm{F}$ \\
\hline Average return-air relative humidity & $47 \%$ \\
\hline Average speed of the supply air fan & $80 \%$ \\
\hline Supply air flow rate & $80,000 \mathrm{cfm}$ \\
\hline Enthalpy dead-band & $1.3 \mathrm{Btu} / \mathrm{lb}$ \\
\hline Actual average minimum outdoor-air fraction & 0.72 \\
\hline Desired minimum outdoor-air fraction & 0.20 \\
\hline
\end{tabular}




\section{User Impressions of the WBD}

An exit interview was conducted with Mr. Dishman, Energy Manager for Symphony Towers, in February 2003. The results of that interview are summarized in this section.

\section{General}

Mr. Dishman thought the WBD diagnostic tool set helped him in evaluating trends and identifying operational issues related to the four AHUs at Symphony Towers. In addition, he expressed that diagnostic tools such as WBD would help building mangers, operators, and owners by providing them with the ability to evaluate real-time data and perform corrective actions as required. He added that more diagnostics tools are needed that cover the entire HVAC systems spectrum. His staff currently spends almost 16 hours a week chasing problems.

\section{OAE Interface and Diagnostics}

On a scale of 1 to 5 ( 1 being very easy and 5 being very difficult to use) Mr. Dishman gave the WBD a rating of 2 on ease of use. This indicates that he found it somewhat easy to use. He indicated that the OAE tool was only relevant for building operators and not the building managers or owners. Although he did not actually configure any AHUs in the OAE diagnostician, his impression was that it is somewhat easy to configure. We, the investigators, are not sure what led him to this conclusion.

Mr. Dishman indicated that he often reviewed results and confirmed problems that the OAE reported by visually inspecting the AHUs. Despite this, none of the problems identified, with the exception of the one found during the off-line tests, were corrected. When asked about recommendations for changes or improvements to the OAE/WBD, Mr. Dishman indicated that the tools were fine and did not need any improvements. When asked if he would install additional sensors if that allowed for better diagnosis of problems, he indicated that he would. Because part of the WBD was run on an operator's workstation, we asked Mr. Dishman if that interfered with the operations, and he reported that he thought it did. He provided no detail regarding how the WBD might have interfered with operations.

Although the building operators were trained on how to view OAE results and interpret the information they provided, none of them actually reviewed the results during the demonstration. This may be a critical missing link in the process of using such tools, needs which further investigation in future applications. 


\section{Conclusions and Recommendations}

The WBD OAE module was shown to successfully identify a number of major problems with the air-handling units at Symphony Towers. These findings are consistent with other demonstrations of the WBD, where OAE found similar problems that should have been detected at the time of commissioning or periodic maintenance.

The OAE diagnostic module identified problems with all four AHUs at the Symphony Towers. Based on the results, we recommend a few corrective actions for the Symphony Towers air handlers:

- modify the minimum damper setting in the control system for AHU-1 to meet ASHRAE Standard 62 (ASHRAE 2001) levels; the current setting significantly exceeds the requirement of the standard and is costing the building over $\mathbf{\$ 1 2 , 0 0 0}$ per year

- calibrate all temperature sensors for AHU-2, in particular the mixed-air temperature sensor, which might need replacement

- calibrate all temperature sensors for AHU-3, in particular the mixed-air temperature sensor, which may need replacement

- calibrate all temperature sensors for AHU-4, in particular the outdoor-air temperature sensor, which may need replacement

- consider reducing the minimum flow rate for all four AHUs. For all four AHUs, the flow rate does not modulate below $50 \%$. Reducing the flow would save cooling/heating energy and fan energy, and correspondingly reduce costs. This was not detected by the $\mathrm{OAE}$, but was found while performing additional analysis off-line.

Observations by users at the building provided mixed results. Although more knowledgeable and experienced users of the WBD were comfortable with the design of the module's user interface and diagnostics, they both proved to make the results difficult for inexperienced users to interpret when several problems occurred simultaneously. This may have implications for interface design changes in the future. For example, a simpler user interface that produces an action item list or list of problems based on OAE results for a block of time may be preferable to users overwhelmed by the detailed hourly results.

Installation of the WBD and collection of data from the air handlers were smooth at this site. The OAE data-collection module has been extensively tested at other field sites with similar control systems, so no significant problems were encountered with the installation at Symphony Towers. The automated processing of the data proceeded very well for all four air handlers, with little or no attention paid to it. However, there were large gaps in the data collected mainly caused by manual shutdown of the data acquisition module on the operator's workstation.

The demonstration reinforced the notion that diagnostic tools produce savings only when the identified problems are fixed. Merely identifying operation problems and their impacts is not 
sufficient by itself; building staff must fix them. If building staff are not able to use their control systems to correct problems, are too busy with other duties, or lack resources to obtain help from contractors, savings will not be realized. A delivery mechanism is needed that helps ensure that building staff take action when alerted to problems with significant impacts.

The time and cost of diagnostic-tool installation is a significant component to implementing diagnostic technologies. Labor costs to set up tools like the WBD ( 1 week) will likely exceed the purchase cost of commercialized software. Sites with larger air handlers $(10,000 \mathrm{cfm}$ or larger air flow rates) have greater savings per problem fixed, while installation costs do not vary with air handler size (i.e., savings are greater relative to costs). Installation costs per air-handler also go down as the number of air handlers at a site increases, provided the units use similar operating control strategies and are part of the same underlying control system.

Overall, the WBD OAE diagnostician was successfully applied at Symphony Towers. It identified problems with significant energy and cost penalties that would provide significant savings if fixed. Getting building staff to correct these problems, however, was difficult. This points to a need to develop a mechanism for delivering the OAE or providing its results to users in a way that better encourages them to correct the problems found. 


\section{References}

American Society of Heating, Refrigerating and Air-Conditioning Engineers, Inc.

ANSI/ASHRAE Standard 62-2001 Ventilation for Acceptable Indoor Air Quality, 2001. Atlanta, Georgia.

Brambley, M.R., R.G. Pratt, D.P. Chassin, and S. Katipamula. 1998. “Automated Diagnostics for Outdoor Air Ventilation and Economizers." ASHRAE Journal, Vol. 40, No. 10, pp. 49-55, October 1998.

Claridge, D.E., C.H. Culp, M. Lui, S. Deng, W.D. Turner, and J.S. Haberl. 2000. "CampusWide Continuous Commissioning ${ }^{\text {SM }}$ of University Buildings." In Proc. of ACEEE 2000 Summer Study on Energy Efficiency in Buildings, Pacific Grove, California, Aug. 20-25, pp. 3.101-3.112.

Daisey, J.M. and W.J. Angell. 1998. A Survey and Critical Review of the Literature on Indoor Air Quality, Ventilation and Health Symptoms in Schools. LBNL-41517, Lawrence Berkeley National Laboratory, Berkeley, California.

Katipamula, S., R.G. Pratt, D.P. Chassin, Z.T. Taylor, K. Gowri, and M.R. Brambley. 1999. "Automated Fault Detection and Diagnostics for Outdoor-Air Ventilation Systems and Economizers: Methodology and Results from Field Testing." ASHRAE Transactions, Vol. 105 Pt. 1.

Lunneberg, T. 1999. "When Good Economizers Go Bad.” E Source Report ER-99-14, E Source, Boulder, Colorado.

http://www.peci.org. Portland Energy Conservation Inc., November 2002. 
Appendix A

Method for Estimating the Annual Energy Savings 


\section{Appendix A: Method for Estimating the Annual Energy Savings}

A simplified method that was used to estimate the cooling energy savings for AHU-1 is described in this appendix. The savings are estimated based on average weather for San Diego, California, as provided by a Typical Meteorological Year (TMY). ${ }^{7}$

The steps to estimate the cooling energy savings are:

1. Extract data for outdoor-air temperature and humidity for each hour of the TMY for San Diego. These data are used to represent outdoor conditions over the 12-month period for which savings are estimated.

2. Values of the return-air temperature and humidity were collected over the time period that the OAE diagnostician was used. Rather than accounting for variations in the conditions hourly over the course of a year, annual averages of the hourly values for times when the building was occupied were used in estimating savings. This was reasonable because return-air conditions did not vary substantially during occupied times. These average values along with values for other key input and calculated variables are shown in Table 9.

3. Several other variables needed to estimated energy savings and savings on energy expenditures were estimated and are shown in Table 9. These included:

- Marginal cost of electricity $\left(\mathrm{P}_{\text {elec }}\right)$, given as an equivalent blended rate that includes both the consumption charge and demand charge

- Full-load supply-air volumetric flow rate $\left(\mathrm{v}_{\text {rated }}\right)$, estimated as the rated airflow rate of this air-handling unit

- Average fan speed expressed as a fraction of full speed (fan speed $_{\text {average }}$ ), which for Symphony Towers is actually measured for use as an indicator of fan status, so an actual average value was determined

- Enthalpy dead-band, obtained from the economizer control code

- Coefficient of performance of the chiller system (COP), which was assumed equal to that of a typical chiller system, including energy use by all system components

- Desired minimum outdoor-air fraction $\left(\mathrm{OAF}_{\text {desired minimum }}\right)$, which is the outdoor-air fraction corresponding to the damper position that provides the minimum outside air flow necessary to meet outdoor-air ventilation

\footnotetext{
${ }^{7}$ TMY weather data can be obtained from National Renewable Energy Laboratory website at the following url: http://rredc.nrel.gov/solar/old data/nsrdb/tmy2/
} 
requirements. For constant volume systems or for estimates made using average flow rates, this OAF can be assumed constant.

4. Determine the times (hours) during which conditions are not favorable for economizing by comparing the outdoor-air enthalpy, determined from temperature and humidity data in the weather file, with the average return-air enthalpy. These are the hours when the outdoor-air damper should be at its minimum position. Conditions are not favorable for economizing when the difference between the return-air enthalpy $\left(\mathrm{h}_{\text {return-air }}\right)$ and outdoorair enthalpy $\left(\mathrm{h}_{\text {outdoor-air }}\right)$ is greater than the enthalpy dead-band $(1.3 \mathrm{Btu} / \mathrm{lb})$, i.e.,

$$
\left(\mathrm{h}_{\text {return-air }}-\mathrm{h}_{\text {outdoor-air }}\right)>1.3 \mathrm{Btu} / \mathrm{lbm}
$$

5. Calculate the actual average minimum outdoor-air fraction $\left(\mathrm{OAF}_{\text {actual avg minimum }}\right)$ from data for the outdoor-air, return-air and mixed-air temperatures at times that the outdoor-air damper should have been at its minimum position (i.e., while not economizing), using the relation

$$
O A F_{\text {actual average min imum }}=\frac{\sum_{\begin{array}{c}
\text { i-hours unfavoratble } \\
\text { for economizing }
\end{array}} \frac{\left(T_{\text {mixed-air }}-T_{\text {return-air }}\right)_{i}}{\left(T_{\text {outdoor-air }}-T_{\text {return-air }}\right)_{i}}}{N}
$$

where $\mathrm{T}$ represents temperature, and $\mathrm{N}$ is the total number of hours unfavorable to economizing.

6. Compute the desired mixed-air enthalpy $\left(\mathrm{h}_{\text {mixed-air, desired min }}\right)$ for each hour when the conditions are not favorable for economizing. The desired enthalpy is obtained when the outdoor-air damper is at its desired minimum position. The desired minimum damper position is the damper position that provides just enough outdoor air to satisfy outdoor-air ventilation requirements. For constant flow systems, that position corresponds to a desired minimum outdoor-air fraction (OAF). As a result, the desired mixed-air enthalpy can be estimated using the relation

$$
h_{\text {mixed-air, desired min imum }}=O A F_{\text {desired } \min \text { imum }} \times h_{\text {outdoor-air }}+\left(1-O A F_{\text {desired min imum }}\right) \times h_{\text {return-air }}
$$

where $\mathrm{h}$ represents enthalpy.

7. Compute the mixed-air enthalpy for all times (hours) when the outdoor-air damper should be at its minimum position, i.e., the actual mixed-air enthalpy $\left(\mathrm{h}_{\text {mixed-air, actual minimum }}\right)$ for hours when the conditions are not favorable for economizing, which is given by

$$
h_{\text {mixed-air, actual min imum }}=O A F_{\text {actual min imum }} \times h_{\text {outdoor-air }}+\left(1-O A F_{\text {actual min imum }}\right) \times h_{\text {return-air }}
$$


8. Compute the difference between item 7 and item 6 at each hour. This is annual enthalpy difference between actual and desired. The cooling energy impacts can be computed as follows (average supply-air flow is computed as a product of full-load supply-air flow and average fan speed over the measured period):

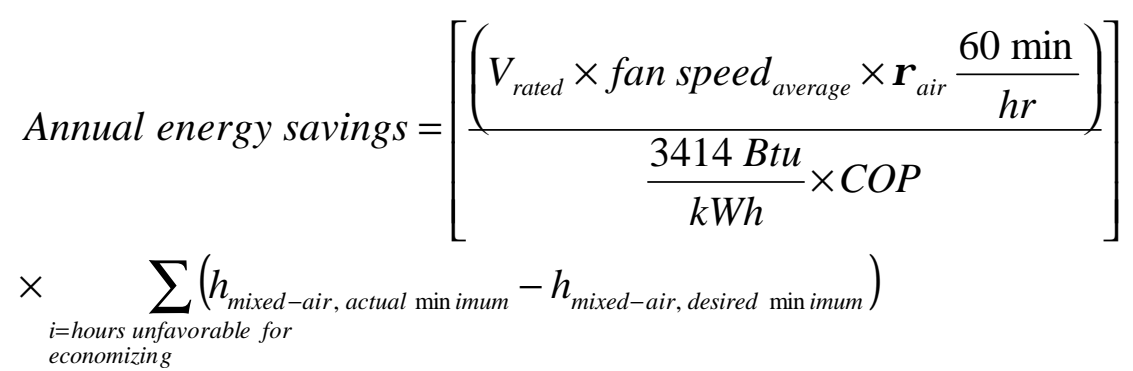

where the annual energy savings are in $\mathrm{kWh} /$ year, the rated volumetric flow rate $\left(v_{\text {rated }}\right)$ is in cubic feet per minute, the average fan speed (fan speed average $_{\text {) }}$ is a dimensionless fraction of the full rated speed, $\rho_{\text {air }}$ is the average density of air in $\mathrm{lbm} / \mathrm{ft}^{3}$, and the values of enthalpy are in Btu/lbm.

9. Compute the annual savings on energy expenditures using the relation

$$
\text { Annual Cost Savings = Annual Energy Savings } \mathrm{x} \mathrm{P}_{\text {elec}} \text {. }
$$

The annual energy and cost savings from correcting the problem with AHU-1 in Symphony Towers are also equal to the annual energy penalty and extra cost if the problem is not fixed. 


\section{Distribution}

No. of

Copies

OFFSITE

U.S. Department of Energy

Office of the Building Technologies FORS EE-2J

Washington, DC 20585

ATTN: D. Hansen
No. of

Copies

ONSITE

DOE Richland Operations Office

K. Williams K8-50

Pacific Northwest National Laboratory

Hanford Tech Library (2) P8-55 